UNIVERSIDADE DE SÃO PAULO

INSTITUTO DE FÍSICA

\title{
Estudo de esforços mastigatórios utilizando técnica de interferometria holográfica.
}

\section{Glaura Caroena Azevedo de Oliveira}

Orientador: Prof. Dr. Mikiya Muramatsu - (IFUSP)

\begin{abstract}
Dissertação apresentada ao Instituto de Física para a obtenção do título de Mestre em Ciências.
\end{abstract}

Comissão examinadora:

Prof. Dr. Mikiya Muramatsu - IFUSP

Prof. Dr. Edson Aparecido Liberti - ICBUSP

Prof. Dr. Said Rahnamaye Rabbani - IFUSP

São Paulo

2007 
A inteligência é o farol que nos guia, mas é a vontade que nos faz caminhar. 


\section{Agradecimentos}

Agradeço ao Prof. Dr. Mikiya Muramatsu, pela orientação.

Agradeço ao Prof. Dr. Matsuyoshi Mori, pela grande ajuda e dedicação com este trabalho.

À minha mãe Joséia de Oliveira, pelo grande apoio em todas as minhas decisões, ajuda em todos os momentos difíceis da minha vida e pelo amor e carinho que sempre me deu.

Ao Renato Germano, por toda compreensão, companheirismo e amizade.

Aos colegas do Laboratório de Óptica, Marcos Gesualdi e Emerson da Silva pela ajuda no laboratório.

Ao Eduardo Ferrara pela grande ajuda no programa computacional.

Agradeço ao CNPq pela concessão da bolsa de mestrado. 


\section{Resumo}

A interferometria holográfica é um poderoso método óptico para observação de fenômenos perturbativos e na análise de superfícies, sendo extremamente útil em aplicações em pesquisa básica, biomédicas e tecnológicas. Os cristais fotorrefrativos se apresentam como um meio atrativo para registro de hologramas. O fenômeno que caracteriza esses cristais é o efeito fotorrefrativo. Tal efeito consiste na modulação do índice de refração através de fotoindução e efeito eletro-óptico linear (Efeito Pockels), o que permite o registro de hologramas de fase em volume. Entre as características que recomendam os cristais fotorrefrativos para interferometria holográfica podemos citar: o processo de registro e leitura ocorre de maneira dinâmica através da técnica de mistura de duas ondas; o fato de serem meios reversíveis dispensando processamento químico e a boa resolução implicando imagens holográficas de boa qualidade. Analisamos as diversas tensões que ocorrem no processo mastigatório, estudando principalmente a concentração de cargas e as dissipações nesse processo, utilizando a técnica holográfica de dupla exposição e o cristal fotorrefrativo $\mathrm{Bi}_{12} \mathrm{SiO}_{20}(\mathrm{BSO})$, da família das Silenitas, como meio de registro. O estudo em crânio seco e a simulação dos principais feixes dos músculos da mastigação permitem realizar a contração dos mesmos, com aproximação melhor que os métodos de elementos finitos e resinas fotoelásticas, em estruturas anisotrópicas como o crânio. 


\section{Abstract}

The holographic interferometry is a powerful optical method for observation of the disturbance phenomena and in the analysis of surface, being extremely useful in application in basic research, biomedical and technological. The photorefractive crystals present as an attractive holographic recording medium. The phenomenon that characterize these crystals is the photorefractive effect. Such effect consistis of the index of refraction modulation grating via the linear eletro-optic effect (the Pockels effect) and photoindution, that it allow phase holographic recording in volume. Among the characteristics that admit the photorefractive crystals for holographic interferometry we can cite: recording and reading tecniques to occur in dynamics way through the tecnique of two-wave mixing, it is reversible medium resulting holographic images of good quality. We analyze the varied strains that occur in the masticatory process, mainly studying the load concentration and the dissipation in this process, using the double-exposure holographic technique and the photorefractive crystals $\mathrm{Bi}_{12} \mathrm{SiO}_{20}(\mathrm{BSO})$, of the sillenite family, as holographic recording medium. The study in dry skull and the simulation of main beams of the mastication muscles allow to realize the concentration of the same ones, with better approach than the methods of finite elements and photoelastics resins, in anisotropic structures as the skull. 


\section{Sumário}

1 Introdução $\quad 8$

2 Propagação de ondas eletromagnéticas em cristais 13

2.1 Ondas eletromagnéticas em cristais . . . . . . . . . . . . . . 14

2.2 O elipsóide de índices . . . . . . . . . . . . . . . . . . . 18

2.3 Efeito Fotorrefrativo . . . . . . . . . . . . . . . . 20

2.3.1 Modelo de transporte de bandas . . . . . . . . . . . 20

2.3.2 Solução para o campo espacial de carga . . . . . . . . 23

2.4 Efeito Eletro-óptico . . . . . . . . . . . . . . . . . . . . . . . . 28

2.5 Processamento da imagem holográfica . . . . . . . . . . . 33

2.5.1 Teoria de ondas acopladas . . . . . . . . . . . 33

2.6 Propriedades de difração anisotrópica . . . . . . . . . . . . . 37

2.7 Hologramas de volume e hologramas planos . . . . . . . . . 42

2.7.1 Capacidade de armazenagem de hologramas . . . . . . 45

$\begin{array}{llr}3 & \text { Parte experimental } & 47\end{array}$

3.1 Aparato experimental . . . . . . . . . . . . . . . . . . . . 48

3.1.1 Metodologia utilizada nas medidas . . . . . . . . 53

3.2 Interpretação do padrão de interferência . . . . . . . . . . . . 56

3.3 Zonas de reforço do esqueleto facial . . . . . . . . . . . 60

3.4 Materiais e métodos . . . . . . . . . . . . . . . . 65

3.5 Resultados experimentais e discussão . . . . . . . . . . . . 67

4 Conclusões e perspectivas $\quad 89$ 
A Programa computacional $\quad 92$

A.1 Perspectivas do programa . . . . . . . . . . . . . . . 96

$\begin{array}{ll}\text { B Lista de siglas } & 98\end{array}$

$\begin{array}{ll}\text { C Documentos da bioética } & 99\end{array}$ 


\section{Capítulo 1}

\section{Introdução}

A holografia foi inventada por Dennis Gabor com o propósito de melhorar a resolução do microscópio eletrônico. A holografia é um processo de gravação e reconstrução de imagens permitindo ter uma réplica da cena em 3D. Antes de 1947 Gabor já havia refletido sobre este tema e na primeira experiência feita por ele que consistia no processo de formação da imagem sem lentes ele registrou fotograficamente o padrão de interferência que resultava da sobreposição da onda coerente de referência com um feixe de luz quase monocromático difundido pelo objeto; o registro fotogáfico deste padrão de interferência foi denominado por ele de holograma. Ele reconstruiu a imagem difratando o feixe coerente pelo holograma revelado. O holograma é um registro da interação entre dois feixes de luz coerentes no qual são mutualmente combinados, na forma de um padrão microscópico de franjas de interferência. O holograma é um registro completo da informação, isto é, da amplitude e da fase da onda difundida pelo objeto e quando é corretamente iluminado reconstrói a frente de onda do objeto permitindo assim que o observador veja a imagem total deste objeto. O desenvolvimento da holografia trouxe grandes progressos em componentes ópticos, emulsões holográficas e métodos de processamentos aliados ao crescimento do domínio das técnicas.

Com a invenção do laser em 1960 houve um grande impulso na holografia, aumentando o interesse pelo processo de reconstrução das frentes de ondas. 
A holografia tornou-se objeto de investigação bastante promissora e com o auxílio dos avanços da tecnologia, este renascimento ocorreu em 1963 na Universidade de Michigan no qual Leith e Upatnieks produziram o primeiro holograma de transmissão a laser de um objeto sólido [1].

Nesta época descobriu-se que quando o objeto era submetido a uma tensão entre duas exposições holográficas aparecia distorções que seriam resultado derivado de franjas desenhadas na superfície da imagem reconstruída [2]. O primeiro artigo publicado na área de interferometria holográfica ocorreu em 1965 por Robert Powell e Karl Steson [3]. A importância desta descoberta para a ciência de medições e para as análises de tensão e vibrações tem sido muito importante.

Em 1968 Stephen Benton produziu um holograma de transmissão no qual poderia ser reconstruído usando luz branca [4].

Em 1970 Dennis Gabor recebeu o prêmio Nobel de Física pelos seus trabalhos. Ao longo da década de 70, as principais atividades no domínio da holografia relacionaram-se com as possibilidades de visualização que ela permitia e esta ênfase também continuou na década de 80 , sendo hoje possível produzir muitos destes hologramas de reflexão em substratos plásticos.

Em 1985 desenvolveu-se polímeros fotossensíveis estáveis, capazes de reproduzir imagens de alta qualidade [5].

A interferometria holográfica é uma das aplicações inovadoras importantes da holografia sendo usada na análise de vibrações, tensões de superfícies e ensaios não destrutivos. É também utilizada como ferramenta investigativa na restauração de trabalhos de arte.

A técnica de interferometria holográfica em tempo real veio sendo utilizada com fototermoplásticos, filmes de haleto de prata, entre outros [6].

A utilização destes tipos de materiais apresentam dificuldades como a necessidade de processamento químico do filme holográfico, o material fototermoplástico também sofre desvantagens para a aplicação de memória óptica, onde o mais sério problema é a degradação da imagem depois de utilizado várias vezes no processo de gravação e apagamento. 
Os cristais fotorrefrativos se apresentam como um meio eficiente para registro holográfico e os cristais eletro-ópticos são atualmente mais promissores para o registro holográfico. Descobriu-se que em diversos cristais ocorria uma mudança do índice de refração quando eram expostos à luz, chamado de dano óptico [7].

A aplicação do efeito de dano óptico para armazenagem óptica de um holograma de fase em volume foi realizado primeiramente por Chen [8].

O fenômeno que caracteriza esses materias é o efeito fotorrefrativo que ocorre devido a um deslocamento de portadores de cargas no qual induz uma mudança de índice de refração via efeito eletro-óptico permitindo assim o registro de hologramas de fase em volume [9]. A gravação através da técnica de mistura de duas ondas [10] ocorre de maneira que o acoplamento dos dois feixes é feito pelo holograma formado por estes mesmos feixes permitindo a utilização da holografia em tempo real.

Os cristais fotorrefrativos são materiais que não precisam de processamento químico, não desgastam ao serem várias vezes utilizados e apresentam alta resolução, sendo possível obter imagens holográficas de boa qualidade.

O efeito fotorrefrativo foi observado em muitos cristais eletroópticos como: $\mathrm{LiNbO}_{3}, \mathrm{LiTaO}_{3}, \mathrm{BaTiO}_{3}, \mathrm{SrBaNb}_{2} \mathrm{O}_{6}, \mathrm{BaNaNb}_{3} \mathrm{O}_{15}, \mathrm{Bi}_{4} \mathrm{Ti}_{4} \mathrm{O}_{12}$. Entre os cristais mais utilizados estão o $\mathrm{LiNbO}_{3}, \mathrm{GaAs}, \mathrm{BaTiO}_{3}, \mathrm{Bi}_{12} \mathrm{SiO}_{20}(\mathrm{BSO})$, $B i_{12} \mathrm{TiO}_{20}(\mathrm{BTO})$ que têm várias características diferentes como a sensibilidade a determinados comprimentos de onda da luz, a eficiência de difração, o tempo de resposta, a bi-refrigência, a atividade óptica, entre outros parâmetros.

Os cristais $B S O, B T O$ e $B i_{12} G e O_{20}(B G O)$ pertencem à família das silenitas, e são apropriados para serem utilizados em interferometria holográfica, apesar de terem baixa eficiência de difração (ao contrário do $\mathrm{LiNbO}_{3}$ ) e tem a vantagem de possuírem uma resposta mais rápida e assim podem ser utilizados em ensaios em tempo real. As propriedades de difração anisotrópica destes cristais [11] permitem que o feixe difratado pelo holograma seja separado do feixe transmitido através de um polarizador posicionado atrás do 
cristal e estas qualidades fazem destes materiais da família das silenitas os mais indicados para experimentos em interferometria holográfica.

As técnicas holográficas de interferometria estão representadas em três métodos distintos com grande utilidade em ensaios não destrutivos, para detecção de distorções micrométricas em objetos que foram sujeitos a tensões, vibrações, aquecimento, etc.. A interferometria holográfica apresenta diversas aplicações em pesquisas na área da Medicina, Biologia e Tecnológicas [12, 13, 14]. As técnicas de interferometria estão representadas nos seguintes métodos:

1. Interferometria holográfica em tempo real (IHTR): O holograma é registrado e no processo de leitura o objeto é iluminado e focalizado no meio de registro, observamos um interferograma que resulta da sobreposição da frente de onda difratada pelo holograma e a frente de onda vinda diretamente do objeto, se variarmos a superfície do objeto observamos tudo em tempo real.

2. Interferometria holográfica de dupla exposição (IHDE): O registro do holograma do objeto é feito e logo após este processo fazemos um outro registro do holograma deste objeto após ser submetido a uma perturbação, desta forma a leitura deste interferograma será a sobreposição de duas ondas que interferem dando origem a um padrão de franjas que é o deslocamento dos vários pontos do objeto

3. Interferometria holográfica em média temporal (IHMT): É aplicada a sistemas que oscilam podendo assim analisar movimentos vibratórios em superfícies. O holograma é registrado durante a vibração do objeto e um intervalo de tempo maior que o período de vibração. A imagem final é resultado da sobreposição de um número grande de imagens que dão origem a um padrão de ondas estacionárias [3].

Neste trabalho iremos estudar, em crânio seco, esforços mastigatórios por meio da interferometria holográfica. 
Este trabalho tem por objetivo avançar no conhecimento de diversas tensões no processo mastigatório, estudando a concentração de cargas e dissipações durante o processo mastigatório utilizando a técnica de interferometria holográfica de dupla exposição e utilizando o cristal $\mathrm{Bi}_{12} \mathrm{SiO}_{20}(\mathrm{BSO})$ como meio de registro. Para atingir este objetivo, iremos utilizar um crânio seco para simular o que ocorre no crânio natural procurando aproximar-se do real. Os músculos da mastigação foram confeccionados em molas de aço para simular a ação dos músculos naturais.

O estudo de crânios secos, simulando esforços mastigatórios e utilizando técnicas de interferometria holográfica apresentam grande interesse para a anatomia e odontologia aplicada, nas áreas de próteses e restaurações entre outros. Os estudos em aplicação de materiais restauradores são geralmente feitos por ensaios mecânicos de fratura, dobramento e infiltração, no entanto nem sempre mostram o que ocorrem antes da fratura. Com a técnica holográfica os padrões de franjas holográficas observados sobre a superfície do objeto a ser analisado tornaram possível avaliar a distribuição das tensões antes do rompimento da restauração do dente permitindo planejar preparos e restaurações ou indicar outros materiais mais adequados. 


\section{Capítulo 2}

\section{Propagação de ondas eletromagnéticas em cristais}

Neste capítulo iremos estudar o que ocorre quando incidimos ondas eletromagnéticas em cristais fotorrefrativos, ou seja, analisaremos quais os principais processos envolvidos neste fenômeno. Para isso, utilizaremos as equações de Maxwell para obter uma relação entre a frequência angular e o vetor de onda e obter os índices de refração para cada direção de propagação da onda. O próximo passo será utilizar o método do elipsóide de índices, que descreve as propriedades ópticas do material anisotrópico, para encontrar o índice de refração associado com as duas ondas eletromagnéticas que se propagam em cristais anisotrópicos.

Durante o processo em que ocorre a incidência de uma onda eletromagnética no cristal ocorre também o efeito fotorrefrativo, que será explicado neste capítulo.

Analisaremos também o comportamento e a relação entre os feixes no interior do cristal fotorrefrativo. E por fim estudaremos algumas propriedades fundamentais de hologramas planos e de hologramas de volume. 


\subsection{Ondas eletromagnéticas em cristais}

Um dos primeiros materiais utilizados como meio de registro holográfico, foram os fototermoplásticos e os filmes de Haleto de prata. Os primeiros apresentavam boa sensibilidade óptica, resolução e alta eficiência de leitura, mas eles apresentavam grandes dificuldades devido à necessidade de processamento químico do filme holográfico e a degradação da imagem depois de utilizado várias vezes, devido ao processo de gravação e apagamento [15].

Durante vários anos foram feitas muitas pesquisas com materiais como os cristais fotorrefrativos, onde se apresentaram como um meio eficiente para registro holográfico, pois poderiam ser reutilizados várias vezes sem apresentarem os problemas dos materiais fototermoplásticos [15]. Os cristais fotorrefrativos são em sua maioria cristais anisotrópicos com permissividade dielétrica $\epsilon$.

Em meios dielétricos, todas as cargas estão ligadas em átomos ou moléculas, estas cargas estão atreladas firmemente podendo se mover dentro da molécula. O deslocamento microscópico destas cargas não é tão importante como o rearranjamento da carga no condutor, mas o efeito acumulativo contribui para o comportamento característico dos materiais dielétricos.

Ao incidirmos um LASER em um material dielétrico, os campos elétricos da radiação eletromagnética podem distorcer a distribuição de cargas nos átomos ou moléculas, através de dois mecanismos: o estiramento desse material e a rotação deste [16].

A propagação dessas ondas eletromagnéticas em um meio dielétrico é descrita pelas equações de Maxwell.

As equações que descrevem o efeito do campo elétrico em um meio material é:

$$
\begin{gathered}
\vec{D}=\epsilon_{0} \vec{E}+\vec{P} \\
D_{i}=\epsilon_{i j} E_{j},
\end{gathered}
$$


onde $\epsilon_{i j}$ é o tensor dielétrico; $\vec{P}$ é a polarização elétrica; $\epsilon_{0}$ é a permissividade do vácuo; e $\vec{D}$ é o vetor deslocamento.

A polarização elétrica, representa a polarização dos materiais dielétricos quando são submetidos à influência de um campo elétrico externo. Da equação (2.1), temos:

$$
\epsilon_{i j}=\epsilon_{0}\left(1+\chi_{i j}\right)
$$

onde $\epsilon_{i j}$ possui nove elementos que constitui o tensor dielétrico; $\chi_{i j}$ é a suscetibilidade do meio. Para um meio anisotrópico $\epsilon_{i j}=\epsilon_{j i}$, ou seja, o tensor dielétrico é simétrico, possuindo assim, apenas seis elementos independentes.

Em um meio anisotrópico, a velocidade de fase da luz depende do seu estado de polarização e da sua direção de propagação. O estado de polarização da onda eletromagnética plana pode variar quando esta propaga num cristal, devido à anisotropia do meio. Isto ocorre porque para cada direção cristalina desses cristais pode-se associar um determinado valor para a constante dielétrica e assim para o índice de refração.

Uma onda plana monocromática de frequência angular $\omega$ e campo elétrico $\vec{E}$, que propaga-se em um meio anisotrópico é expresso desta forma:

$$
\begin{aligned}
& \vec{E}=E_{0} e^{i(\omega t-\vec{K} \cdot \vec{r})}, \\
& \vec{B}=B_{0} e^{i(\omega t-\vec{K} \cdot \vec{r})} .
\end{aligned}
$$

Onde $\vec{K}$ é o vetor de onda dado por:

$$
\vec{K}=\frac{\omega}{c} n \vec{S}
$$

onde $\vec{S}$ é o vetor unitário na direção de propagação da onda no cristal e $n$ é o índice de refração. No qual $\overrightarrow{S^{2}}=1$.

A partír da equação de Maxwell:

$$
\vec{\nabla} \times \vec{E}+\frac{\partial\left(\mu_{0} \vec{H}\right)}{\partial t}=0
$$


sabendo que $\vec{D}=\epsilon \vec{E}$ e substituindo $\vec{\nabla} \times \vec{H}=\frac{\partial \vec{D}}{\partial t}$, encontramos:

$$
\begin{aligned}
\vec{\nabla} \times\left(\vec{\nabla} \times \vec{E}+\frac{\partial\left(\mu_{0} \vec{H}\right)}{\partial t}\right) & =\vec{\nabla} \times(\vec{\nabla} \times \vec{E})+\mu_{0} \epsilon \frac{\partial^{2} \vec{E}}{\partial t^{2}} \\
\vec{\nabla} \times(\vec{\nabla} \times \vec{E})+\mu_{0} \epsilon \frac{\partial^{2} \vec{E}}{\partial t^{2}} & =0
\end{aligned}
$$

a equação (2.9) depende somente do campo elétrico. Como utilizamos ondas eletromagnéticas planas, $\vec{E}$ e $\vec{B}$ serão sempre perpendiculares à direção de propagação $\vec{K}[17]$.

Substituindo então (2.4) na equação (2.9), encontramos:

$$
\vec{K} \times(\vec{K} \times \vec{E})+\mu_{0} \epsilon \omega^{2} \vec{E}=0
$$

onde $\vec{K}=K_{x}+K_{y}+K_{z} ; \vec{E}=E_{x}+E_{y}+E_{z}$, e o tensor de permissividade dielétrica é expresso, para a maioria dos cristais anisotrópicos, como:

$$
\epsilon=\left(\begin{array}{ccc}
\epsilon_{x} & 0 & 0 \\
0 & \epsilon_{y} & 0 \\
0 & 0 & \epsilon_{z}
\end{array}\right)
$$

Substituindo estes termos na equação (2.10) juntamente com a substituição da matriz $\epsilon$ e desenvolvendo esta equação chegaremos a um produto matricial cuja solução, não trivial, é dada por:

$$
\operatorname{det}\left|\begin{array}{ccc}
\mu_{0} \omega^{2} \epsilon_{x}-K_{y}^{2}-K_{z}^{2} & K_{y} K_{x} & K_{z} K_{x} \\
K_{x} K_{y} & \mu_{0} \omega^{2} \epsilon_{y}-K_{z}^{2}-K_{x}^{2} & K_{z} K_{y} \\
K_{x} K_{z} & K_{y} K_{z} & \mu_{0} \omega^{2} \epsilon_{z}-K_{x}^{2}-K_{y}^{2}
\end{array}\right|=0 .
$$

Desta forma, encontramos uma relação entre a frequência angular $\omega$ e o vetor de onda $\vec{K}$ e esta equação é representada por uma superfície tridimensional no espaço dos $\vec{K}$ ou espaço dos momentos.

Quando determinamos a direção de propagação da onda, há em geral dois valores do vetor de onda que correspondem a duas diferentes velocidades 
de fase destas ondas se propagando ao longo da direção que foi escolhida, correspondendo a equação (2.6)

Substituindo (2.4) na expresão (2.10), e utilizando a identidade: $\vec{A} \times(\vec{B} \times$ $\vec{C})=(\vec{A} \cdot \vec{C}) \vec{B}-(\vec{A} \cdot \vec{B}) \vec{C}$ e substituindo a expressão (2.6) no valor de $\vec{K}$, encontramos:

$$
\begin{aligned}
& \vec{K} \times\left(\vec{K} \times \overrightarrow{E_{0}}\right)=-\mu_{0} \epsilon \omega^{2} \vec{E}_{0}=-\vec{K} \times\left(\overrightarrow{E_{0}} \times \vec{K}\right) \\
& K^{2} \overrightarrow{E_{0}}-\left(\vec{K} \cdot \overrightarrow{E_{0}}\right) \vec{K}=\mu_{0} \epsilon \omega^{2} \overrightarrow{E_{0}}=K_{0}^{2} n^{2} S^{2} \overrightarrow{E_{0}}-\left(K_{0} n \vec{S} \cdot \overrightarrow{E_{0}}\right) K_{0} n \vec{S} \\
& \epsilon_{0} n^{2} \overrightarrow{E_{0}}-\epsilon_{0} n^{2} \vec{S}\left(\vec{S} \cdot \overrightarrow{E_{0}}\right)=\epsilon \vec{E}_{0}
\end{aligned}
$$

onde $K_{0}=\frac{\omega}{c}$ e sabemos que $\epsilon_{i}=n_{i}^{2} \epsilon_{0}$ e que $c^{2}=\frac{1}{\mu_{0} \epsilon_{0}}$, substituindo na equação (2.13). Teremos, para iésima componente do vetor:

$$
\begin{gathered}
\epsilon_{0} n^{2} E_{0 i}-\epsilon_{0} n^{2} S_{i}\left(\vec{S} \cdot \vec{E}_{0}\right)=\epsilon_{i} E_{0 i}=\left(n^{2}-n_{i}^{2}\right) E_{0 i}=n^{2} S_{i}\left(\vec{S} \cdot \vec{E}_{0}\right) \\
E_{0 i}=\frac{n^{2} S_{i}\left(\vec{S} \cdot \vec{E}_{0}\right)}{n^{2}-n_{i}^{2}}
\end{gathered}
$$

construindo a expressão $\left(\vec{S} \cdot \vec{E}_{0}\right)=S_{1} E_{01}+S_{1} E_{02}+S_{1} E_{03}$, sabemos também que $S^{2}=S_{1}^{2}+S_{2}^{2}+S_{3}^{2}$ e multiplicando $S_{i}$ dos dois lados da equação (2.15); com $i=x, y, z$, encontramos:

$$
\begin{aligned}
S_{i} E_{0 i} & =\frac{n^{2} S_{i}^{2}\left(\vec{S} \cdot \vec{E}_{0}\right)}{n^{2}-n_{i}^{2}} ; \\
\frac{1}{n^{2}} & =\frac{S_{i}^{2}}{n^{2}-n_{i}^{2}},
\end{aligned}
$$

substituindo o valor de $n_{i}^{2}$ e abrindo os termos de $i$ da equação (2.17), encontramos:

$$
\frac{S_{x}^{2}}{n^{2}-\left(\frac{\epsilon_{x}}{\epsilon_{0}}\right)}+\frac{S_{y}^{2}}{n^{2}-\left(\frac{\epsilon_{y}}{\epsilon_{0}}\right)}+\frac{S_{z}^{2}}{n^{2}-\left(\frac{\epsilon_{z}}{\epsilon_{0}}\right)}=\frac{1}{n^{2}},
$$

a equação (2.18) é chamada de equação de Fresnel de ondas normais. Para cada direção de propagação $\left(S_{x}, S_{y}, S_{z}\right)$, obtemos duas soluções para $n^{2}$. Desta forma, teremos também duas velocidades de fase $\frac{c}{n}$. 
Os índices de refração e as direções de $\vec{D}, \vec{H}$ e o vetor campo elétrico $\vec{E}$ dos modos normais de propagação, podem ser encontrados utilizando as equações de Maxwell, mas é frequentemente utilizado o método do elipsóide de índices que é descrito a seguir.

\subsection{O elipsóide de índices}

O método do elipsóide de índice é usado para descrever as propriedades ópticas de um material anisotrópico, principalmente para encontrar os dois índices de refração e as duas correspondentes direções de $\vec{D}$ associada com as duas ondas planas que podem se propagar ao longo da direção arbitrária $\vec{S}$ no cristal.

A densidade de energia, em um meio anisotrópico, é descrito como:

$$
U_{e}=\frac{1}{2} E_{i} \epsilon_{i j} E_{j}
$$

A superfície de densidade de energia constante $U_{e}$ no espaço $\vec{D}$ pode ser escrita:

$$
\frac{D_{x}^{2}}{\epsilon_{x}}+\frac{D_{y}^{2}}{\epsilon_{y}}+\frac{D_{z}^{2}}{\epsilon_{z}}=2 U_{e},
$$

onde $\epsilon_{x}, \epsilon_{y}, \epsilon_{z}$ são as constantes dielétricas principais.

Para chegar a equação geral do elipsóide, substituimos $\frac{\vec{D}}{\sqrt{2 U_{e} \epsilon_{0}}}$ por $\vec{r}$ e definindo o índice de refração principal por $n_{i}^{2}=\frac{\epsilon_{i}}{\epsilon_{0}}$; com $i=x, y$, $z$, a equação (2.20) fica:

$$
\frac{x^{2}}{n_{x}^{2}}+\frac{y^{2}}{n_{y}^{2}}+\frac{z^{2}}{n_{z}^{2}}=1,
$$

esta é a equação geral do elipsóide com o eixo maior paralelo às direções $x, y, z$, cujos respectivos comprimentos são $2 n_{x}, 2 n_{y}, 2 n_{z}$.

Para uma dada direção de propagação dentro do cristal, é construído um plano perpendicular ao vetor de propagação, passando através do centro do elipsóide. A curva formada pela intersecção deste plano com o elipsóide de 
índice, forma uma elípse. O semi eixo maior e menor desta elípse nos dá os dois valores permitidos do índice de refração para esta particular direção de propagação. As orientações desses eixos nos dão a direção de polarização do vetor $\vec{D}$ associada com esses índices refrativos.

Este método mostrou que a superfície normal (determinada pelos índices principais de refração), contém uma boa quantidade de informação a respeito da propagação da onda em um meio anisotrópico.

Em muitos cristais fotorrefrativos dois índices principais de refração são iguais devido as propriedades de simetria, e a equação para a superfície normal que descreve esse fato é:

$$
\begin{gathered}
\left(\frac{k_{x}^{2}+k_{y}^{2}}{n_{e}^{2}}+\frac{k_{z}^{2}}{n_{0}^{2}}-\frac{\omega^{2}}{c^{2}}\right)\left(\frac{k^{2}}{n_{0}^{2}}-\frac{\omega^{2}}{c^{2}}\right)=0 ; \\
n_{0}^{2}=\frac{\epsilon_{x}}{\epsilon_{0}}=\frac{\epsilon_{y}}{\epsilon_{0}}, \\
n_{e}^{2}=\frac{\epsilon_{z}}{\epsilon_{0}} .
\end{gathered}
$$

Onde $n_{0}$ é chamado de índice de refração ordinário e $n_{e}$ é chamado de índice de refração extraordinário.

Os cristais fotorrefrativos como o $\mathrm{Bi}_{12} \mathrm{SiO}_{20}(\mathrm{BSO}), \mathrm{Bi}_{12} \mathrm{TiO}_{20}(\mathrm{BTO})$, $B i_{12} G e O_{20}(B G O)$ que pertencem a família das silenitas, apresentam uma atividade óptica que devemos levar em consideração ao utilizá-los em medidas, pois estes tipos de cristais causam uma rotação no plano de polarização da luz linearmente polarizada que passa através deles.

Se o sentido de rotação do plano de polarização da luz é contrária a direção dos ponteiros do relógio a substância é chamada de Dextrógira, mas se o sentido de rotação é o mesmo sentido dos ponteiros do relógio a substância é chamada de Levógira.

A atividade óptica no material surge de uma dupla refração, no qual os modos normais de propagação da luz são duas ondas circulamente polarizadas esquerda e direita. Estas ondas atravessam o meio com velocidades diferentes 
acarretando numa diferença de fase entre as duas ondas e por consequência aos índices de refração diferentes associados a essas ondas.

\subsection{Efeito Fotorrefrativo}

O efeito fotorrefrativo é uma mudança no índice de refração de um material óptico, resultante de uma nova distribuição opticamente induzida dos elétrons e buracos, isto acontece devido estes cristais possuírem a característica de apresentarem uma modulação em seu índice de refração ao serem iluminados por um padrão luminoso não uniforme.

O efeito fotorrefrativo é diferente da maioria dos outros efeitos ópticos não linear, onde este efeito não é descrito pela suscetibilidade $\chi$, e desta forma métodos especiais podem ser empregados para descrevê-lo. O efeito fotorrefrativo consiste de dois processos:

- Migração de portadores de cargas de regiões iluminadas para as regiões escuras do cristal.

- Alteração do índice de refração causada pela redistribuição espacial destas cargas.

O primeiro processo é chamado de foto-indução e pode ser notado em qualquer material fotocondutor. O segundo processo é denominado de efeito eletro-óptico, e ocorre somente em cristais que não apresentam simetria de inversão ${ }^{1}[18]$.

\subsubsection{Modelo de transporte de bandas}

É um modelo teórico bastante usado para explicar a maioria dos fenômenos fotorrefrativos observados como é exposto em [19]. Neste modelo assumimos que os cristais têm certos tipos de impurezas e de imperfeições.

\footnotetext{
${ }^{1}$ Se o cristal contêm pontos tal que a inversão destes pontos deixa a estrutura cristalina invariante, o cristal é dito possuir inversão de simetria.
} 
Por simplicidade, assumiremos que todas as impurezas doadoras são idênticas e possuem o mesmo estado de energia, no meio do gap (A energia do gap é definida como energia de separação entre os estados de energia cheio e vazio). Estas impurezas doadoras podem ser ionizadas pela absorção de fótons, devido à incidência de luz LASER, como resultado dessa ionização elétrons serão gerados na banda de condução (banda vazia). Estes por sua vez, serão capturados por impurezas ionizadas. Para toda impureza ionizada, haverá um elétron gerado.

Definimos a densidade de impurezas doadoras como $N_{D}$, e $N_{D}^{i}$ como a densidade de impurezas ionizadas.

A taxa de geração de elétrons será:

$$
(S I+\beta)\left(N_{D}-N_{D}^{i}\right)
$$

Onde $S$ é a seção de choque para fotoexcitação, $I$ é a intensidade da luz e $\beta$ é o coeficiente de geração térmica.

A taxa de recombinação de fotoelétrons será:

$$
\gamma N N_{D}^{i}
$$

onde $N$ é a densidade de elétrons e $\gamma$ é o coeficiente de recombinação,

A taxa de recombinação de fotoelétrons é linearmente proporcional ao número de elétrons e ao número de impurezas ionizadas. O tempo de vida dos fotoelétrons na banda de condução é $\tau=\frac{1}{\gamma N_{D}^{i}}$.

Encontraremos agora a variação temporal de impurezas ionizadas, para isto ignoraremos o coeficiente de geração térmica, pois $\beta<<S I$, temos:

$$
\frac{\partial N_{D}^{i}}{\partial t}=S I\left(N_{D}-N_{D}^{i}\right)-\gamma N N_{D}^{i}
$$

como foi dito anteriormente, para toda impureza ionizada será gerado um fotoelétron, e assim a taxa de geração destes elétrons serão a mesma que a de impurezas ionizadas, onde os elétrons são móveis e as impurezas são estáticas. 
O transporte de elétrons implica numa variação da densidade de corrente, como é descrita na equação:

$$
\begin{aligned}
& \frac{\partial N}{\partial t}-\frac{\partial N_{D}^{i}}{\partial t}=\frac{1}{q} \vec{\nabla} \cdot \vec{J} ; \\
& \vec{J}=q N \mu \vec{E}+q L_{d} \nabla N,
\end{aligned}
$$

onde $L_{d}=\frac{K_{B} T \mu}{q}$ é o coeficiente de difusão; $\mu$ é a mobilidade dos elétrons na banda de condução; e $q$ é a carga.

A equação (2.27) é a densidade de corrente, onde o primeiro termo representa uma contribuição de arraste para a corrente, onde o campo elétrico $\vec{E}$ é uma combinação de um campo $E_{0}$ aplicado externamente no cristal e do campo $\overrightarrow{E_{s c}}$ originado de uma distribuição não uniforme de carga (a presença dos elétrons portadores de carga, geram um campo elétrico espacial que por sua vez afeta o transporte dos portadores de carga). O segundo termo é a contribuição à densidade de corrente, através da difusão de cargas.

A figura 2.1 mostra o processo em que ocorre a incidência sobre o cristal de dois feixes laser de intensidades $I_{R}$ e $I_{S}$.

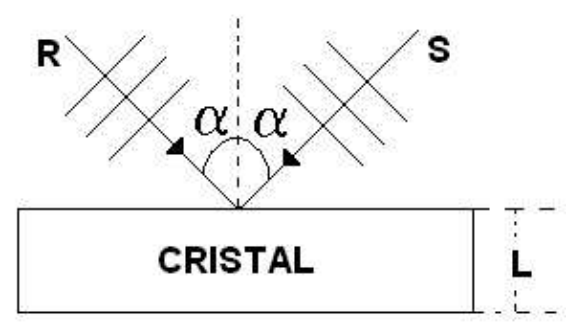

Figura 2.1: Feixes coerentes $R$ e $S$ incidindo sobre o cristal fotorrefrativo.

O campo elétrico dentro do cristal é descrito como:

$$
\vec{E}=\vec{E}_{R} e^{i\left(\omega t-\vec{K}_{R} \cdot \vec{r}\right)}+\vec{E}_{S} e^{i\left(\omega t-\vec{K}_{S} \cdot \vec{r}\right)} .
$$


Assumimos que as frequências dos feixes são idênticas, $\overrightarrow{E_{R}}$ e $\overrightarrow{E_{S}}$ são amplitudes dos campos e $\vec{K}_{R}$ e $\vec{K}_{S}$ são vetores de ondas.

Devido a resposta não linear do cristal, esta distribuição de intensidade não uniforme, produz uma rede de índice refrativo dentro do cristal.

$$
\begin{gathered}
I(\vec{r})=I_{0}+\operatorname{Re}\left\{I_{1} e^{-i(\vec{K} \cdot \vec{r})}\right\} ; \\
I_{0}=\left|\vec{E}_{R}\right|^{2}+\left|\vec{E}_{S}\right|^{2}, \\
I_{1}=2 \vec{E}_{S} \cdot \vec{E}_{R}^{*} .
\end{gathered}
$$

Onde $\vec{K}=\vec{K}_{S}-\vec{K}_{R}$ no qual é definido como $\vec{K}=\frac{2 \pi}{\Lambda}$ que é o vetor de onda da rede e $\Lambda$ é a periodicidade da rede.

Substituindo $I_{0}$ e $I_{1}$ na equação (2.29) encontramos:

$$
I=I_{0}[1+|m| \cos (K x+\varphi)],
$$

onde $\varphi$ é uma fase arbitrária do feixe $S$ e $m=\frac{2\left|I_{1}\right| e^{i \varphi}}{I_{0}}$ é conhecido como o contraste do padrão de interferência.

A visibilidade máxima da franja ocorre quando as duas ondas são polarizadas ao longo da mesma direção, e com a mesma magnitude $E_{R}=E_{S}$. A intensidade para este caso é:

$$
I=I_{0}(1+\cos \vec{K} \cdot \vec{r}),
$$

onde esta equação representa as franjas de interferência.

\subsubsection{Solução para o campo espacial de carga}

Para determinar como as propriedades ópticas dos materiais fotorrefrativos são modificadas na presença de um campo elétrico, nós primeiramente resolvemos a equação (2.25) de Kukhtarev [20] para encontrar o campo elétrico estático induzido pela distribuição de intensidade da equação (2.29). 
O campo elétrico que aparece na equação (2.27) é um campo elétrico estático aparecendo dentro do cristal devido a uma voltagem aplicada ou a uma separação de cargas dentro do cristal. Isto satisfaz a equação de Maxwell.

$$
\epsilon \nabla \cdot \vec{E}=\rho=-q\left(N+N_{A}-N_{D}^{i}\right),
$$

onde $\epsilon$ é a constante dielétrica do cristal e $N_{A}$ é a densidade de impurezas receptoras.

As equações são não lineares, contêm produtos de quantidades não conhecidas e desta forma não podem ser facilmente resolvidas exatamente. Por este motivo, assumimos que $m<<1$, ou seja, $\left|I_{1}\right|<<I_{0}$ e buscamos uma solução para aproximação de estado estacionário da equação (2.25), através da equação (2.34).

No estado estacionário, a derivada temporal da equação fundamental do modelo de transporte de bandas, para o efeito fotorrefrativo, é dada por:

$$
\begin{gathered}
\frac{\partial N_{D}^{i}}{\partial t}=S I\left(N_{D}-N_{D}^{i}\right)-\gamma N N_{D}^{i}=0 \\
S I\left(N_{D}-N_{D}^{i}\right)-\gamma N N_{D}^{i}=0 .
\end{gathered}
$$

Para o caso em que a iluminação é uniforme, $I_{1}=0$ (tem uma iluminação uniforme de um único feixe ou dois feixes com polarização ortogonal $\left(I_{1}=\right.$ $\left.2 \vec{E}_{S} \cdot \vec{E}^{*}{ }_{R}=0\right)$ ), não há variação espacial das quantidades físicas, desta forma a densidade dos portadores de carga será dada por:

$$
S I\left(N_{D}-N_{D}^{i}\right)=\gamma N N_{D}^{i}
$$

E através da equação (2.34), sabendo que $\nabla \cdot \vec{J}=0$, temos:

$$
\left(N+N_{A}-N_{D}^{i}\right)=0
$$


Isolando $N_{D}^{i}$ (densidade de impurezas doadoras) da equação (2.37) encontramos:

$$
N_{D}^{i}=\frac{S I N_{D}}{(\gamma N+S I)} .
$$

Para casos realísticos $N<<N_{A}$ é satisfeito, através disso encontraremos a densidade de elétrons e a densidade de impurezas doadoras. Isolamos $N$ da equação (2.38) e encontramos:

$$
N=\frac{S I\left(N_{D}-N_{A}\right)}{\gamma N_{A}} .
$$

Sabendo que $N_{D}^{i}=N_{A}+N$, então $N_{D}^{i}$ pode ser escrito como:

$$
N_{D}^{i}=N_{A}+\frac{S I\left(N_{D}-N_{A}\right)}{\gamma N_{A}} .
$$

As equações (2.40) e (2.41) são as densidades de fotoelétrons sob uma incidência de iluminação de intensidade uniforme $I$.

Para o caso em que a iluminação não é uniforme, ou seja, iluminação periódica, $I_{1} \neq 0$, os dois feixes incidentes no cristal fotorrefrativo se interceptam gerando um padrão de interferência, e assim temos:

$$
\begin{gathered}
I=I_{0}+I_{1}, \\
N_{D}^{i}=N_{D 0}^{i}+N_{D 1}^{i}, \\
N=N_{0}+N_{1} .
\end{gathered}
$$

Substituindo $I, N_{D}^{i}$ e $N$ na equação (2.36), temos:

$$
S I_{1}\left(N_{D}-N_{D 0}^{i}\right)+S I_{0}\left(-N_{D 1}^{i}\right)-\gamma N_{1} N_{D 0}^{i}-\gamma N_{0} N_{D 1}^{i}=0
$$

e negligenciando termos de ordens altas, encontramos:

$$
S I\left(N_{D}-N_{D 0}^{i}\right)-\gamma N_{0} N_{D 0}^{i}=0
$$


De acordo com a equação $(2.27)$, faremos $\nabla \cdot \vec{J}=0$, onde $\vec{J}$ é composto por:

$$
\vec{J}(\vec{r})=\overrightarrow{J_{0}}+\operatorname{Re}\left\{\vec{J}_{1} e^{(-i \vec{K} \cdot \vec{r})}\right\}
$$

como sabemos que $\vec{\nabla}=-i \vec{K}$, pois estamos trabalhando com ondas transversais. O campo elétrico $\vec{E}$ é composto por $\vec{E}(\vec{r})=\vec{E}_{0}+R e\left\{\vec{E}_{1} e^{(-i \vec{K} \cdot \vec{r})}\right\}$.

Resolvendo esta equação, encontramos:

$$
\vec{K} \cdot\left(q N_{1} \mu \vec{E}_{0}+q N_{0} \mu \vec{E}_{1}-i k_{B} T \mu \vec{K} N_{1}\right)=0,
$$

utilizando a equação (2.34) onde $N_{D}^{i}=N_{A}+N$, sabendo também que $\left(N_{0}+\right.$ $\left.N_{A}-N_{D 0}^{i}=0\right)$, e fazendo todos os cálculos, encontramos:

$$
-i \vec{K} \cdot \epsilon \vec{E}_{1}=-q\left(N_{1}-N_{D 1}^{i}\right)
$$

$\mathrm{O}$ valor de $E_{0}$ depende das propriedades de algum circuito elétrico externo que está conectado ao cristal. Na situação em que não há voltagem aplicada externamente no cristal, $J_{0}$ desaparece.

Então consideramos que $E_{0}=0$, assim teremos equações apenas de primeira ordem. Neste caso os fotoelétrons são transportados por difusão e as cargas são separadas gerando um campo elétrico estático onde os elétrons se deslocam em direções opostas.

Utilizando as equações $(2.48)$ e (2.49) para $E_{0}=0$ e no caso em que $N<<N_{A}$, temos:

$$
E_{1}=i\left(\frac{I_{1}}{I_{0}}\right) \frac{E_{d}}{\left(1+\frac{E_{d}}{E_{q}}\right)},
$$

a equação (2.50) é o campo espacial de cargas, onde:

$$
\begin{gathered}
E_{d}=\frac{\vec{K} k_{B} T}{q} ; \\
E_{q}=\left(\frac{q}{\epsilon \vec{K}}\right) N_{e f f}
\end{gathered}
$$




$$
N_{e f f}=\frac{N_{A}\left(N_{D}-N_{A}\right)}{N_{D}},
$$

em que $E_{d}$ é o campo de difusão, e $E_{q}$ é o campo máximo espacial de carga. $E_{q}$ é uma medida de campo elétrico máximo que pode ser criado pela redistribuição de carga que quer dizer a densidade $q N_{\text {eff }}$ sobre a distância característica $\frac{2 \pi}{\vec{K}}$.

$E_{d}$ é uma medida de intensidade de campo necessária para impedir a separação de cargas devido a agitação térmica.

O fator $i$ na equação (2.50) representa que quando a formação do campo elétrico ocorre por difusão, ele está defasado de $\frac{\pi}{2}$ em relação ao padrão de interferência. Como a modulação do índice de refração está em fase com o campo elétrico, temos que o holograma formado também está defasado de $\frac{\pi}{2}$ em relação ao padrão luminoso.

A figura 2.2 mostra o processo de modulação no efeito fotorrefrativo.
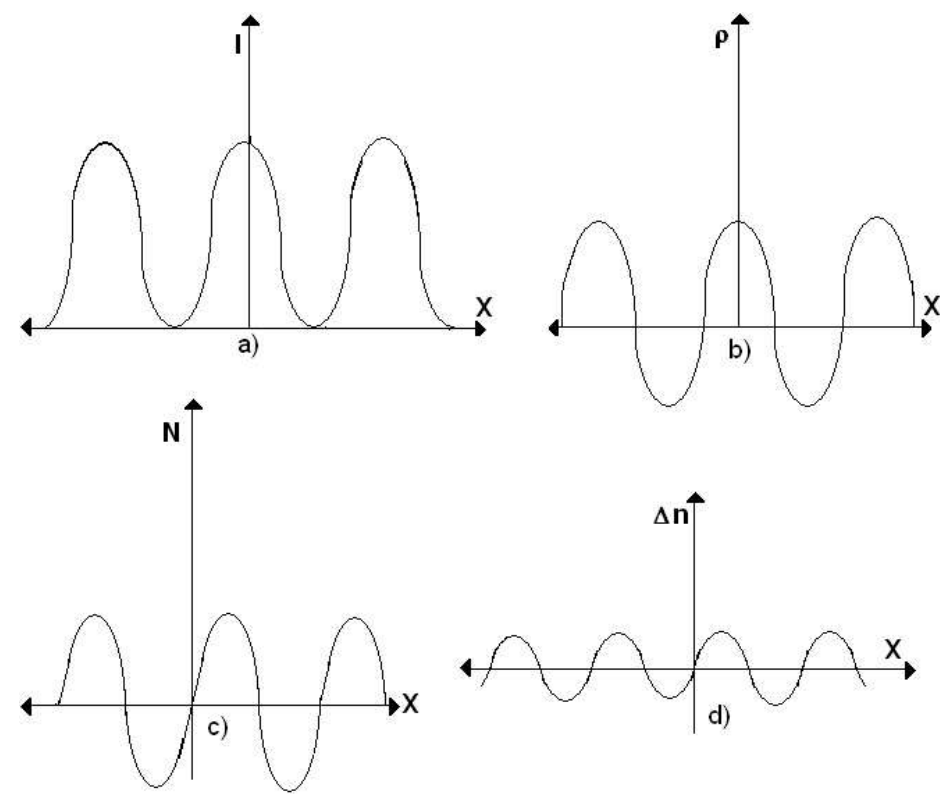

Figura 2.2: a) É o padrão de interferência $I$ incidente sobre o cristal; b) É a distribuição de cargas $\rho$; c) É o transporte de elétrons $N$ e d) É a variação do índice de refração $\Delta n$. 


\subsection{Efeito Eletro-óptico}

O efeito eletro-óptico é a mudança no índice de refração do material induzido pela presença de um campo elétrico. Em muitos materiais, a mudança no índice de refração depende linearmente da intensidade do campo elétrico. Essa mudança é conhecida como efeito eletro-óptico linear ou efeito pockels.

A formação de um holograma de fase no cristal fotorrefrativo é devido ao efeito eletro-óptico.

As equações de Maxwell mostram que a velocidade de propagação da luz em um material anisotrópico depende da sua direção de polarização, pois para cada direção desse tipo de material pode-se associar um determinado valor da constante dielétrica, e desta forma, do índice de refração.

A propagação da radiação no cristal pode ser descrita completamente em termos do tensor impermeabilidade $\eta_{i j}$. As duas direções de polarização, assim como os correspondentes índices de refração (velocidade de propagação) dos modos normais, são encontrados mais facilmente usando o método do elipsóide de índice, equação (2.21), onde $x, y, z$ são chamados de eixos principais que são as duas direções ao longo do cristal no qual $\vec{D}$ e $\vec{E}$ são paralelos. $\frac{1}{n_{x}^{2}}, \frac{1}{n_{y}^{2}}, \frac{1}{n_{z}^{2}}$ são os valores principais do tensor impermeabilidade, dado por: $\eta_{i j}=\epsilon_{0}\left(\epsilon^{-1}\right)_{i j}$.

De acordo com a teoria quântica de sólidos, o tensor óptico de impermeabilidade dielétrica, depende da distribuição de cargas no cristal. A aplicação de um campo elétrico externo, resultaria na redistribuição destas cargas e possivelmente uma deformação superficial na rede do íon. O resultado é uma mudança no tensor impermeabilidade óptico. Isto é conhecido como efeito eletro-óptico, que existe apenas em cristais que não possui inversão de simetria.

Para o caso em que há a ação de um campo elétrico externo no interior de um cristal sem inversão de simetria, temos que a equação do elipsóide de 
índice é descrita como:

$\left(\frac{1}{n^{2}}\right)_{1} x^{2}+\left(\frac{1}{n^{2}}\right)_{2} y^{2}+\left(\frac{1}{n^{2}}\right)_{3} z^{2}+2\left(\frac{1}{n^{2}}\right)_{4} y z+2\left(\frac{1}{n^{2}}\right)_{5} x z+2\left(\frac{1}{n^{2}}\right)_{6} x y=1$,

os termos $\left(\frac{1}{n^{2}}\right)_{4-6}$ são nulos caso não haja campo elétrico externo no cristal, e estes podem ser obtidos através da definição do coeficiente eletro-óptico:

$$
\Delta\left(\frac{1}{n^{2}}\right)_{i}=\sum_{j=1}^{3} r_{i j} E_{j}
$$

onde $r_{i j}$ são os coeficientes eletro-óptico que formam o tensor $(6 \times 3)$ eletroóptico, $E_{j}$ é a componente do campo elétrico.

A forma tensorial de $r_{i j}$ é dada como:

$$
r_{i j}=\left|\begin{array}{lll}
r_{11} & r_{12} & r_{13} \\
r_{21} & r_{22} & r_{23} \\
r_{31} & r_{32} & r_{33} \\
r_{41} & r_{42} & r_{43} \\
r_{51} & r_{52} & r_{53} \\
r_{61} & r_{62} & r_{63}
\end{array}\right|,
$$

cada grupo de simetria de cristais possui um tensor eletro-óptico característico, onde são bem conhecidos na literatura[21]. Para cristais que têm simetria de inversão, sabemos que $r_{i j}=0$.

Os cristais da família das silenitas $(B S O, B G O, B T O)$, com grupo de simetria de ponto 23 [22] tornam-se bi-refringentes na presença de um campo elétrico, além de possuírem atividade óptica.

O tensor eletro-óptico destes cristais depende somente dos coeficientes $r_{41}, r_{52}, r_{63}$ sendo que $r_{41}=r_{52}=r_{63}$, assim temos: 


$$
r_{i j}=\left|\begin{array}{ccc}
0 & 0 & 0 \\
0 & 0 & 0 \\
0 & 0 & 0 \\
r_{41} & 0 & 0 \\
0 & r_{41} & 0 \\
0 & 0 & r_{41}
\end{array}\right|
$$

através do tensor descrito acima podemos determinar os três últimos termos do primeiro membro da equação (2.51):

$$
\begin{aligned}
& \Delta\left(\frac{1}{n^{2}}\right)_{4}=r_{41} E_{X}, \\
& \Delta\left(\frac{1}{n^{2}}\right)_{5}=r_{41} E_{Y}, \\
& \Delta\left(\frac{1}{n^{2}}\right)_{6}=r_{41} E_{Z} .
\end{aligned}
$$

Para calcularmos a variação do índice de refração, consideramos que o exemplo aqui será referente a um padrão de interferência incidindo sobre o cristal fotorrefrativo da família das silenitas de acordo com a figura 2.3

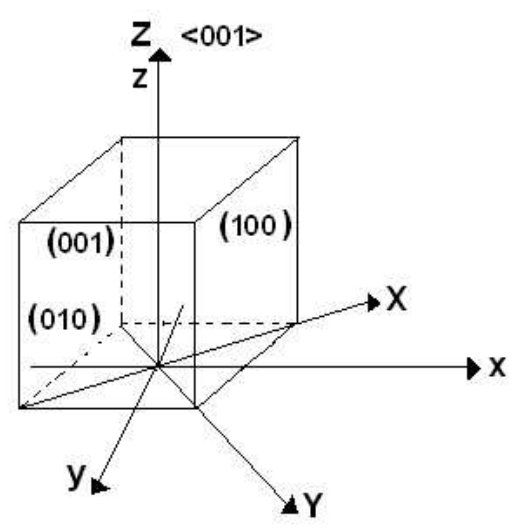

Figura 2.3: Orientação dos eixos cristalinos segundo a configuração eletro-óptica transversa. 
Consideraremos desprezível a espessura do cristal, afim de facilitar os cálculos, e além disso consideraremos as direções definidas pelos eixos $X, Y, Z$ relativas aos eixos cristalográficos $\langle 100\rangle,\langle 010\rangle,\langle 001\rangle$ respectivamente.

A equação para o elipsóide de índice tem a forma:

$$
\left(\frac{X^{2}}{n_{0}^{2}}\right)+\left(\frac{Y^{2}}{n_{0}^{2}}\right)+\left(\frac{Z^{2}}{n_{0}^{2}}\right)+2 r_{41} E_{X} Y Z+2 r_{41} E_{Y} X Z+2 r_{41} E_{Z} X Y=1
$$

Sendo $n_{1}=n_{2}=n_{3}=n_{0}$.

As faces do cristal são orientadas de acordo com a figura 2.3. Utilizamos a configuração eletro-óptica transversa, onde os eixos $x$ e $y$ são girados a $45^{0}$ em relação aos eixos $X$ e $Y$.

A mudança de coordenadas é expressa por:

$$
\begin{aligned}
& X=x \cos 45^{\circ}+y \operatorname{sen} 45^{0} \\
& Y=x \operatorname{sen} 45^{0}-y \cos 45^{\circ} .
\end{aligned}
$$

Substituindo $X$ e $Y$ na equação (2.56) e substituindo $E_{X}, E_{Y}, E_{Z}$, onde sabemos que o campo elétrico que provoca a modulação do índice de refração, $E_{s c}$, está na direção $x$, podemos escrever então $E_{s c}$ em termos de $E_{X}$ e $E_{Y}$, e sabendo que $E_{Z}=0$ :

$$
E_{X}=E_{Y}=\sqrt{2} E_{s c}
$$

Encontramos:

$$
\left(\frac{x^{2}}{n_{0}^{2}}\right)+\left(\frac{y^{2}}{n_{0}^{2}}\right)+\left(\frac{z^{2}}{n_{0}^{2}}\right)+2 E_{s c} r_{41} x z=1 .
$$

A equação (2.59) será descrita na forma de um elipsóide para avaliarmos a variação sofrida pelo índice de refração.

Faremos uma nova rotação do sistema de coordenadas em torno do eixo y, obtendo assim uma equação para o elipsóide em termos das coordenadas 
$x^{\prime}, y, z^{\prime}$. Desta forma, temos:

$$
\begin{gathered}
x=x^{\prime} \cos 45^{0}+z^{\prime} \operatorname{sen} 45^{0} ; \\
z=-x^{\prime} \cos 45^{0}+z^{\prime} \operatorname{sen} 45^{0} .
\end{gathered}
$$

Substituindo na equação (2.59), encontramos:

$$
\left(\frac{1}{n^{2}}+E_{s c} r_{41}\right) x^{\prime 2}+\frac{y^{2}}{n^{2}}+\left(\frac{1}{n^{2}}-E_{s c} r_{41}\right) z^{\prime 2}=1
$$

escrevendo a equação (2.62) como:

$$
\frac{x^{\prime 2}}{n_{x^{\prime}}^{2}}+\frac{y^{2}}{n_{0}^{2}}+\frac{z^{\prime 2}}{n_{z^{\prime}}^{2}}=1
$$

sabendo que:

$$
\begin{aligned}
& \frac{1}{n_{x^{\prime}}^{2}}=\left(\frac{1}{n^{2}}+E_{s c} r_{41}\right) ; \\
& \frac{1}{n_{z^{\prime}}^{2}}=\left(\frac{1}{n^{2}}-E_{s c} r_{41}\right),
\end{aligned}
$$

usando a relação diferencial $d_{n}=-\frac{1}{2} n^{3} d\left(\frac{1}{n^{2}}\right)$, podemos obter a modulação do índice de refração $\Delta n_{x^{\prime}}$ e $\Delta n_{z^{\prime}}$ :

$$
\begin{gathered}
\Delta n_{x^{\prime}}=-\frac{1}{2} n_{0}^{3} E_{s c} r_{41} ; \\
\Delta n_{z^{\prime}}=\frac{1}{2} n_{0}^{3} E_{s c} r_{41} .
\end{gathered}
$$

Onde $n_{0}$ é o índice de refração não modulado do próprio cristal.

De acordo com as equações acima sabemos que o holograma de fase resultante tem o mesmo perfil do campo elétrico de distribuição de cargas e aproximadamente a mesma forma do padrão de interferência incidente no cristal. 
Podemos concluir que quando no registro holográfico predomina o regime de difusão (sem aplicação de campo elétrico externo), a diferença de fase entre o padrão de interferência e o holograma é de $\frac{\pi}{2}$.

\subsection{Processamento da imagem holográfica}

Quando dois feixes de luz coerentes incidem em um cristal fotorrefrativo, e assim interferem dentro deste meio, ocorre uma variação periódica da intensidade devido a interferência que por sua vez induz uma rede de índice em volume.

Mostraremos o processo de reconstrução de frentes de ondas por um holograma de volume gravado no cristal fotorrefrativo.

A técnica de mistura de duas ondas [10], é muito apropriada para a prática de interferometria holográfica, principalmente por permitir a obtenção de interferogramas de boa visibilidade em tempo real.

Para a obtenção destes interferogramas, utilizamos os cristais da família das silenitas ( $B T O, B S O, B G O)$ que têm a característica de baixa eficiência de difração o que compromete a visibilidade do padrão de franjas formado sobre o objeto analisado.

Através da técnica de difração anisotrópica [23] pode-se eliminar este problema.

\subsubsection{Teoria de ondas acopladas}

A teoria de Kogelnik é formulada para situações em que um feixe de luz monocromático incide em um holograma de volume, onde a modulação espacial de índices de refração é fixa e independente do tempo. A teoria de ondas acopladas nos permite analisar o comportamento e a relação entre os feixes no interior do cristal fotorrefrativo.

Consideramos dois feixes de amplitudes $R$ e $S$ monocromáticos, coerentes e de mesma polarização, incidindo sobre o holograma de volume de fase, como mostrado na figura 2.1. 
O campo elétrico das ondas incidentes e difratadas é dado por:

$$
\vec{E}=R e^{i\left(\omega t-\vec{K}_{1} \cdot \vec{r}\right)}+S e^{i\left(\omega t-\vec{K}_{2} \cdot \vec{r}\right)} .
$$

Onde $\vec{K}_{1}$ e $\vec{K}_{2}$ são respectivamente vetores de propagação das duas ondas e $\omega$ é a frequência das ondas.

O campo elétrico pode ser escrito como:

$$
\vec{E}=R e^{i\left(\omega t-\alpha_{1} y-\beta_{1} z\right)}+S e^{i\left(\omega t-\alpha_{2} y-\beta_{2} z\right)}
$$

onde $\beta_{1}$ e $\beta_{2}$ são as componentes $z$ dos vetores de onda $\vec{K}_{1}$ e $\vec{K}_{2}$ respectivamente e $\alpha_{1,2}$ são as componentes destes vetores de onda paralelo a frente de onda da rede.

Assumimos que a rede é infinita na direção $z$ e que $R$ e $S$ são funções de $y$ dado pela condição de contorno, e as duas ondas irão se propagar em um meio no qual o índice de refração é espacialmente modulado, descrito por:

$$
n(r)=n_{0}+\Delta n \cos (\vec{K} z)
$$

Onde $\vec{K}$ é o vetor holográfico.

A condição de Bragg é satisfeita para este caso, como ocorre em mistura de duas ondas em cristais fotorrefrativos. Temos:

$$
\vec{K}=\vec{K}_{1}+\vec{K}_{2}
$$

onde $\left|\vec{K}_{1}\right|=\left|\vec{K}_{2}\right|=\omega \mu \epsilon_{0} n_{0}$

A partir das equações de Maxwell, obtemos a equação que descreve o acoplamento das ondas no volume do cristal:

$$
\nabla^{2} \vec{E}+\omega^{2} \mu \epsilon(\vec{r}) \vec{E}=0
$$

onde $\omega$ é a frequência angular da onda. A constante dielétrica é dada por:

$$
\epsilon(r)=\epsilon_{0} n^{2}(r)
$$


Substituindo a equação (2.70) na equação (2.73) e assumindo que $\Delta n^{2}<<$ $\Delta n n_{0}$, obtemos:

$$
\epsilon(r) \approx \epsilon_{0}\left\{n_{0}^{2}+n_{0} \Delta n \cos (K z)\right\}
$$

Substituindo a equação (2.69) e (2.74) na equação (2.72), teremos:

$$
\begin{aligned}
& -2 i \alpha_{1} \frac{d R}{d y} e^{\left(-i \alpha_{1} y-i \beta_{1} z\right)}-2 i \frac{d S}{d y} e^{\left(-i \alpha_{2} y-i \beta_{2} z\right)}= \\
& -\omega^{2} \Delta n n_{0} \epsilon_{0} \mu\left(e^{-i \vec{K} z}+e^{i \vec{K} z}\right)\left[R e^{-i \alpha_{1} y-i \beta_{1} z}+S e^{-i \alpha_{2} y-i \beta_{2} z}\right]
\end{aligned}
$$

desprezamos o termo de segunda derivada espacial de $R$ e $S$, pois na maioria dos casos a variação das amplitudes $R$ e $S$ ao longo da direção $y$ ocorre de maneira lenta, então podemos considerar $\frac{\partial^{2} E}{\partial y^{2}}<<K \frac{\partial E}{\partial y}$.

A condição é satisfeita para $\beta_{2}=\beta_{1} \pm \vec{K}$ e substituindo na equação 2.75 e fazendo os devidos cálculos algébricos, encontramos:

$$
\left\{\begin{array}{c}
-2 i \alpha_{1} \frac{d R}{d y} e^{-i \alpha_{1} y}+\omega^{2} \Delta n n_{0} \epsilon_{0} \mu S e^{-i \alpha_{2} y}=0 \\
-2 i \alpha_{2} \frac{d S}{d y} e^{-i \alpha_{2} y}+\omega^{2} \Delta n n_{0} \epsilon_{0} \mu R e^{-i \alpha_{1} y}=0
\end{array}\right.
$$

sabendo que $\alpha_{1}=\alpha_{2}=\Delta \alpha ; \alpha_{1}=\frac{2 \pi}{\lambda} n_{0} \cos \alpha$ e $\beta_{1}=\beta_{2}=\frac{2 \pi}{\lambda} n_{0} \operatorname{sen} \alpha$, e assim as equações que acoplam $R$ e $S$ são:

$$
\begin{aligned}
& \frac{\partial R}{\partial y}=-i K^{\prime} S(y), \\
& \frac{\partial S}{\partial y}=-i K^{\prime} R(y),
\end{aligned}
$$

onde $K^{\prime}=\frac{\pi \Delta n}{\lambda \cos \alpha}$ é a constante de acoplamento.

As equações (2.76) e (2.77) são chamadas de ondas acopladas de Kogelnik.

O ângulo que se forma entre os dois feixes na entrada do holograma é $2 \alpha$, figura 2.1.

Para este caso foi desprezado qualquer tipo de absorção da rede.

$R$ é a onda incidente sobre o holograma e $S$ é a onda difratada. 
As equações de Kogelnik podem ser usadas para estudar o acoplamento de ondas num cristal fotorrefrativo. A solução geral das equações (2.76) e (2.77) é dada por:

$$
\begin{gathered}
R(y)=a e^{i K^{\prime} y}+b e^{-i K^{\prime} y} ; \\
S(y)=-a e^{i K^{\prime} y}+b e^{-i K^{\prime} y},
\end{gathered}
$$

onde $a, b, c, d$ são encontrados através da condição de contorno em $y=0$.

Para um holograma de transmissão, temos como condição de contorno: $R(0)=R_{0}$ e $S(0)=S_{0} e^{i \phi}$.

O expoente $\phi$ é inserido aqui considerando a probabilidade de haver uma defasagem entre o holograma e o padrão de interferência, que é o que ocorre em hologramas gravados em cristais fotorrefrativos por processo de difusão, ou seja, sem aplicação de campo elétrico externo.

As amplitudes do feixe são descrito como:

$$
\begin{gathered}
R(y)=R_{0} \cos \left(K^{\prime} y\right)-i S_{0} e^{-i \phi} \operatorname{sen}\left(K^{\prime} y\right) \\
S(y)=-i R_{0} \operatorname{sen}\left(K^{\prime} y\right)+S_{0} e^{-i \phi} \cos \left(K^{\prime} y\right),
\end{gathered}
$$

as intensidades associadas com as ondas $S$ e $R$ são dadas por:

$$
\begin{aligned}
& I_{R}=\left|R^{2}\right|=R_{0}^{2} \cos ^{2}\left(K^{\prime} y\right)+S_{0}^{2} \operatorname{sen}^{2}\left(K^{\prime} y\right)-R_{0} S_{0} \operatorname{sen}\left(2 K^{\prime} y\right) \operatorname{sen} \phi \\
& I_{S}=\left|S^{2}\right|=R_{0}^{2} \operatorname{sen}^{2}\left(K^{\prime} y\right)+S_{0}^{2} \cos ^{2}\left(K^{\prime} y\right)+R_{0} S_{0} \operatorname{sen}\left(2 K^{\prime} y\right) \operatorname{sen} \phi
\end{aligned}
$$

o termo sen $\phi$ nas equações acima, indicam que ao longo da direção $y$ do holograma ocorre transferência de energia entre os feixes $I_{R}$ e $I_{S}$.

Para o caso de registro em cristais fotorrefrativos em regime de difusão, temos uma defasagem de $\phi=\frac{\pi}{2}$, no qual a transferência de energia é máxima. 
Quando o holograma é gravado pelo regime de arraste, ou seja, onde há aplicação de um campo elétrico externo, temos $\phi=0$ ou $\phi=\pi$ e assim vemos que a transferência de energia não ocorre.

No caso em que fazemos a "leitura" do holograma, onde o feixe $S$ é bloqueado, temos que as condições de contorno são dadas por:

$$
\begin{aligned}
& S(0)=0, \\
& R(0)=1 .
\end{aligned}
$$

As equações (2.78) e (2.79) fornecem o feixe difratado $S(L)$ que emerge do holograma de espessura L:

$$
\begin{gathered}
R(L)=\cos \left(K^{\prime} L\right) ; \\
S(L)=-i \operatorname{sen}\left(K^{\prime} L\right),
\end{gathered}
$$

a equação (2.87) nos mostra que o feixe difratado está defasado de $\frac{\pi}{2} \mathrm{em}$ relação ao feixe referência $R$. Dessa forma, temos que a eficiência de difração que é definida por:

$$
\eta=\frac{|S(L)|^{2}}{|R(0)|^{2}}
$$

será dada como:

$$
\eta=\operatorname{sen}^{2}\left(K^{\prime} L\right)=\operatorname{sen}^{2}\left(\frac{\pi \Delta n}{\lambda \cos \alpha} L\right)
$$

\subsection{Propriedades de difração anisotrópica}

O holograma influencia a relação de intensidades entre os feixes $R$ e $S$ no interior do cristal como é observado nas equações (2.82) e (2.83), essa influência faz com que o contraste $m$ do padrão seja variável ao longo da direção $z$ do cristal afetando a modulação do índice de refração. 
A teoria de Kogelnik não considerou o fato do material apresentar birefrigência natural (não induzida), e a atividade óptica do meio de registro holográfico. Neste caso a polarização das ondas que interagem tornam-se relevantes. O efeito do feixe acoplado no cristal fotorrefrativo opticamente ativo como por exemplo o $B S O$, é muito influenciado pela direção de polarização do feixe interagente[24].

Para $K \|\langle 110\rangle$ a modulação do índice de refração pode ser dada pelas equações (2.66) e (2.67):

$$
\Delta n_{x^{\prime}}=-\frac{1}{2} n_{0}^{3} E_{s c} r_{41}=-\Delta n_{z^{\prime}} .
$$

Onde $x y$ é considerado ser o plano de incidência dos feixes objeto e referência, respectivamente $S_{0}$ e $R_{0}$, e estes incidem no cristal com polarização segundo um ângulo $\theta$ em relação ao eixo $x^{\prime}$ de acordo com a figura 2.4.

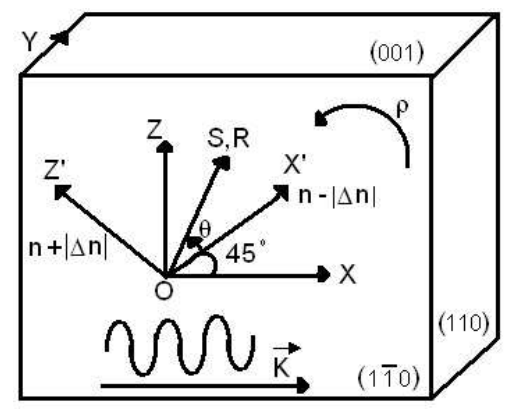

Figura 2.4: Orientação cristalográfica do cristal, onde a configuração do vetor da rede é $\vec{K} \|\langle 110\rangle$.

O contraste $m$ do padrão de interferência na entrada do cristal segue a equação $m=\frac{2\left|I_{1}\right| e^{i \varphi}}{I_{0}}$, no qual esta será dada por:

$$
m=\frac{2 R_{0} S_{0}}{R_{0}^{2}+S_{0}^{2}} .
$$

No caso de holografia com objetos reais, o feixe espalhado pelo objeto é bem menos intenso que o feixe referência, ou seja, $R_{0}^{2}>>S_{0}^{2}$, assim a equação 
de $m$ fica:

$$
m \cong \frac{2 S_{0}}{R_{0}} .
$$

Podemos assumir que ao longo da direção $y$ a intensidade do feixe referência permanece praticamente inalterada, devido a baixa eficiência de difração, caracterítica desse tipo de cristal, e a pequena intensidade do feixe objeto. A uma profundidade $l$ do cristal, $m$ será escrito como:

$$
m=\frac{2\left(S_{0}+U\right)}{R_{0}},
$$

onde $U$ é a componente da amplitude da onda difratada pelo holograma até $y=l$, no qual possui a mesma direção de propagação do feixe objeto como mostra a figura 2.5 .

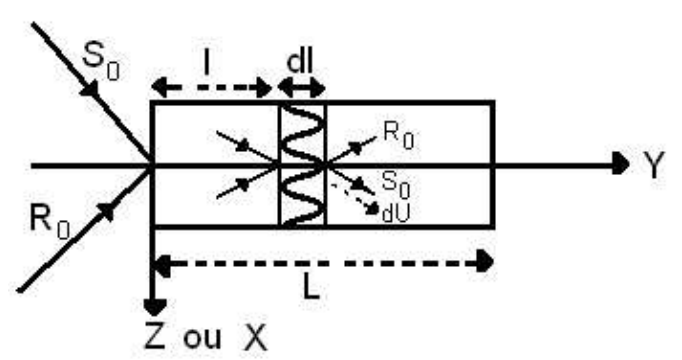

Figura 2.5: "Rede infinitesimal". $d U$ é a amplitude da onda difratada devido à rede de espessura $d l$ situada a uma profundidade $l$ no cristal.

A variação do contraste $m$ em uma "Rede infinitesimal" de espessura $d l$ é dada por:

$$
\frac{\partial m}{\partial l}=\left(\frac{2}{R_{0}}\right)\left(\frac{\partial U}{\partial l}\right),
$$

onde $d U$ é a amplitude da luz difratada que é encontrada com a ajuda da equação (2.89), sabendo que $\Delta n_{x^{\prime}, z^{\prime}}<<1$ a eficiência de difração será escrita 
como:

$$
\eta \cong\left(\frac{\pi \Delta n}{\lambda \cos \alpha} L\right)^{2} .
$$

As componentes $x^{\prime}$ e $z^{\prime}$ da amplitude difratada serão dadas por:

$$
\begin{gathered}
d U_{x^{\prime}}=\left(\frac{-\pi|\Delta n|}{\lambda \cos \alpha}\right) m(l) R_{0} \cos (\theta+\rho l) d l ; \\
d U_{z^{\prime}}=\left(\frac{\pi|\Delta n|}{\lambda \cos \alpha}\right) m(l) R_{0} \operatorname{sen}(\theta+\rho l) d l,
\end{gathered}
$$

onde levou-se em conta o fato de que a polarização do feixe referência está a um ângulo $(\theta+\rho l)$ em relação ao eixo $o x^{\prime}$ como é mostrado na figura $2.4, \rho$ é a atividade óptica do cristal.

$\Delta n$ é a modulação de índice de refração por unidade de valor do contraste $m$.

A amplitude difratada $d U$ é obtida considerando as componentes $d U_{x^{\prime}}$ e $d U_{z^{\prime}}$ paralelas à direção de polarização do feixe objeto.

$$
d U=\beta m(l) R_{0}\left[\operatorname{sen}^{2}(\theta+\rho l)-\cos ^{2}(\theta+\rho l)\right] d l,
$$

onde $\beta \equiv \frac{\pi|\Delta n|}{\lambda \cos \alpha}$.

Substituindo $d U$ na equação (2.94) e integrando, obtemos:

$$
m=\frac{2 S_{0}}{R_{0}} \exp \left\{-2 \beta \frac{\operatorname{sen}(\rho l)}{\rho} \cos (2 \theta+\rho l)\right\} .
$$

Na saída do cristal, o feixe difratado, propaga-se ao longo do comprimento $(L-l), L$ é a espessura total do cristal. O vetor difratado sofre uma rotação de um ângulo $\rho(L-l)$ sendo as equações (2.96) e (2.97) descritas como:

$$
d U_{x^{\prime}}=-2 S_{0} \beta\{\cos (\theta+\rho l) \cos [\rho(L-l)]+\operatorname{sen}(\theta+\rho l) \operatorname{sen}[\rho(L-l)]\} d l
$$




$$
d U_{z^{\prime}}=2 S_{0} \beta\{-\cos (\theta+\rho l) \operatorname{sen}[\rho(L-l)]+\operatorname{sen}(\theta+\rho l) \cos [\rho(L-l)]\} d l,
$$

integrando $d U_{x^{\prime}}$ e $d U_{z^{\prime}}$ ao longo da espessura $L$, obtemos a componente $x^{\prime}$ e $z^{\prime}$ da amplitude difratada:

$$
\begin{aligned}
& U_{x^{\prime}}=-2 S_{0} \beta \frac{\operatorname{sen}(\rho L)}{\rho} \cos \theta \\
& U_{z^{\prime}}=2 S_{0} \beta \frac{\operatorname{sen}(\rho L)}{\rho} \operatorname{sen} \theta .
\end{aligned}
$$

Sabemos que a amplitude total $S$ que emerge do cristal é dada por: $S^{2}=$ $S_{x^{\prime}}^{2}+S_{z^{\prime}}^{2}$, onde temos:

$$
\begin{aligned}
& S_{x^{\prime}}=U_{x^{\prime}}+S_{0} \cos (\theta+\rho L), \\
& S_{z^{\prime}}=U_{z^{\prime}}+S_{0} \operatorname{sen}(\theta+\rho L) .
\end{aligned}
$$

Podemos calcular $\gamma$, que é o ganho, e a eficiência de difração $\eta$ para a configuração que está se utilizando.

$\gamma$ é definido como sendo a razão entre as intensidades do feixe emergente e do feixe incidente no meio:

$$
\gamma=\frac{S_{x^{\prime}}^{2}+S_{z^{\prime}}^{2}}{S_{0}^{2}}=1+4 \beta^{2} \frac{\operatorname{sen}^{2}(\rho L)}{\rho^{2}}-4 \beta \frac{\operatorname{sen}(\rho L)}{\rho} \cos (2 \theta+\rho L) .
$$

A eficiência de difração é escrita como:

$$
\begin{gathered}
\eta=\frac{U_{x^{\prime}}^{2}+U_{z^{\prime}}^{2}}{R_{0}^{2}}=\beta^{2}\left(\frac{2 S_{0}}{R_{0}}\right)^{2} L^{2}\left(\frac{\operatorname{sen}(\rho L)}{\rho L}\right)^{2} ; \\
\eta=\left[\frac{\pi n_{0}^{3} r_{41} E_{s c}}{2 \lambda \cos \alpha} m \frac{\operatorname{sen}(\rho L)}{\rho}\right]^{2} .
\end{gathered}
$$

Aqui a eficiência de difração não depende do ângulo de incidência $\theta$, tornando assim a montagem mais flexível e nos permite uma escolha mais apropriada da direção de polarização dos feixes incidentes no cristal. 


\subsection{Hologramas de volume e hologramas pla- nos}

O holograma é um sistema de camada tridimensional que corresponde a uma variação periódica de absorção ou de índice refrativo, e a amplitude difratada é um máximo apenas quando a condição de Bragg é satisfeita [25].

Sabemos que os materiais fotorrefrativos são usados como meio de registro holográfico, onde a variação foto-induzida periódica do índice $\Delta n$ é produzida quando a amplitude complexa da onda objeto é registrada no meio pelo padrão de interferência [22].

No registro holográfico, o feixe referência é usualmente uma onda plana. Quando o feixe objeto é também uma onda plana o padrão de interferência é uma função senoidal da posição. A variação senoidal do índice de refração é chamado de rede de difração.

Desde que uma onda plana carrega informação não espacial, o holograma consiste de diversas redes para registro de informação espacial de um objeto qualquer, dessa forma, um objeto que contem informação espacial pode sempre ser representado como uma superposição linear de várias ondas planas. Utilizando onda plana de referência na interferometria, cada componente da onda plana do feixe objeto formaria uma rede com o feixe referência.

Assim, o holograma registrado seria a soma destas redes, onde cada uma delas teria diferentes vetores de onda.

O padrão de interferência entre o feixe objeto e o feixe referência era registrado em filmes holográficos finos que resultavam em hologramas planos. Com os meios fotorrefrativos registramos hologramas de volume.

Estudaremos a diferença fundamental entre o holograma plano e o holograma de volume.

Uma rede de transmissão com o índice de refração dado por:

$$
n=\left\{\begin{array}{r}
n_{0}+n_{1} \cos (\vec{K} \cdot \vec{r}), \quad|z|<\frac{L}{2} \\
n_{0}, \quad \text { de outra maneira }
\end{array}\right.
$$


onde $n_{0}$ e $n_{1}$ são constantes; $\vec{K}$ é o vetor de onda da rede e $L$ é a espessura da rede.

Sabemos que o fator de largura da rede é definido por:

$$
Q=\frac{2 \pi \lambda L}{n_{0} \Lambda^{2}}
$$

onde $\Lambda=\frac{2 \pi}{|\vec{K}|}$ é o período da rede.

$Q>1$ é o regime de Bragg na difração óptica.

Se $Q>1$ temos uma rede de volume, mas se $Q<1$ temos uma rede plana.

Numa rede plana a espessura, ou comprimento de interação, é pequeno e é dado por:

$$
L<\frac{n_{0} \Lambda^{2}}{2 \pi \lambda}
$$

A espessura finita, leva a uma incerteza em $K_{z}$ dada por:

$$
\Delta K_{z}=\frac{2 \pi}{L}
$$

quando $L$ é próximo de zero, a incerteza em $K_{z}$ torna-se infinita.

Em uma rede de volume, a eficiência de difração exige ser:

$$
\vec{k}^{\prime}=\vec{k}+\vec{K}
$$

onde é conhecida como a condição de Bragg que representa a conservação do momento, onde $\vec{k}$ é o vetor de onda incidente e $\vec{k}^{\prime}$ é o vetor de onda do feixe difratado.

A magnitude do vetor de onda $\vec{k}$ e $\vec{k}^{\prime}$ é dada por:

$$
\left|\vec{k}^{\prime}\right|=|\vec{k}|=\frac{\omega n_{0}}{c} .
$$

Estas duas condições dão uma única direção de incidência para a eficiência de difração. 
Em uma rede plana a conservação do momento é dada por:

$$
\vec{k}_{\|}^{\prime}=\vec{k}_{\|}+\vec{K}_{\|}
$$

o símbolo (||) indica uma componente paralela ao plano da rede.

Consideramos o registro de uma onda objeto em um meio plano, $z=0$. O feixe referência é dado como:

$$
\vec{E}_{R}=\vec{A}_{R} e^{\left\{i\left(\omega t-\vec{K}_{R} \cdot \vec{r}\right)\right\}},
$$

onde $\vec{K}_{R}$ é o vetor de onda do feixe referência e $\vec{A}_{R}$ é uma constante.

A onda objeto é escrita como $\vec{E}_{S}=\vec{A}_{S} e^{\left\{i\left(\omega t-\vec{K}_{S} \cdot z\right)\right\}}$ e se propaga ao longo da direção $+z ; \overrightarrow{A_{S}}$ é a amplitude da onda.

Do resultado da interferência e do registro, o holograma será formado com $\Delta n$ descrito por:

$$
\Delta n=n_{1} \vec{A}_{R}^{*} \vec{A}_{S} e^{\left\{i\left(\vec{K}_{R, x} x+\vec{K}_{R, y} y\right)\right\}+c . c .},
$$

no qual $n_{1}$ é uma constante.

Se o holograma é iluminado com o mesmo feixe referência da equação (2.115), a luz transmitida pelo holograma é descrita por:

$$
\vec{E}_{T}=\vec{E}_{R} e^{\left\{-i\left(\frac{2 \pi \Delta n d}{\lambda}\right)\right\}}
$$

onde $d$ é a espessura do holograma.

Para este holograma $\frac{2 \pi \Delta n d}{\lambda}<<1$ e substituindo este valor na equação (2.117) encontramos que a onda transmitida será descrita como:

$$
\vec{E}_{T} \approx \vec{E}_{R}-i\left(\frac{2 \pi d \Delta n}{\lambda}\right) \vec{E}_{R}
$$

esta equação consiste de uma parte $\vec{E}_{R}$ não-difratada e uma difratada.

Utilizando as equações (2.116) e (2.117), a onda difratada para $z=0$ pode ser escrita como:

$$
\vec{E}_{D}=-i\left(\frac{2 \pi d \Delta n}{\lambda}\right) \vec{E}_{R}=-i\left(\frac{2 \pi d n_{1}}{\lambda}\right)\left|A_{R}\right|^{2} A_{S} e^{i \omega t}
$$


onde $E_{D}$ é exatamente proporcional a onda objeto $E_{S}$ para $z=0$.

De acordo com a equação acima $E_{D}$, seria exatamente proporcional a onda $E_{S}$ em toda parte para $z>d$.

Hologramas planos são adequados para reconstrução de ondas objetos, mas a alta eficiência de difração e a seletividade de Bragg, são importantes resultados associados com hologramas de volume.

A difração de hologramas de volume exige um alinhamento preciso do feixe de leitura, ou seja, o feixe de leitura deve ser exatamente paralelo ao feixe referência para reconstrução da onda objeto.

A espessura do holograma impõe limites a condição de Bragg e também provoca um aumento da eficiência de difração.

A eficiência de difração de hologramas planos é relativamente pequena por causa do insuficiente comprimento de interação.

\subsubsection{Capacidade de armazenagem de hologramas}

A capacidade de armazenagem em cristais fotorrefrativos é um número máximo de redes distinguíveis que podem ser armazenadas. Os valores podem ser obtidos da representação do espaço- $\vec{K}$ da rede, no qual cada ponto $\vec{K}$ representa, matematicamente, um conjunto de franjas senoidais se extendendo do infinito no espaço real. A superposição espacial das múltiplas redes no cristal fotorrefrativo é descrito como a distribuição de pontos no espaço- $\vec{K}$.

Então a capacidade de armazenagem do cristal fotorrefrativo é definido como o número máximo de redes distinguíveis que podem ser confinadas por uma rede espacial. Isto é um limite superior teórico baseado em condições de incertezas.

Para determinar este limite superior, a rede tem que estar dentro do espaço- $\vec{K}$. Duas redes adjacentes são distinguíveis, e tendo o volume no espaço- $\vec{K}$ de cada rede independente do vetor de onda da rede, o número total de redes distinguíveis é a razão entre o volume da rede espacial e o 
volume no espaço- $\vec{K}$ de cada rede que é descrito como:

$$
C=\frac{V_{K}}{v_{g}}=\frac{16 \pi n_{e}^{2} n_{0}}{3} \frac{V_{\text {cristal }}}{\lambda^{3}},
$$

onde $V_{\text {cristal }}=L_{x} \times L_{y} \times L_{z}$ é o volume do cristal e $\lambda$ é o comprimento de onda da luz no vácuo.

A capacidade de armazenamento de um meio holográfico plano é menor que um meio de volume com tamanho comparável.

Para hologramas planos no espaço- $\vec{K}$ encontramos que a capacidade de armazenagem será:

$$
\begin{array}{r}
\delta K_{x}=\frac{2 \pi}{L_{x}}, \delta K_{y}=\frac{2 \pi}{L_{y}} \text { e } K=\frac{2 \pi n}{\lambda} \text { obtemos: } \\
C=4 \pi n^{2} \frac{A_{\text {cristal }}}{\lambda^{2}},
\end{array}
$$

onde $n$ é o índice de refração do material e $A=L_{x} L_{y}$ é a área do meio holográfico plano. 


\section{Capítulo 3}

\section{Parte experimental}

A interferometria holográfica é uma técnica não-destrutiva de análise de superfícies, com aplicações em diversas áreas de pesquisa como biomédicas e tecnológicas.

Neste trabalho a técnica interferométrica que foi utilizada para a análise da superfície estudada foi a técnica de dupla exposição em regime de difusão, onde utilizou-se o cristal fotorrefrativo da família das silenitas $\mathrm{Bi}_{12} \mathrm{SiO}_{20}$ $(B S O)$ como meio de registro holográfico.

Como já foi descrito no capítulo 1, o objetivo deste trabalho foi medir e analisar as distribuições de tensão que ocorrem em um crânio humano seco no processo mastigatório, e para isso foram feitas várias medidas com o crânio no qual foi aplicada diferentes tensões nos músculos da mastigação.

A técnica utilizada neste trabalho torna os resultados mais realísticos comparados com outros métodos de análises.

Neste capítulo é mostrado a metodologia aplicada para a obtenção das medidas e os equipamentos ópticos utilizados no arranjo experimental, assim como a descrição deste.

Em seguida é mostrado uma discussão teórica sobre a interpretação do padrão de interferência que foi obtido nas medidas e a utilização desta teoria para construir um programa computacional que calcula os micro-deslocamentos da superfície do crânio. 
Na última seção foram feitas análises das medidas obtidas com uma discussão global e local das superfícies do crânio, qualitativamente e quantitativamente, com o auxílio do programa computacional, calculando os microdeslocamentos sofridos nas regiões deste crânio e comparando com ossos que sofreram diferentes aplicações de tensão nos músculos.

\subsection{Aparato experimental}

As medidas foram feitas a partir do arranjo experimental esquematizado na figura 3.1, que foi, montado e ajustado numa mesa holográfica estabilizada (Newport Co.). Para a montagem do aparato experimental, utilizamos os seguintes equipamentos:

- LASER de Argônio sintonizável em frequência, Spectra-Physics (Comprimento de onda de $514 \mathrm{~nm}$ e potência nominal de $600 \mathrm{~mW}$ );

- componentes ópticos: espelhos planos, divisores de feixe 50/50, lentes, filtro espacial, filtro de densidade neutra, polarizadores e objetiva;

- cristal fotorrefrativo, da família das Silenitas $\mathrm{Bi}_{12} \mathrm{SiO}_{20}$, com configuração eletro-óptica transversa, tem dimensão de $10 \times 10 \times 3 \mathrm{~mm}^{3}$, inserido numa armadura de baquelite e banhado em óleo isolante, com faces perpendiculares ao plano de incidência dos feixes de registro. Esse cristal apresenta boa sensibilidade óptica, boa eficiência de difração, curto tempo de resposta, bi-refrigência e atividade óptica. Estes cristais são indicados para trabalhos em regime de difusão com configuração de anisotropia de difração;

- um fotodiodo detector (Ophir optronics);

- um shutter (Newport);

- uma câmera CCD (Coupled Charge Device), (Hitachi-KPM1); 
- componentes ópto-eletrônicos, para posicionamento fino dos dispositivos ópticos.

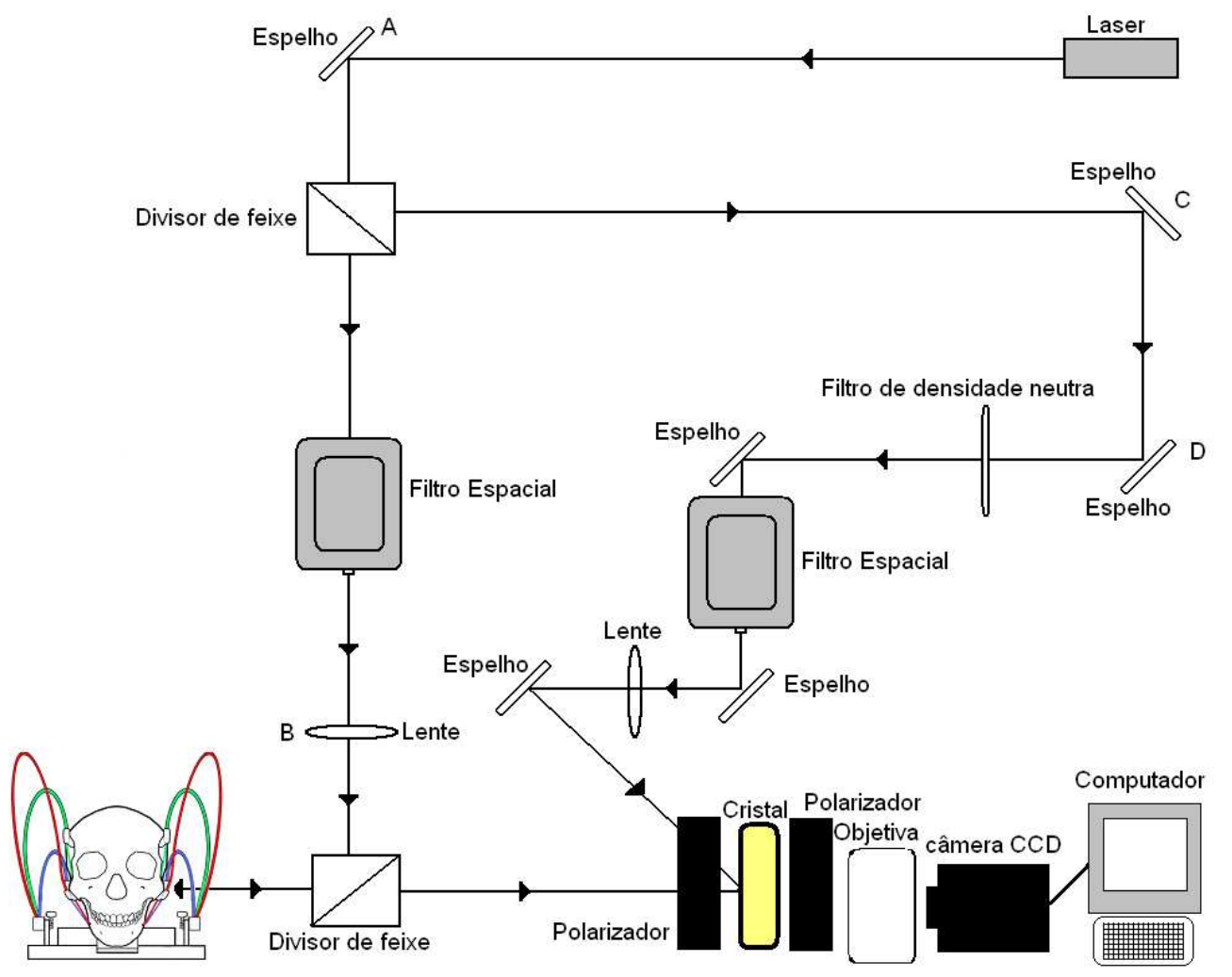

Figura 3.1: Aparato experimental utilizado para a obtenção das medidas.

O aparato descrito na figura 3.1, é uma variante do arranjo experimental descrito em [26].

Para medir e analisar as distribuições de tensões que ocorrem em um crânio humano no processo mastigatório, utilizamos um crânio humano seco, preparado adequadamente, simulando o que ocorre em um crânio natural durante a mastigação.

Para simular a contração muscular, neste crânio, os feixes básicos que compõem os principais músculos da mastigação, foram confeccionados com fios de aço, inseridos nas regiões onde os músculos atuavam naturalmente, 
envoltos por tubos semi-rígidos de plástico e fixados com resina acrílica auto polimerizável. O tracionamento do cabo de aço, foi obtido por um sistema mecânico de rosca sem-fim, como mosta a figura 3.2.

O crânio foi pintado com uma tinta refletiva (White 8015, 3M), para melhor refletir a luz do laser que incide neste. O crânio foi fixado numa base de alumínio.
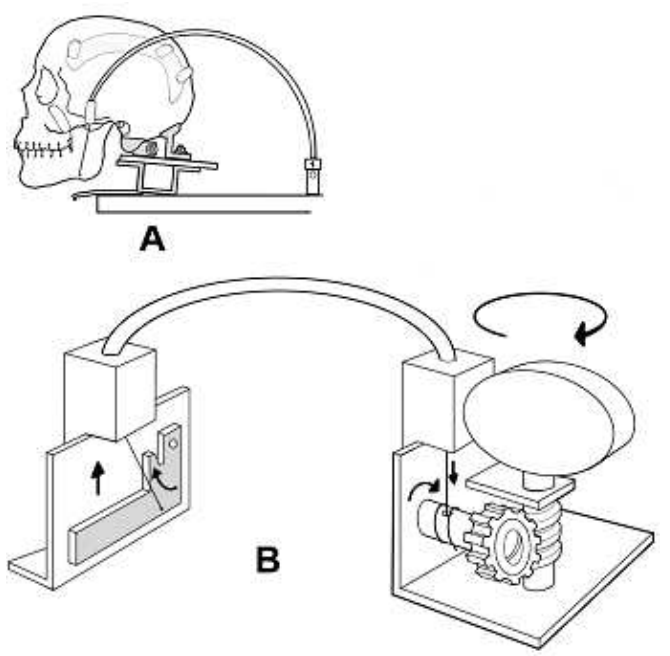

Figura 3.2: A) mostra o crânio com o fio de aço inserido nas regiões onde os músculos atuavam naturalmente; B) mostra o esquema do mecanismo de rosca sem fim para a tração da mandíbula do crânio.

Foi medido as forças resultante nos dentes utilizando o aparelho chamado gnatodinamômetro, como mostra as figuras 3.3 e 3.4, sobre o primeiro molar superior esquerdo (dente 26, segundo quadrante) e sobre o primeiro molar inferior esquerdo (dente 36, terceiro quadrante), relacionada ao número de voltas nos pinos. 


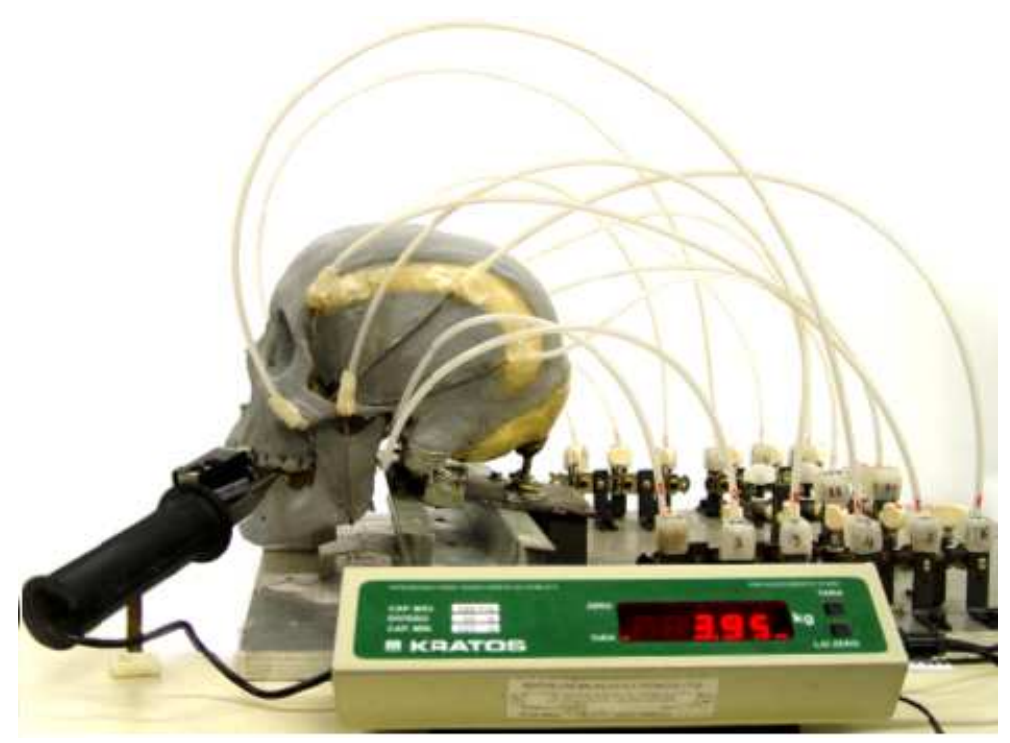

Figura 3.3: Gnatodinamômetro posicionado e visor digital com valores em quilograma-força.

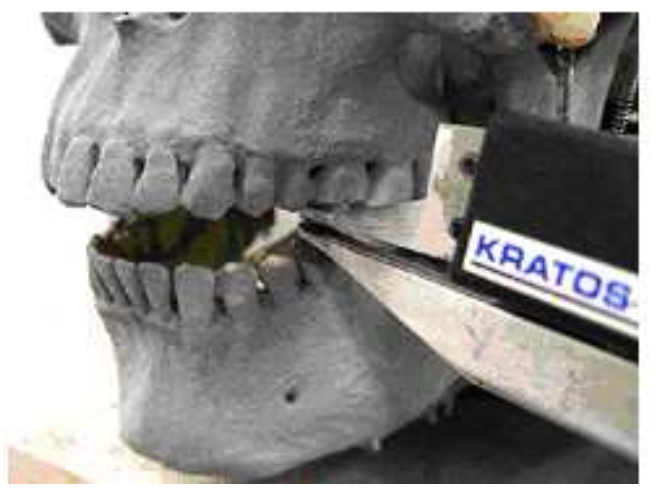

Figura 3.4: Ponta medidora do gnatodinamômetro, posicionada entre os primeiros molares (superior e inferior) do lado esquerdo.

Foi feito um gráfico destas forças em função do número de voltas no pino três (MPE), de acordo com o gráfico, 3.5, existe uma relação direta entre 
o número de voltas e a força aplicada sobre os dentes 26 e 36. Para o experimento, as cargas resultantes foram distribuídas entre os dentes canino, primeiro e segundo pré-molares e primeiro molar do lado esquerdo, sendo que a maior concentração de carga ocorreu de posterior para anterior, isto é, do primeiro molar para canino. Os molares recebem maior carregamento por estarem próximas e paralelas às linhas de força dos músculos estudados (MPE) e (TAE), deve-se ressaltar que também no lado direito ocorrem contatos dentais, porém, com um carregamento menor.

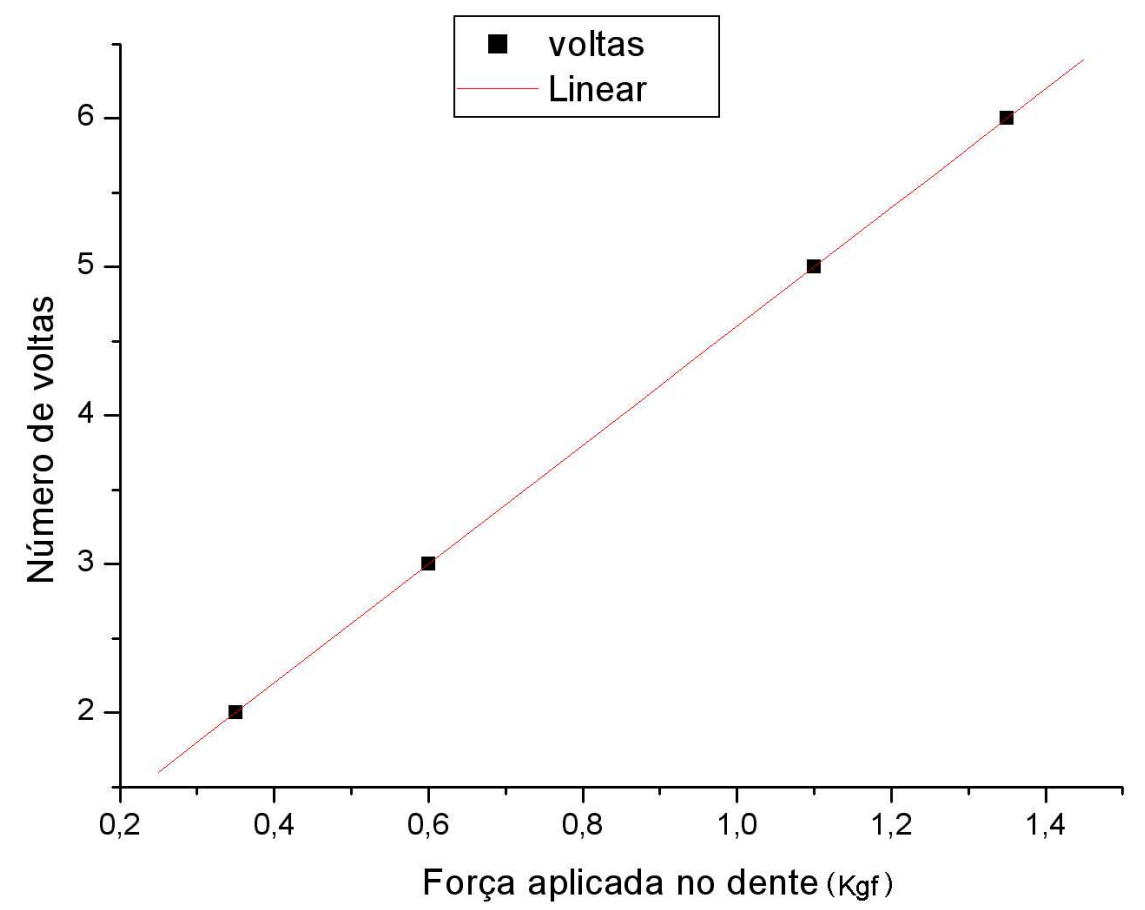

Figura 3.5: Gráfico do número de voltas $\times$ força aplicada no dente.

O objeto de estudo (crânio), apresentou contatos dentários no lado esquerdo que aumentavam progressivamente do canino até molar semelhante a uma boca ideal, onde os caninos tem a função de perfurar e rasgar, os prémolares tem a função de romper e triturar e os molares fazem a pulverização 
(reduzir o alimento em pequenos fragmentos) do alimento que junto com a saliva preparam-no para a deglutição (engolir), pois é na mastigação que se inicia o processo da digestão.

O número de voltas dadas nos pinos três e cinco, que simulam a contração do MPE e TAE respectivamente, estão relacionadas com a forças resultantes que foram medidas, como por exemplo mostra o gráfico 3.5, neste trabalho será falado somente número de voltas, mas estes se referem a forças resultantes nos dentes.

\subsubsection{Metodologia utilizada nas medidas}

As medidas foram feitas utilizando a técnica de interferometria holográfica de dupla exposição (IHDE), em regime de difusão, onde o registro do holograma do crânio é feito, e após este processo, faz-se um outro registro do mesmo crânio submetido a uma perturbação, desta forma a leitura deste interferograma é a superposição das duas ondas que interferem no cristal fotorrefrativo, dando origem a um padrão de franjas, devido ao deslocamento do objeto.

A descrição do experimento da figura 3.1 é como segue:

A luz incidente do LASER propaga-se em direção ao espelho plano (A), refletindo para um divisor de feixe, que divide a luz parcialmente refletida e parcialmente transmitida. A luz transmitida passa por um filtro espacial ${ }^{1}$ em direção a uma lente (B) até chegar a um outro divisor de feixe, que divide novamente a luz parcialmente refletida e parcialmente transmitida. Essa luz refletida, por sua vez, irá se espalhar para iluminar o objeto inteiro (crânio) e retornará espalhando luz em todas as direções e alguns destes feixes irão incidir no cristal $(B S O)$. Este feixe é chamado de feixe objeto.

A outra parte do feixe que é parcialmente refletida proveniente do primeiro divisor de feixe, propaga até o espelho plano (C), refletindo e incidindo em outro espelho plano (D) que é refletida novamente passando por um filtro

\footnotetext{
${ }^{1}$ Sua função é filtrar espacialmente o feixe LASER e expandí-lo, dessa forma o feixe transmitido terá um perfil "suave".
} 
de densidade neutra ${ }^{2}$, e um espelho plano direciona o feixe até um filtro espacial incidindo-o em um espelho plano e refletindo-o para uma lente onde é expandido, e finalmente um outro espelho plano direciona para o cristal. Este feixe é chamado de feixe referência.

Aqui o feixe é colimado por uma lente, isto não é essencial mas é importante que o feixe referência tenha uma iluminação uniforme ao incidir no cristal e além disso toda a montagem é feita de tal modo que a diferença de caminho óptico entre os dois feixes deve ser nula, com isso o contraste das franjas é máximo, e quando desloca-se a superfície do crânio analisada ocorre uma diferença de fase dando origem às franjas de interferência.

Os feixes referência e objeto passam por um primeiro polarizador que incide no cristal, os feixes vindos do cristal passam por um segundo polarizador (analizador) e vão em direção à câmera CCD.

Durante o processo de gravação, bloqueamos o feixe objeto, com o auxílio de um shutter, para fazermos uma perturbação no crânio, tracionando a mandíbula, e simulando os músculos, através do mecanismo de rosca sem fim, figura 3.2. Logo após desbloqueamos este feixe, ocorrendo assim uma superposição das duas ondas (feixe referência e feixe objeto) dando origem a um padrão de franjas.

O holograma no cristal é visto num computador, por meio do programa Global Lab image, que é ligado à câmera CCD, no qual podemos salvar a imagem do holograma no computador.

Com as medidas obtidas através do arranjo experimental descrito acima, podemos observar como se distribuem as tensões no crânio durante o processo de mastigação.

A figura 3.6 mostra a descrição dos músculos e a figura 3.7 mostra a descrição do crânio em quadrantes.

\footnotetext{
${ }^{2}$ Para controlar a intensidade de luz que chega até o cristal.
} 


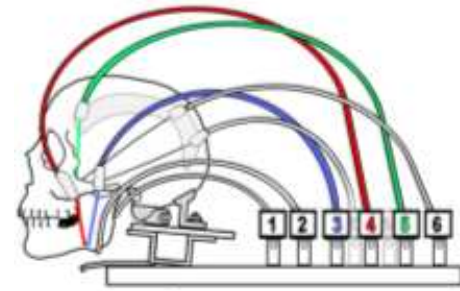

A

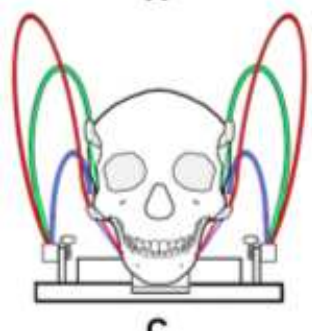

C

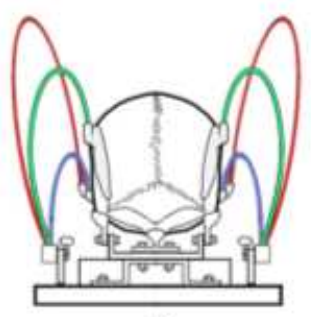

D

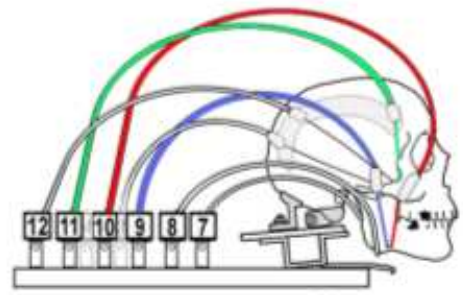

B

Figura 3.6: Representação esquemática dos feixes dos músculos da mastigação: A) Vista lateral esquerda; B) Vista lateral direita; C) Vista frontal; D) Vista posterior); E) Esquema de corte frontal na região do forame magno e processos mastóideos, exibindo o sistema de fixação intra e extra cranianos. 1) Músculo pterigóideo lateral direito (PLD); 2) Músculo pterigóideo medial direito (PMD); 3) Músculo masseter profundo esquerdo (MPE); 4) Músculo masseter superficial esquerdo (MSE); 5) Músculo temporal anterior esquerdo (TAE); 6) Músculo temporal médio esquerdo (TME); 7) Músculo pterigóideo lateral esquerdo (PLE); 8) Músculo pterigóideo medial esquerdo (PME); 9) Músculo masseter profundo direito (MPD); 10) Músculo masseter superficial direito (MSD); 11) Músculo temporal anterior direito (TAD); 12) Músculo temporal médio direito (TMD); 13) Músculo temporal posterior esquerdo (TPE), medialmente fixado, entre os pinos 3 e 4; 14) Músculo temporal posterior direito (TPD).

Dentes ausentes: lado esquerdo - $2^{\underline{O}}$ molar inferior (37) e $3^{0}$ molar inferior (38); lado direito - $1^{\mathrm{O}}$ molar superior (16) e $2^{\mathrm{O}}$ molar inferior (47). Apesar das ausências dos dentes, há contato bilateral e simultâneo. 


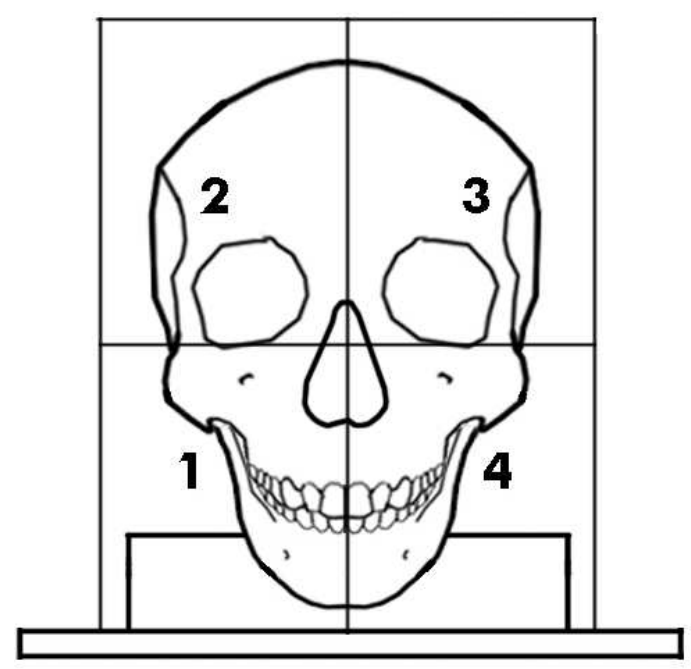

Figura 3.7: Divisão do crânio em quadrantes.

\subsection{Interpretação do padrão de interferência}

Na técnica de interferometria de dupla exposição, como foi dito anteriormente, faz-se duas exposições do objeto no mesmo holograma, onde há um registro deste antes e depois de ser submetido a uma perturbação. Através deste holograma podemos observar a interferência entre os feixes objeto e referência como um padrão de franjas.

A interferometria holográfica possibilita que a onda espalhada do objeto no estado referência descrita como $u_{1}=U_{1} e^{i \varphi_{1}}$ e a onda espalhada do objeto no estado deformado descrita como $u_{2}=U_{2} e^{i \varphi_{2}}$ ocorram simultaneamente. A deformação real seria tão pequena que podemos considerar $U_{1}=U_{2}=U$. Estes dois estados formariam um padrão de interferência dado por:

$$
I=2 U^{2}[1+\cos \Delta \phi]
$$

onde $I$ é a distribuição de intensidades no holograma, e $\phi$ é a fase da onda. 
Temos que encontrar a relação entre $\Delta \phi=\left(\phi_{1}-\phi_{2}\right)$ e a deformação do objeto.

Na figura 3.8, o ponto $\mathrm{O}$ no objeto é movido ao longo do vetor deslocamento $\vec{d}$ para o ponto O' devido a deformação do objeto. O objeto é iluminado e a direção de propagação da onda $\vec{n}_{1}$ forma um ângulo $\theta_{1} \mathrm{com}$ $\vec{d}$. Assumimos que estamos observando através do holograma ao longo da direção $\vec{n}_{2}$ formando um ângulo $\theta_{2}$ com $\vec{d}$.

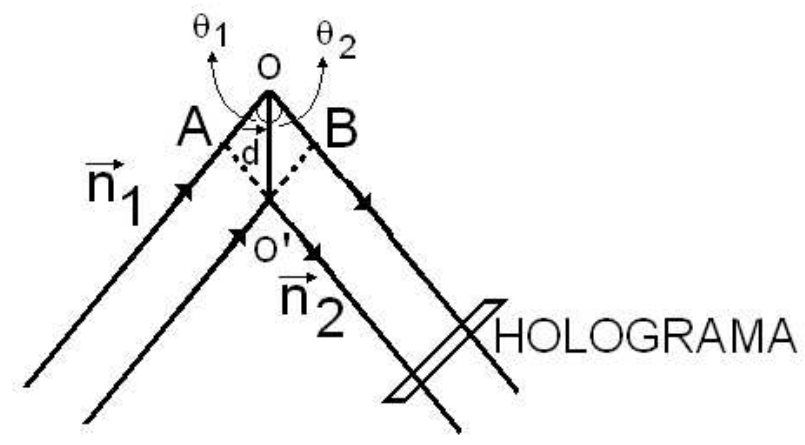

Figura 3.8: Ocorreu um deslocamento do ponto $\mathrm{O}$ no objeto para o ponto $O$ ' devido a deformação deste objeto.

A diferença de caminho óptico será:

$$
L=A O+O B=d\left(\cos \theta_{1}+\cos \theta_{2}\right) .
$$

Sabemos que a diferença de fase é dada por:

$$
\Delta \phi=K n L
$$

onde $K=\frac{2 \pi}{\lambda}$ é o número de onda e $n=0,1,2, \ldots$.

Assim a diferença de fase será:

$$
\Delta \phi=K d\left(\cos \theta_{1}+\cos \theta_{2}\right)
$$


Na figura 3.9 é colocada uma linha bissetriz do ângulo $2 \theta$ entre $\vec{n}_{1}$ e $\vec{n}_{2}$. Esta linha que intersecta estes ângulos, está inclinada e forma um ângulo $\gamma$ com $\vec{d}$.

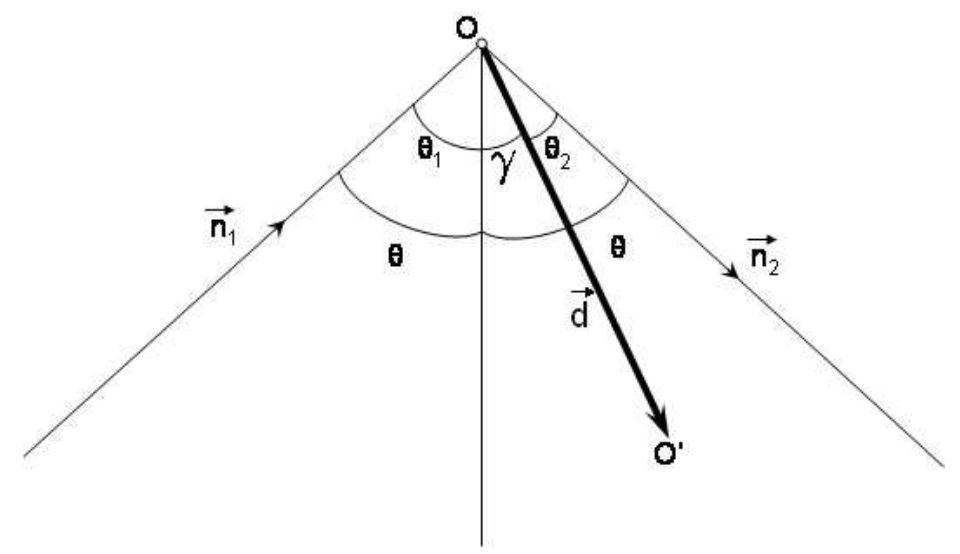

Figura 3.9: A figura mostra a bissetriz do ângulo $2 \theta$ inclinada de um ângulo $\gamma$ de $d$.

Queremos encontrar $\left(\cos \theta_{1}+\cos \theta_{2}\right)$, depois de introduzido esta bissetriz. Através de fórmulas trigonométricas, temos:

$$
\left(\cos \theta_{1}+\cos \theta_{2}\right)=(\cos (\theta+\gamma)+\cos (\theta-\gamma))=2 \cos \theta \cos \gamma
$$

da equação (3.4), encontramos:

$$
\Delta \phi=\frac{2 \pi}{\lambda} 2 d \cos \theta \cos \gamma
$$

Assim, o padrão de interferência tem um máximo (franja clara) em:

$$
\Delta \phi=\frac{2 \pi}{\lambda} 2 d \cos \theta \cos \gamma=2 \pi n .
$$

Onde $n=0,1,2, \ldots$.

Resultando:

$$
d \cos \gamma=n \frac{\lambda}{2 \cos \theta} .
$$


Onde $d \cos \gamma$ é a componente do vetor deslocamento na bissetriz do ângulo entre as direções de iluminação e observação.

E o padrão de interferência tem um mínimo (franja escura) quando:

$$
\Delta \phi=\frac{2 \pi}{\lambda} 2 d \cos \theta \cos \gamma=(2 n+1) \pi .
$$

Onde $n=0,1,2, \ldots$.

Resultando:

$$
d \cos \gamma=\frac{2 n+1}{2} \frac{\lambda}{2 \cos \theta} .
$$

Para medir a deformação de um dado ponto, conta-se o número de franjas e multiplica-se por $\frac{\lambda}{2 \cos \theta}$, como mostra a figura 3.10 .

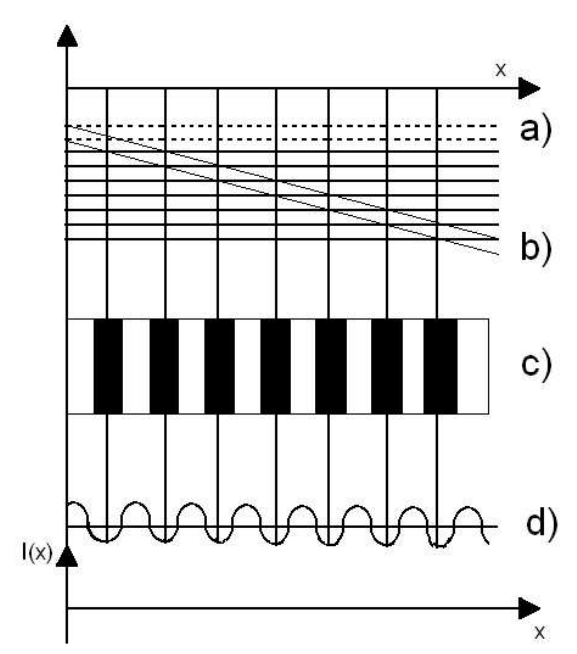

Figura 3.10: Padrão de interferência de uma barra fixa deslocada da sua posição original. a) Posição inicial da barra; b) Barra deslocada da posição inicial; c) Padrão de franjas de interferência, devido ao deslocamento mecânico da barra; d) Padrão de intensidade correspondente a estas franjas.

A maior sensibilidade é obtida quando as direções de iluminação e observação são paralelas ao vetor deslocamento, ou seja, quando $\gamma=\theta_{1}=\theta_{2}=\theta=0$, como descrito em [27]. 


\subsection{Zonas de reforço do esqueleto facial}

O modelo que explica a distribuição de tensões ou as zonas de reforço do crânio foram descritos por Sicher e Tandler que utilizaram cortes do osso e estudos antropométricos para este estudo [28]. A dissipação das cargas mastigatórias na maxila (um osso delgado e altamente pneumatizado) para os ossos do crânio, ocorre por meio dos pilares: canino, zigomático e pterigóideo. A deposição óssea ocorre nas áreas solicitadas durante as funções (mastigação, locomoção, fonação, etc) e o trabeculado ósseo orientam-se na direção das linhas de força (direção da tensão sobre o osso) para suportar os esforços, figura 3.11 .

A mandíbula, como um osso móvel e separado, articula contra o crânio, deve ser suficientemente forte e reforçado com uma cortical espessa ${ }^{3}$, figura 3.11, e pelo grande número de linhas de reforço, figura 3.12. A condição mecânica da mandíbula pode ser considerada da seguinte forma: as forças da mastigação são transmitidas para o alvéolo dentário ${ }^{4}$, osso medular, cortical, até a cabeça da mandíbula.

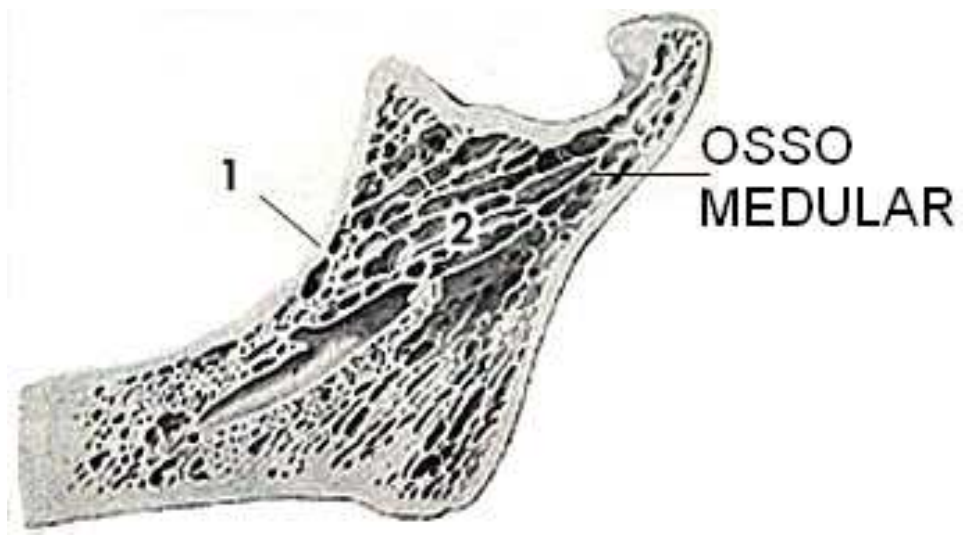

Figura 3.11: (1) Cortical, (2) Trabeculado com lâminas paralelas dirigindo-se para a cabeça da mandíbula.

[Modificado de Sicher e Tandler-1930.]

\footnotetext{
${ }^{3}$ Espessura externa do osso.

${ }^{4}$ Onde se aloja os dentes.
} 


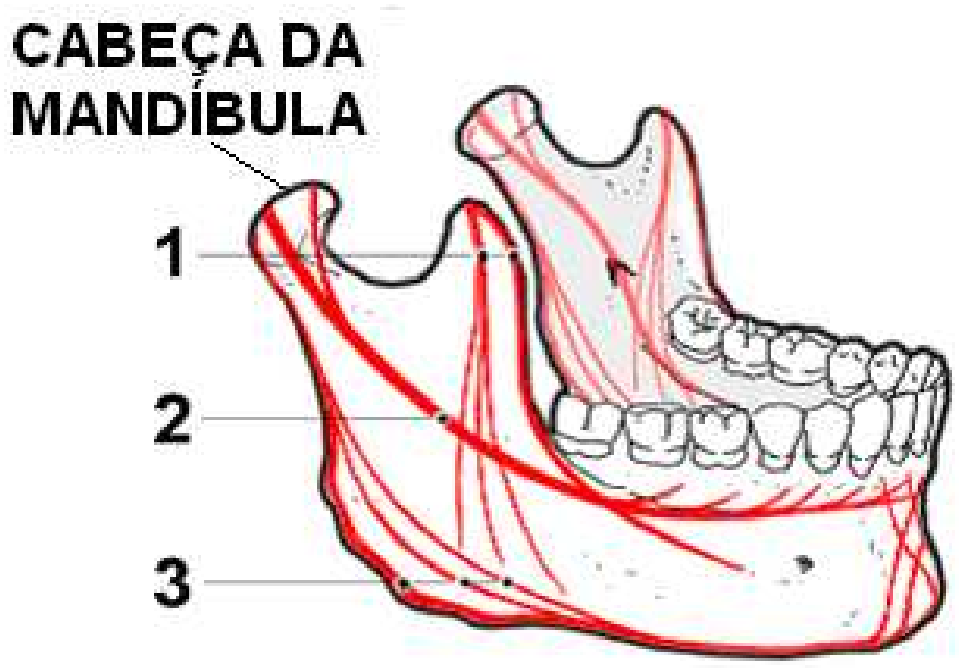

Figura 3.12: Linhas de força da mandíbula. (1) Trajetórias temporais, (2) Trajetória dentária, (3) Trajetória marginal.

[Modificado de Sicher e Tandler-1930.]

A maxila que está apoiada na base do crânio, desenvolveu em certas áreas, pilares (recebe a tensão que cai sobre os dentes) que são espessamentos da cortical óssea e em outras trajetórias no trabeculado ósseo (é um osso esponjoso, ele está disposto nesta configuração de maneira a dar resistência à estrutura óssea), figura 3.11. Entre os pilares de reforço, o osso tornase delgado e formam-se espaços vazios que alojam certos órgãos (órbita e fossa nasal), no qual são chamados de cavidades pneumáticas e podem ser consideradas áreas mecanicamente mortas, como mostra a figura 3.13 da vista frontal do crânio. 


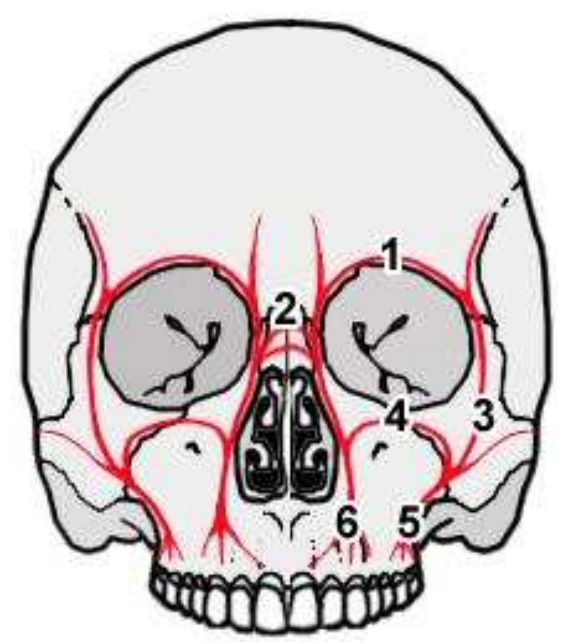

Figura 3.13: Vista frontal do crânio. (1) margem supra-orbitária, (2) traves que unem os pilares caninos, (3) segmento ascendente do pilar zigomático, (4) margem infra-orbitária, (5) pilar zigomático, (6) pilar canino.

[Modificado de Sicher e Tandler-1930.]

Os pilares da maxila circundam a cavidade orbital (região onde localiza-se os olhos) e nasal (região do nariz) e fogem da trajetória retilínea e devem ser unidos por cristas de reforço. A maxila está unida à base do crânio por meio de três pilares de cada lado, de acordo com a figura 3.14. Onde mostra as linhas de força no crânio, estas linhas de força são resultantes da função de todos os músculos da mastigação sobre o crânio. 


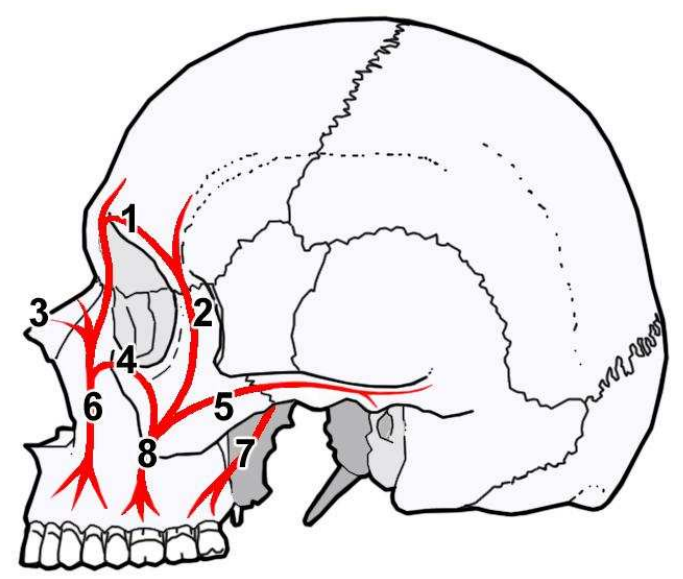

Figura 3.14: Vista lateral do crânio. (1) rebordo supra-orbitário, (2) segmento ascendente do pilar zigomático, (3) travas que unem os pilares canino, (4) pilar infra-orbitário, (5) segmento horizontal do pilar zigomático, (6) pilar canino, (7) pilar pterigóideo, (8) pilar zigomático. [Modificado de Sicher e Tandler-1930.]

- Pilar canino (6):

inicia-se na região do alvéolo do canino superior e segue a margem lateral da abertura piriforme, ou bordo lateral da fossa nasal (4) e segue até a porção medial do rebordo supra-orbitário (1).

- Pilar pterigóideo (7):

é a própria apófise pterigóidea do osso esfenóide. A extremidade inferior, ligase a apófise alveolar da maxila por meio da apófise piramidal do osso palatino, figura 3.18, e superiormente está unido diretamente à base do crânio.

- Pilar zigomático (8):

começa na altura do primeiro molar superior, segue pelo osso zigomático (2) até o osso frontal (1). No corpo do zigomático divide-se num ramo que segue pelo arco zigomático (5) e outro que segue pelo bordo inferior da órbita até alcançar o pilar canino (4). 
Os pilares anteriores e médio (canino e zigomático), são unidos por travas de conexões horizontais que são de grande importância. Os pilares canino e zigomático são unidos acima e abaixo da abertura orbital por duas travas ósseas, os rebordos infra e supra-orbitários (4) e (1), respectivamente.

O reforço superior é de especial importância por suportar as forças transmitidas pelos pilares maxilares anterior e médio. A região supra-orbitária desenvolvida dos homens primitivos nada mais é do que a adaptação a uma pressão mastigatória muito acentuada. 


\subsection{Materiais e métodos}

A técnica de interferometria holográfica utilizada para registrar as deformações ocorridas nas estruturas ósseas do crânio seco, com a SCI (simulação da contração isolada), dos músculos: TAE (temporal anterior esquerdo) e do MPE (masseter profundo esquerdo) é um método não destrutivo e oferece informações sobre as deformações superficiais, de estruturas ósseas complexas, compostas de suturas, osso medular, osso cortical e articulação dente/osso. Outros métodos utilizados para o estudo de distribuição de tensões em estruturas ósseas são: simulação matemática por meio de elementos finitos ${ }^{5} \mathrm{e}$ por meio de modelos reproduzidos em resinas fotoelásticas ${ }^{6}$.

As medidas foram realizadas sobre um crânio macerado e seco preparado para esta finalidade, figura 3.6, onde foram aplicada diferentes tensões em cada um dos músculos.

Nesta abordagem, procurou-se verificar o deslocamento do osso zigomático esquerdo e do rebordo alveolar esquerdo, na região dos molares, aplicando-se diferentes números de voltas nos pinos 3 e 5, figura 3.6. As voltas no pino 3, simularam a contração do músculo masseter profundo esquerdo e as no pino 5 a simulação do músculo temporal anterior esquerdo.

Fixamos o crânio através do forame magno (orifício de estruturas do crânio à coluna cervical), apófises mastóideas direita e esquerda e a protuberância occipital externa (região da nuca), simulando a região de apoio do crânio. Como mostra a figura 3.15.

\footnotetext{
${ }^{5}$ Utiliza modelos matemáticos para verificar as tensões desenvolvidas nas várias estruturas que compõem o objeto de estudo, é um método quantitativo.

${ }^{6}$ Método de observação das tensões por meio de luz polarizadas, submetendo a resina fotoelástica a carregamento, esse método considera o objeto como tendo o mesmo comportamento em todas as direções, é um método qualitativo.
} 


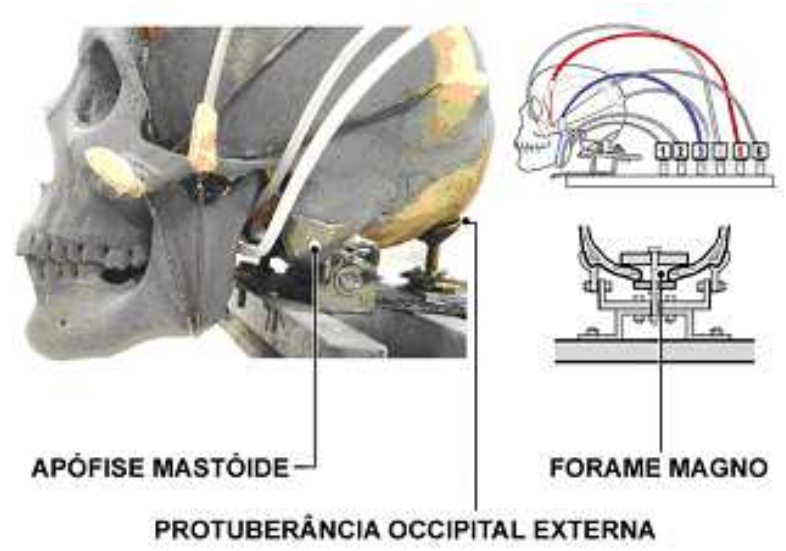

Figura 3.15: Posicionamento do crânio na mesa pneumática para obtenção dos interferogramas e apoio deste nas apófises mastóideas direita e esquerda, na protuberância occipital externa e no forame magno.

Observa-se que a mandíbula do lado esquerdo apresenta-se sem o segundo e o terceiro molar. Portanto, os contatos oclusais (superfície mastigatória em contato com os dentes antagonistas) entre os dentes superiores e inferiores ocorrem até os primeiros molares. O experimento representa a distribuição de tensões do espécime em particular. 


\subsection{Resultados experimentais e discussão}

Os resultados experimentais ilustram diferentes interferogramas com aplicações de tensão no músculo masseter profundo esquerdo (MPE) e temporal anterior esquerdo (TAE), no osso alveolar e no osso zigomático. Estas medidas foram analisadas qualitativamente e quantitativamente, através do programa computacional ${ }^{7}$ que calcula o deslocamento da região em análise.

Os resultados a seguir foram obtidos com aplicação de tensão no MPE, figura 3.16:

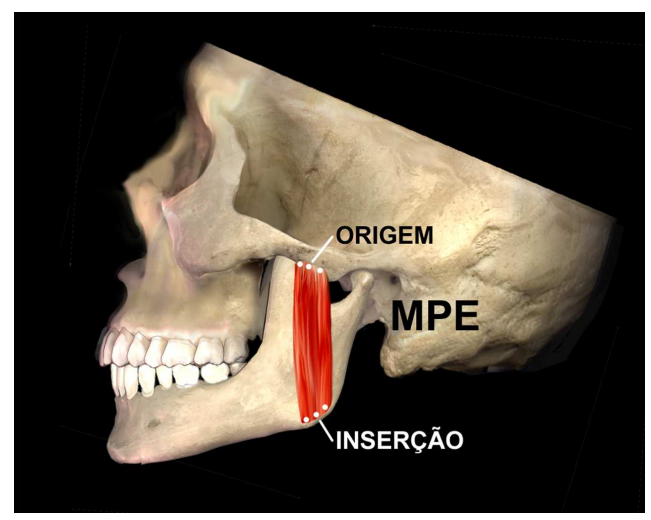

Figura 3.16: Origem e inserção do músculo MPE. Origem no arco zigomático, e a contração do músculo aproxima a inserção, realizando a elevação da mandíbula.

E a figura 3.17 mostra a maxila e a denominação das áreas estudadas.

As medidas foram feitas na maxila esquerda do crânio e são resultados da SCI (simulação da contração isolada) no masseter profundo esquerdo.

\footnotetext{
${ }^{7}$ Ver apêndice A.
} 


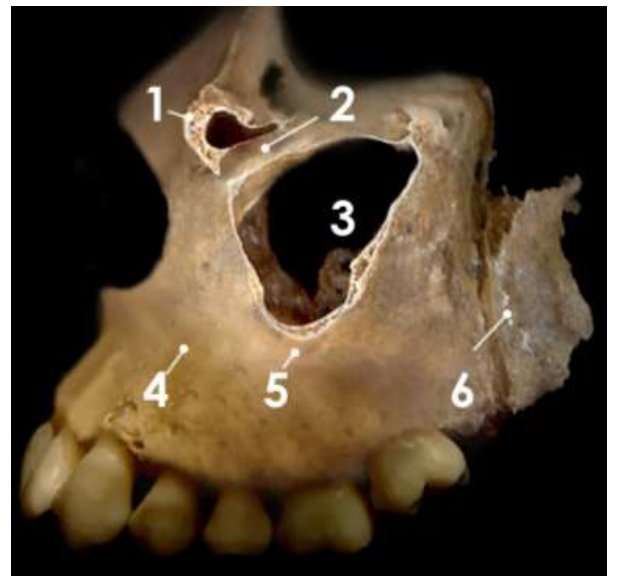

Figura 3.17: Maxila esquerda com corte sagital na região do forame infra-orbital e parte da apófise pterigóidea. (1) borda infra-orbital, (2) canal infra-orbital, (3) seio maxilar, (4) pilar canino, (5) pilar zigomático, (6) pilar pterigóideo.

A vista lateral esquerda do crânio é mostrada na figura 3.18, onde evidenciase a região na maxila com as raízes dos dentes. 


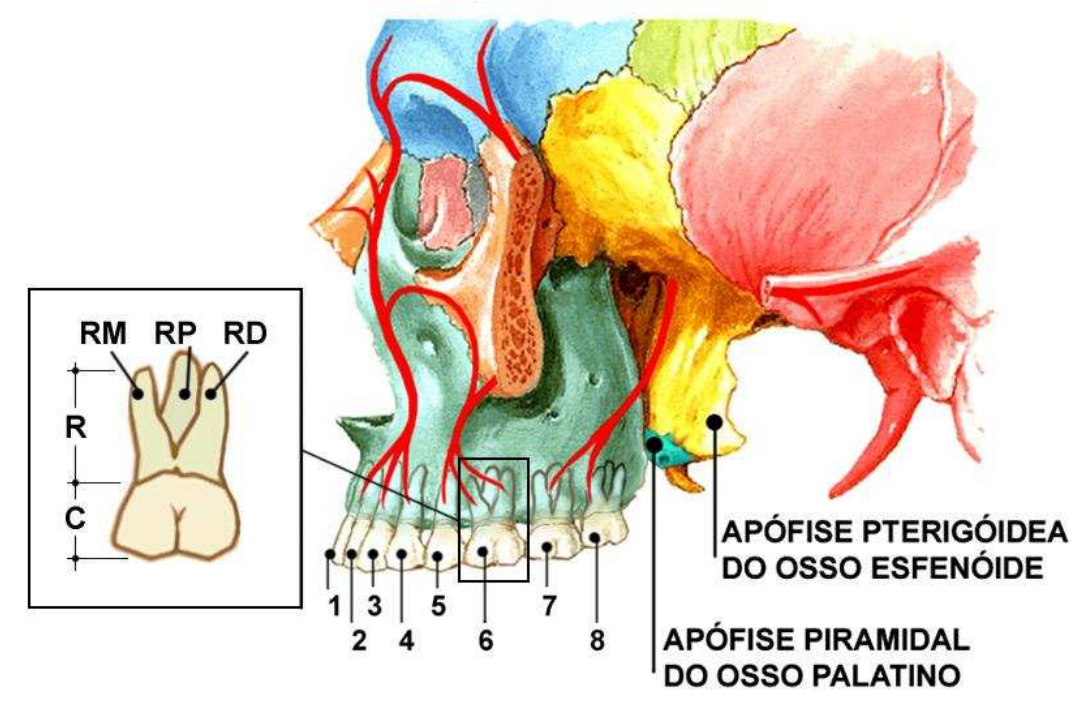

Figura 3.18: Vista lateral esquerda. 1) Incisivo central, 2) Incisivo lateral, 3) Canino, 4) Primeiro pré-molar, 5) Segundo pré-molar, 6) Primeiro molar, 7) Segundo molar, 8) terceiro molar.

[Adaptação da fonte: Netter, F.H. Atlas interativo de anatomia humana, Novartis medical education-ARTMED editora, 1999.]

Onde, $\mathrm{R}=$ Raiz, $\mathrm{C}=$ Coroa, $\mathrm{RM}=$ Raiz mesial, $\mathrm{RP}=$ Raiz palatina e $\mathrm{RD}=$ Raiz distal.

O holograma da maxila sem aplicação de tensão é mostrado na figura 3.19 


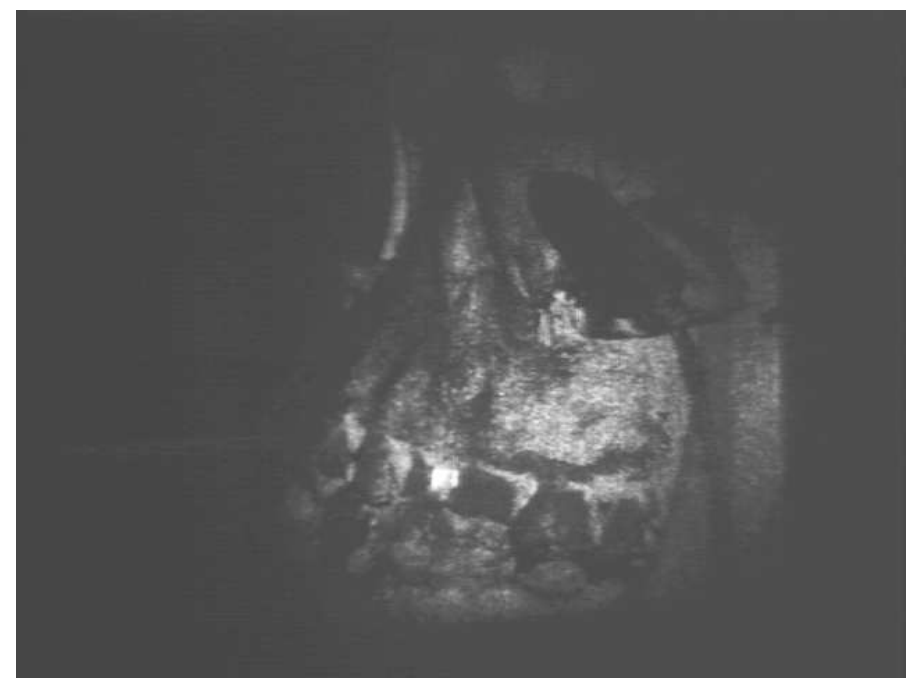

Figura 3.19: Holograma do osso alveolar esquerdo.

A simulação da contração isolada do músculo masseter profundo esquerdo, com duas voltas no MPE, figura 3.20, mostraram franjas distribuídas da região anterior para a posterior, respectivamente de canino para molares, esquema na figura 3.18. As franjas na região dos pré-molares, apresentam a porção apical (ápice da raiz) voltada para mesial (linha média da face). Na região do primeiro para o segundo molar, envolve a vertente anterior do pilar zigomático, esquema na figura 3.17, e na região mais posterior em direção ao terceiro molar as franjas se distribuem mais verticais provavelmente pela ausência dos dentes antagonistas (segundo e terceiro molar inferior). 


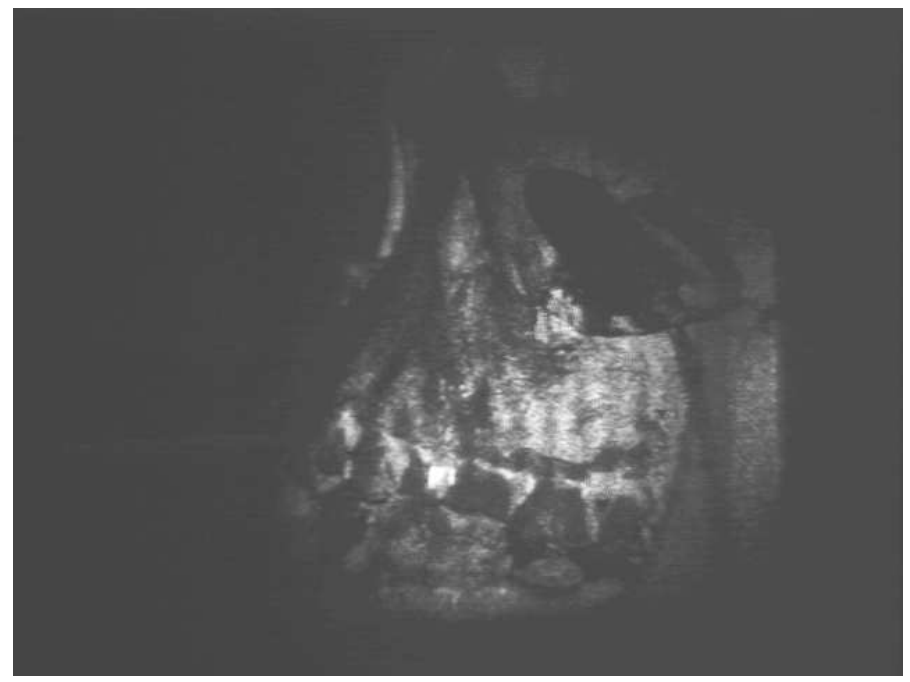

Figura 3.20: Tensões resultantes após duas voltas no pino três (MPE).

A área selecionada para análise com o programa é igual para todas as medidas feitas na região do osso alveolar, a primeira região vai do canino até o terceiro molar (1) e a segunda é na região da vertente anterior do pilar zigomático (2), como mostra a figura 3.21. Estas regiões foram selecionadas de acordo com a densidade de franjas que o programa computacional é capaz de distinguir e não tem nenhuma relação com as estruturas atômicas. 


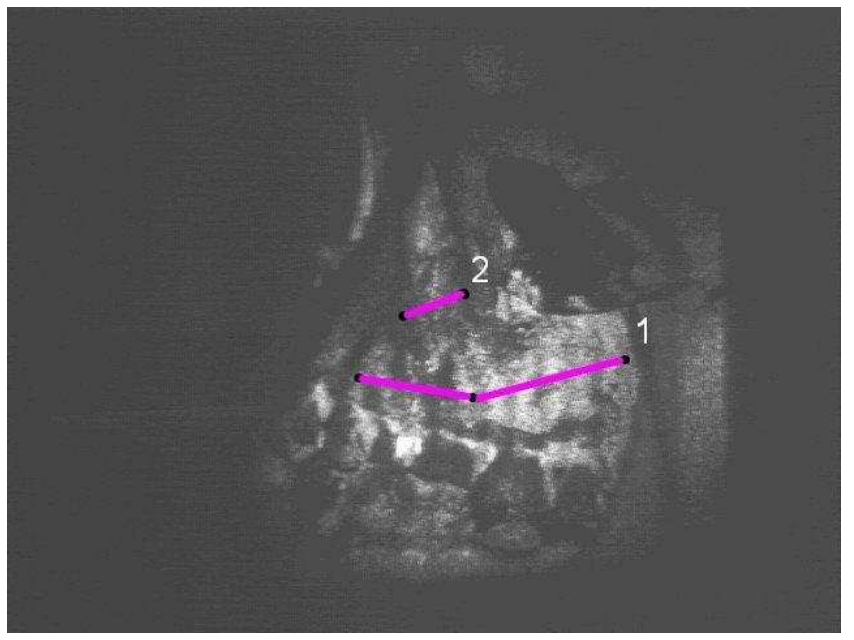

Figura 3.21: Regiões 1 e 2 selecionadas para análise com o programa computacional.

Com duas voltas no MPE, ocorreu um deslocamento da região 1 de $2,313 \mu m$ e da região 2 de $0,771 \mu m$.

A figura 3.22 mostra a sobreposição do interferograma do osso alveolar sobre o crânio.

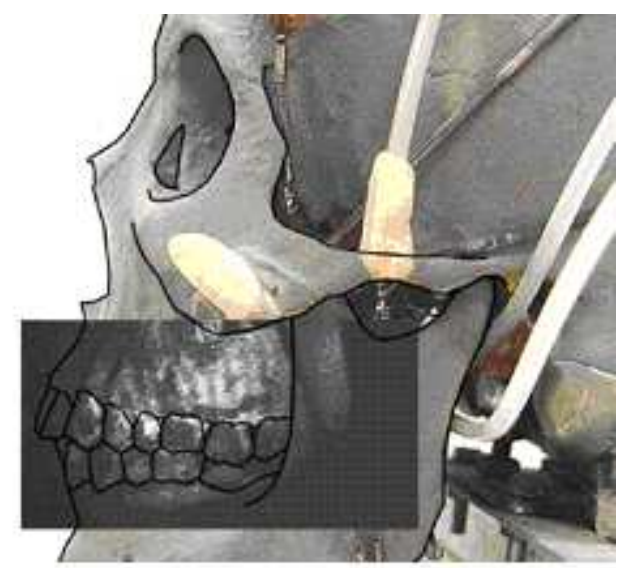

Figura 3.22: Sobreposição do interferograma do osso alveolar sobre o crânio para localização das franjas, sobre a maxila esquerda. 
Na SCI, com três voltas no MPE, figura 3.23, houve uma densidade maior de franjas porque foi aplicada uma tensão maior e evidenciou a dissipação de cargas pelo pilar zigomático principalmente pela cortical externa (osso da parede anterior da maxila). Foi demonstrado através da análise computacional que estas regiões tiveram um deslocamento maior em comparação com a medida feita com duas voltas no MPE, aqui o deslocamento da região 1 aumentou para $2,827 \mu \mathrm{m}$ e a região 2 teve um aumento para $1,285 \mu \mathrm{m}$.

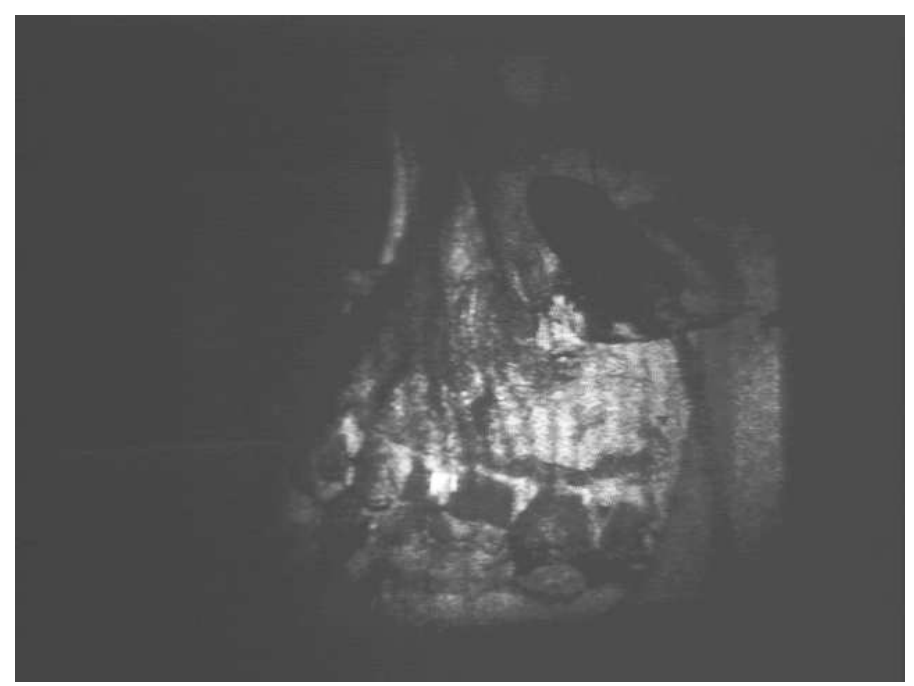

Figura 3.23: Tensões resultantes após três voltas no pino três (MPE).

Na SCI com quatro voltas no MPE, figura 3.24, observa-se, pela maior carga aplicada, a mudança na direção do deslocamento na região correspondente ao ápice da raiz distal (ponta da raiz distal) do primeiro molar superior esquerdo com franjas distribuídas mais horizontais, e um aumento da densidade das franjas na região do pilar zigomático.

Na região 1 o deslocamento foi de $2,570 \mu \mathrm{m}$ e na região 2 foi de $1,285 \mu \mathrm{m}$.

A região 2 não se deslocou apesar de termos aplicado uma tensão maior pelo fato desta região ser bastante resistente e flexível suportando bastante tensão e funcionando como uma zona de dissipação de carga, outro motivo é que o osso não é homogêneo e desta forma, o comportamento do deslocamento 
não é linear.

A região 1 teve um deslocamento menor em relação a medida anterior pelo fato de ter dissipado toda a tensão para esta região 2 .

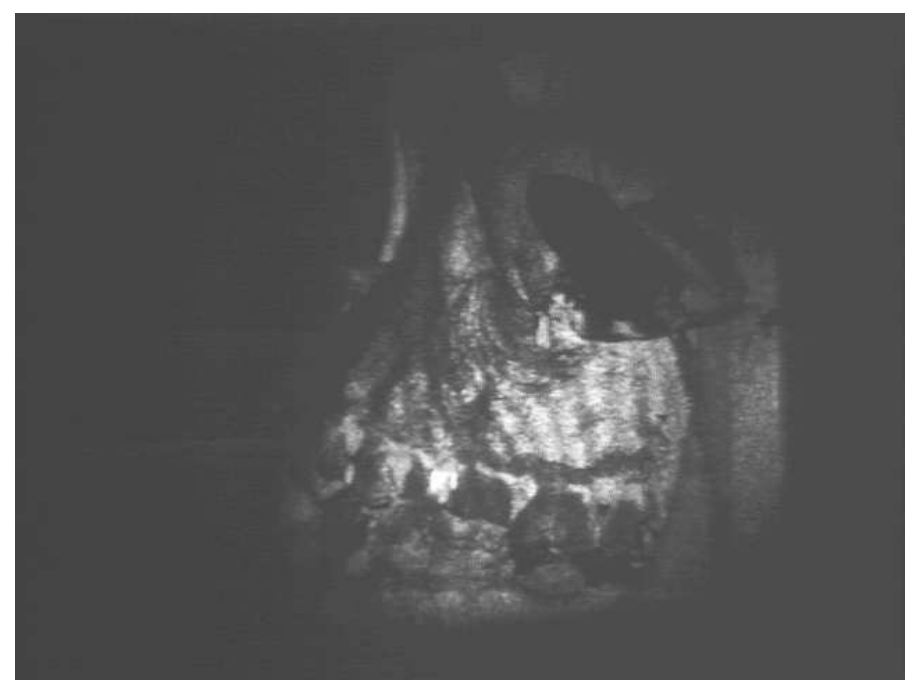

Figura 3.24: Tensões resultantes após quatro voltas no pino três (MPE).

A tabela abaixo mostra o deslocamento das regiões que foram selecionadas para a análise quantitativa:

\begin{tabular}{|c|c|c|}
\hline Pino3 & Região $1 \mathrm{em} \mu \mathrm{m}$ & Região $2 \mathrm{em} \mu \mathrm{m}$ \\
\hline \hline Duas voltas & 2,313 & 0,771 \\
\hline Três voltas & 2,827 & 1,285 \\
\hline Quatro voltas & 2,570 & 1,285 \\
\hline
\end{tabular}

Possível ocorrência da diminuição do deslocamento de três para quatro voltas (como mostrado na tabela acima), como mostra a figura 3.25. 

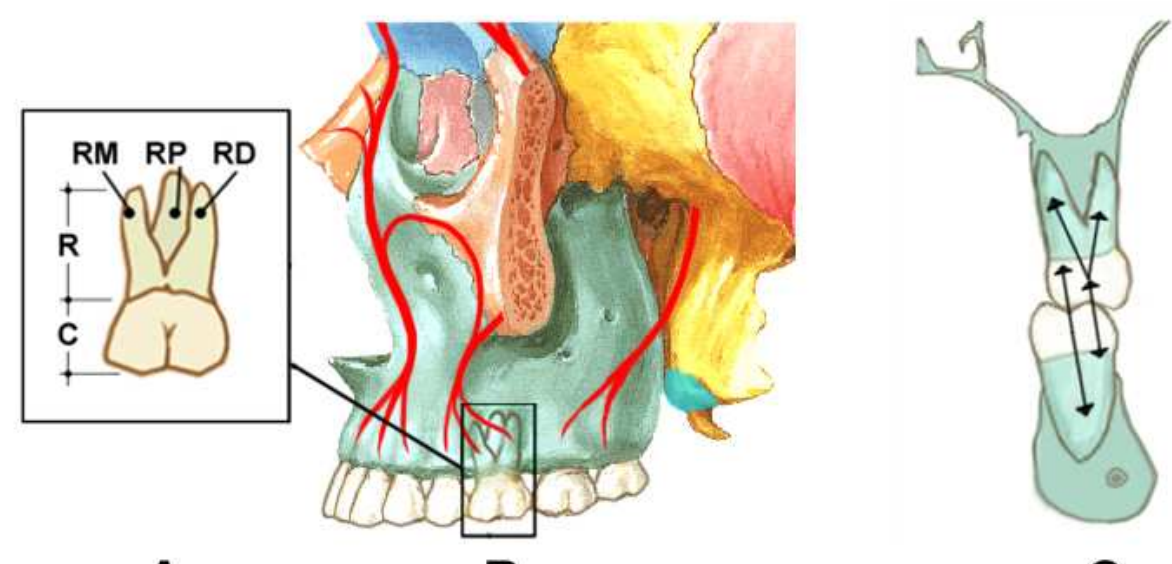

A

B

C

Figura 3.25: $\mathbf{A}=$ Vista vestibular do molar; $\mathbf{B}=$ Localização do primeiro molar superior esquerdo; $\mathrm{C}=\mathrm{Corte}$ frontal da região do primeiro molar superior esquerdo e esquema da distribuição das cargas e a possível dissipação para o osso palatino.

A superfície externa da região que apresenta a diminuição deve ser observada como parte da maxila, estrutura tridimensional, com zonas de dissipação de tensões na abóbada palatina (céu da boca), onde está alojada a raíz palatina do primeiro molar superior, que apresenta-se inclinada e mais volumosa que as duas raízes vestibulares, provalvemente dissipa e recebe mais tensão.

O seio maxilar (cavidade pneumática) pode apresentar septos que auxiliam na dissipação de tensões assim como o assoalho da cavidade orbitária (parte superior da maxila), com o sulco e canal infra-orbitário formam zonas de reforço e dissipação de carga. Desta forma, a diminuição do deslocamento na região 1 pode ser entendida como a mudança de direção na distribuição das tensões, poupando a cortical externa na região estudada.

É mostrado um esquema com as denominações da segunda área envolvida no trabalho na figura 3.26 . 


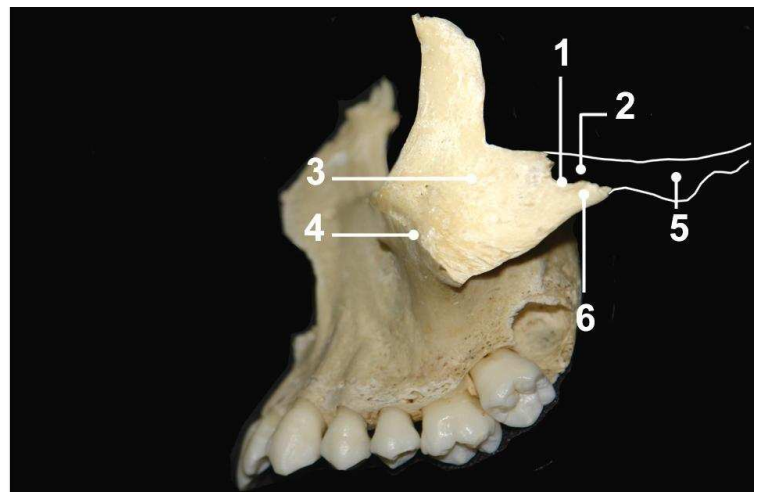

Figura 3.26: (1) sutura zigomático-temporal, (2) apófise zigomática do temporal, (3) osso zigomático: (4) sutura maxilo-zigomática, (5) apófise zigomática do temporal, (6) apófise temporal do zigomático, (5 e 6 juntas) arco zigomático.

A área estudada é do osso zigomático esquerdo, figura 3.26, com a simulação da contração isolada do músculo masseter profundo esquerdo com duas voltas, figura 3.27. O deslocamento ocorreu na direção da borda lateral da cavidade orbitária esquerda (região da borda da órbita), as franjas no osso zigomático, aparecem bem nítidas e definidas com apenas duas voltas. 


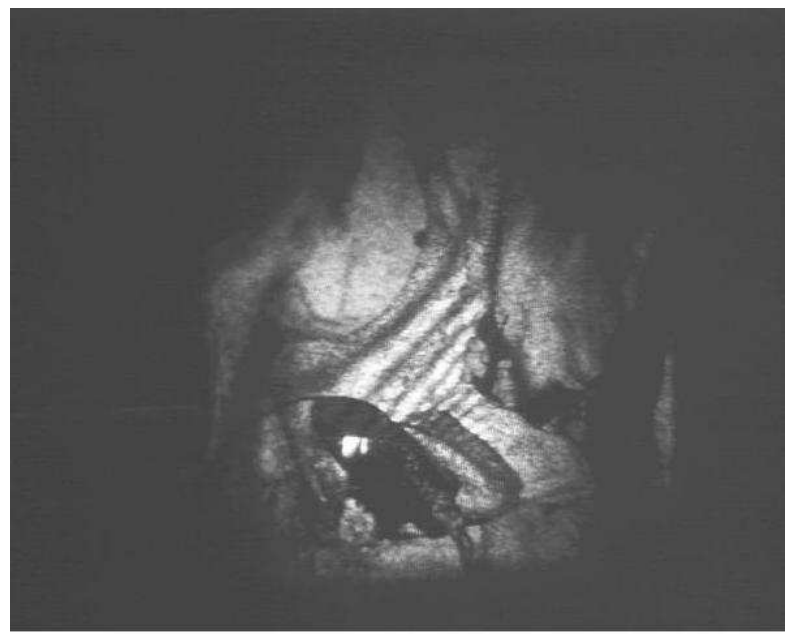

Figura 3.27: Franjas sobre o osso zigomático, após a aplicação de tensão por meio de duas voltas no pino três (MPE).

A área selecionada para análise, corresponde à borda lateral externa da cavidade orbitária esquerda, duas áreas foram demarcadas (inferior e superior) no osso zigomático, como mostra a figura 3.28. As regiões selecionadas são iguais para todas as medidas com aplicação de tensão no pino três (MPE).

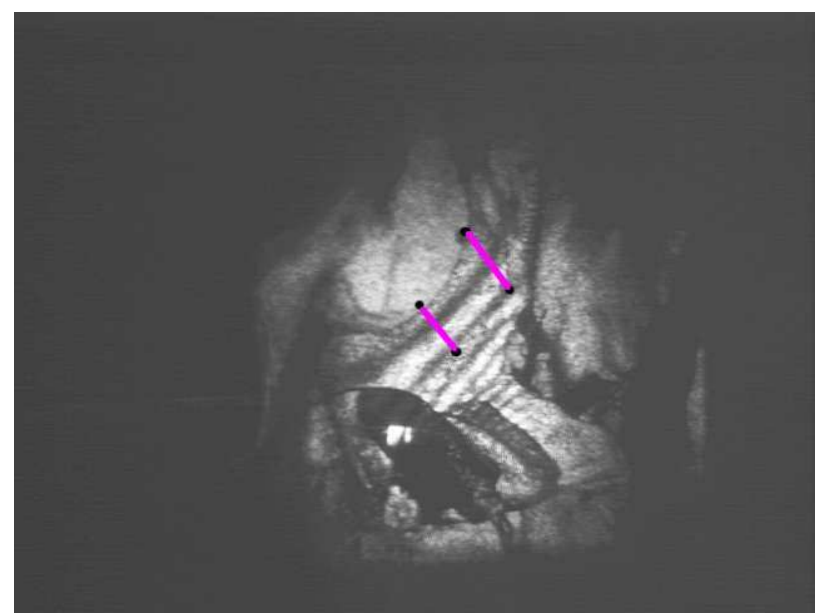

Figura 3.28: Área selecionada para análise das medidas com aplicação de tensão no pino três (MPE). 
O deslocamento destas regiões, com duas voltas no pino três foi de $0,514 \mu \mathrm{m}$. O deslocamento do osso zigomático é perpendicular às franjas.

A figura 3.29, mostra a sobreposição do interferograma sobre o crânio. A mancha preta sobre o osso zigomático é o suporte em resina simulando a origem do músculo masseter superficial esquerdo.

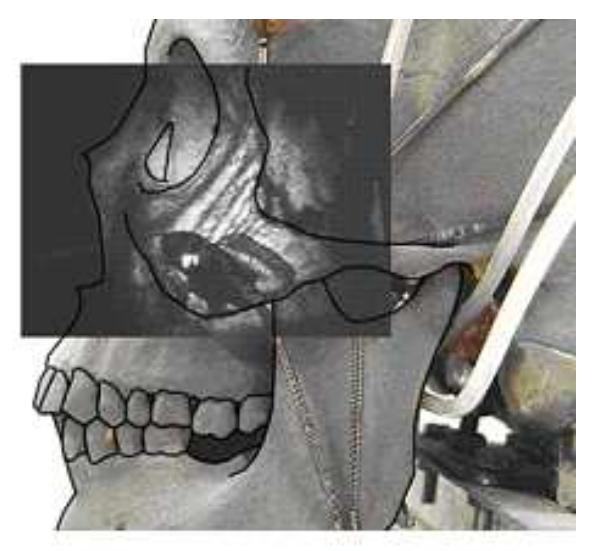

Figura 3.29: Sobreposição do interferograma sobre o crânio e a localização das franjas sobre o osso zigomático esquerdo.

A SCI com três voltas no MPE, figura 3.30, mostra um maior deslocamento na região do corpo do zigomático, pela maior densidade de franjas. As franjas contornam a região da borda inferior da órbita, da lateral e o início da região supra-orbitária (região superior da órbita). Comprova-se através do programa que ocorreu um aumento do deslocamento das duas áreas selecionadas para $0,771 \mu m$. 


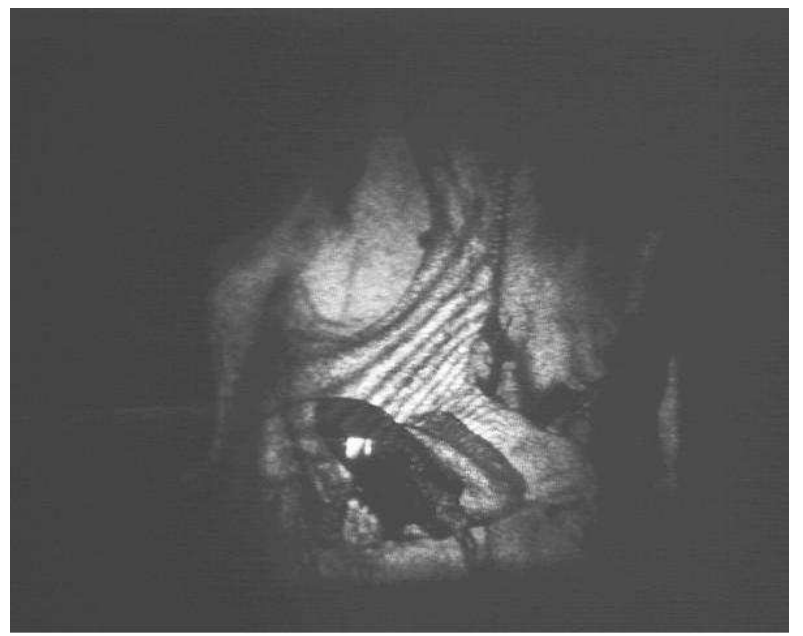

Figura 3.30: Tensões resultantes após três voltas no pino três (MPE).

A SCI com cinco voltas no MPE, figura 3.31, mostrou o aumento na densidade das franjas, principalmente em direção à apófise temporal do zigomático, esquema na figura 3.26. As franjas distribuem-se por todo o corpo do zigomático, até os ossos maxilar e frontal através das respectivas suturas: a maxilo-zigomática e a zigomático-frontal, esquema na figura 3.32. O deslocamento das regiões selecionadas foi de 1,285 $\mu \mathrm{m}$.

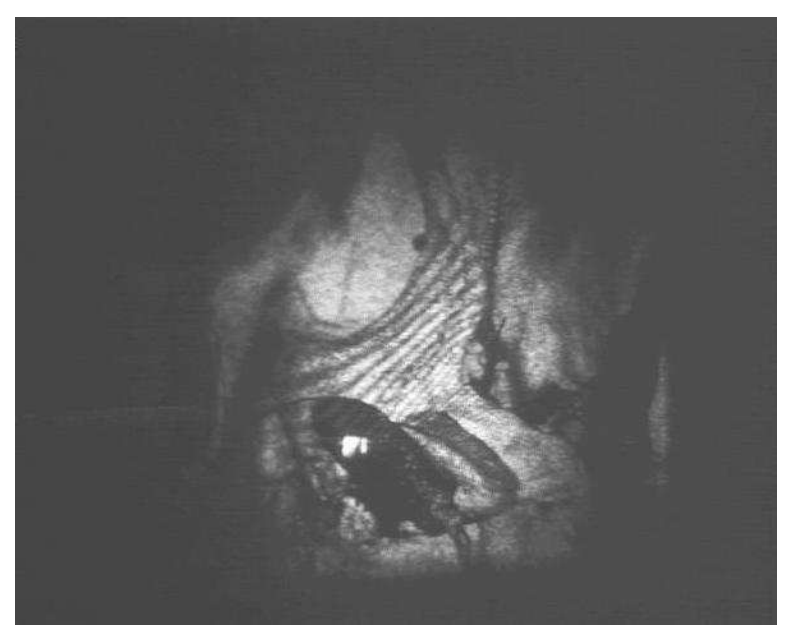

Figura 3.31: Tensões resultantes após cinco voltas no pino três (MPE). 


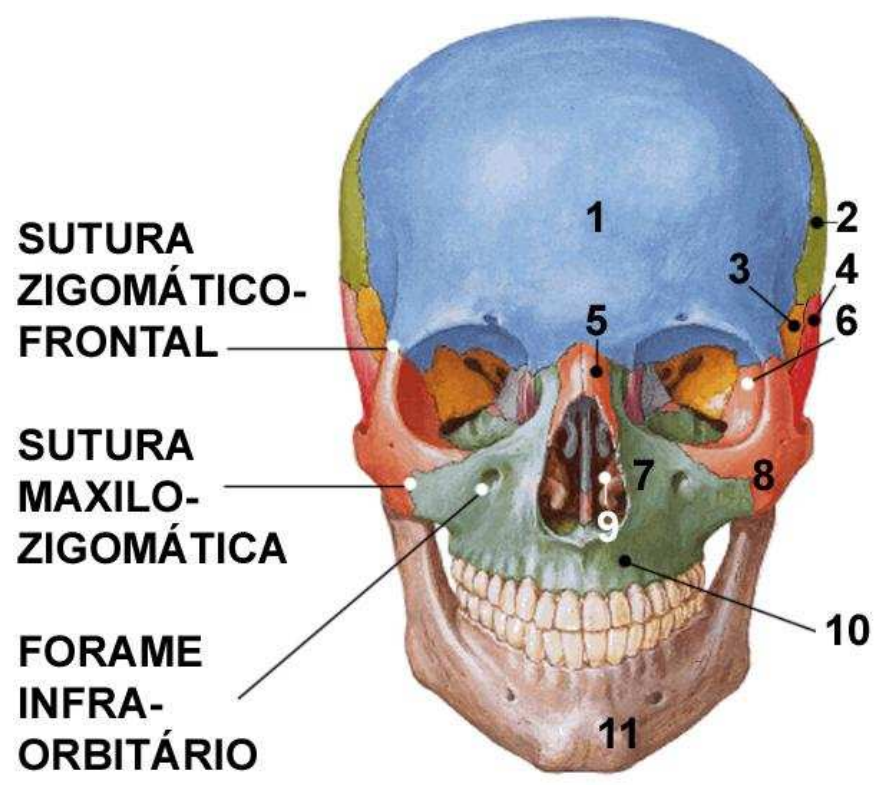

Figura 3.32: Vista frontal da face. Ossos, cavidades e suturas. 1)frontal; 2)parietal; 3)esfenóide; 4)temporal; 5)nasal; 6)cavidade orbital; 7)maxila; 8)zigomático; 9)cavidade nasal; 10)maxila; 11)mandíbula.

[Fonte: Netter, F.H. Atlas interativo de anatomia humana, Novartis medical education-ARTMED editora, 1999.]

Na SCI com seis voltas no MPE, figura 3.33, as franjas se distribuem de forma a acompanhar totalmente a anatomia da região infra, lateral e o início da região supra-orbitária. A grande densidade de franjas na região da apófise temporal do osso zigomático indica uma maior deformação desta comparada com os interferogramas anteriores, e isto pôde ser comprovado com a análise feita pelo programa onde o deslocamento da região selecionada teve um aumento para $1,542 \mu \mathrm{m}$. 


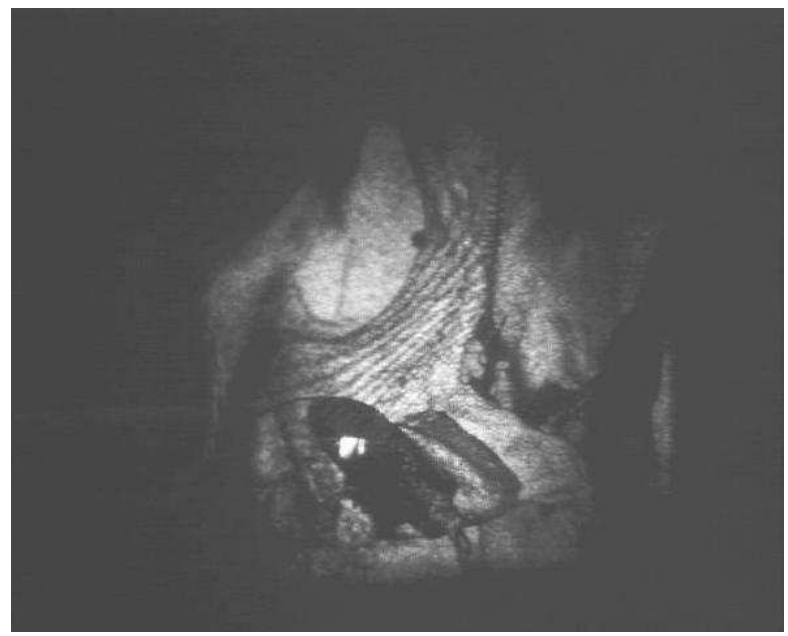

Figura 3.33: Tensões resultantes após seis voltas no pino três (MPE).

A tabela abaixo mostra a aplicação de força nestes dentes e o deslocamento das regiões analisadas nas medidas:

\begin{tabular}{|c|c|c|}
\hline Pino3 & Aplicação de força em $K g f$ & Deslocamento em $\mu m$ \\
\hline \hline Duas voltas & 0,35 & 0,514 \\
\hline Três voltas & 0,60 & 0,771 \\
\hline Cinco voltas & 1,10 & 1,285 \\
\hline Seis voltas & 1,35 & 1,542 \\
\hline
\end{tabular}

A seguir é mostrado os resultados experimentais dos interferogramas resultantes da aplicação de diferentes tensões no músculo temporal anterior esquerdo, figura 3.34 . 


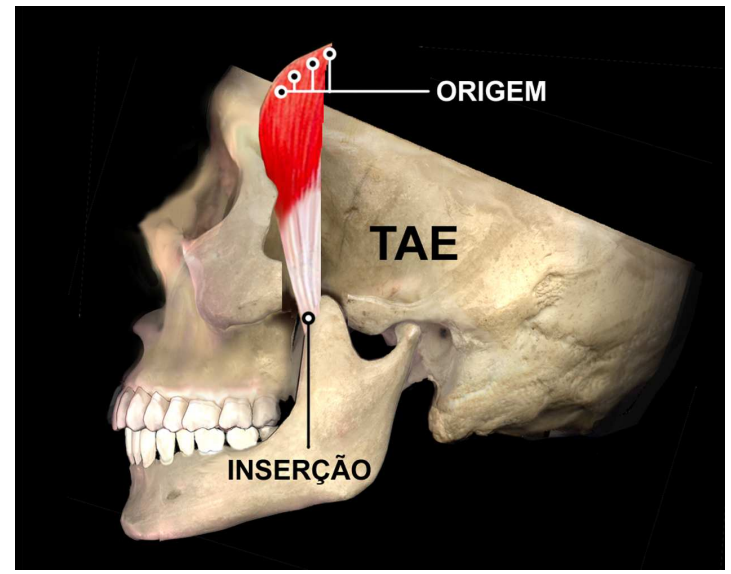

Figura 3.34: Esquema do feixe anterior do músculo temporal esquerdo. Origem na linha temporal do osso frontal e inserção na apófise coronóide da mandíbula. Sua contração eleva a mandíbula.

A SCI do músculo TAE, necessitou de seis voltas, para o aparecimento das primeiras franjas visíveis no osso zigomático, figura 3.35, as franjas são concêntricas.

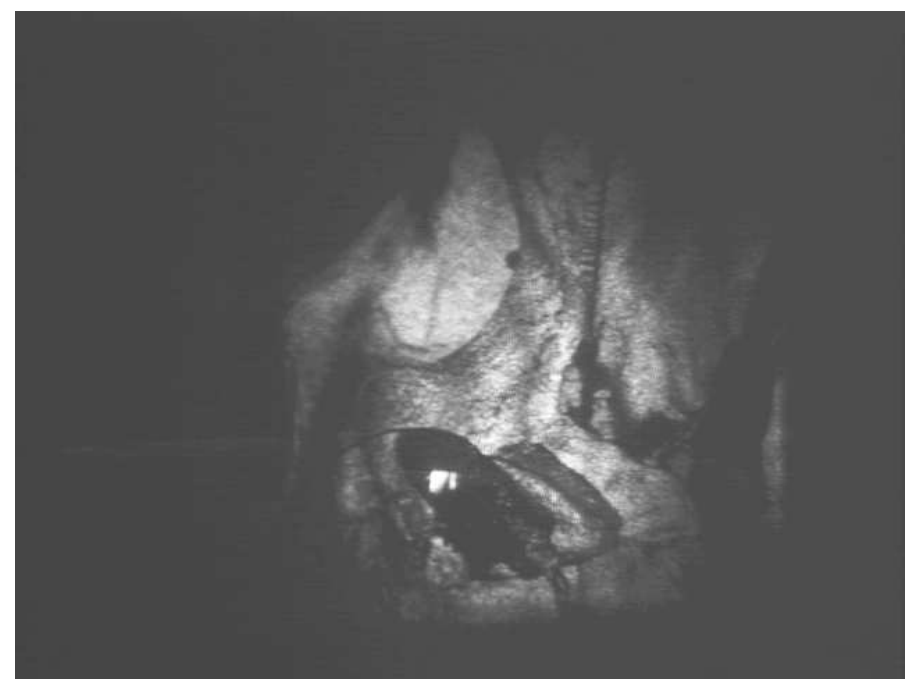

Figura 3.35: Tensões resultantes após seis voltas no pino cinco (TAE).

As medidas foram analisadas pelo programa em duas regiões: uma ascen- 
dente que segue a lateral externa da órbita em direção ao osso frontal; e outra horizontal em direção ao arco zigomático do osso temporal, como mostra a figura 3.36. As regiões selecionadas são iguais para todas as medidas com aplicação de tensão no pino cinco (TAE).

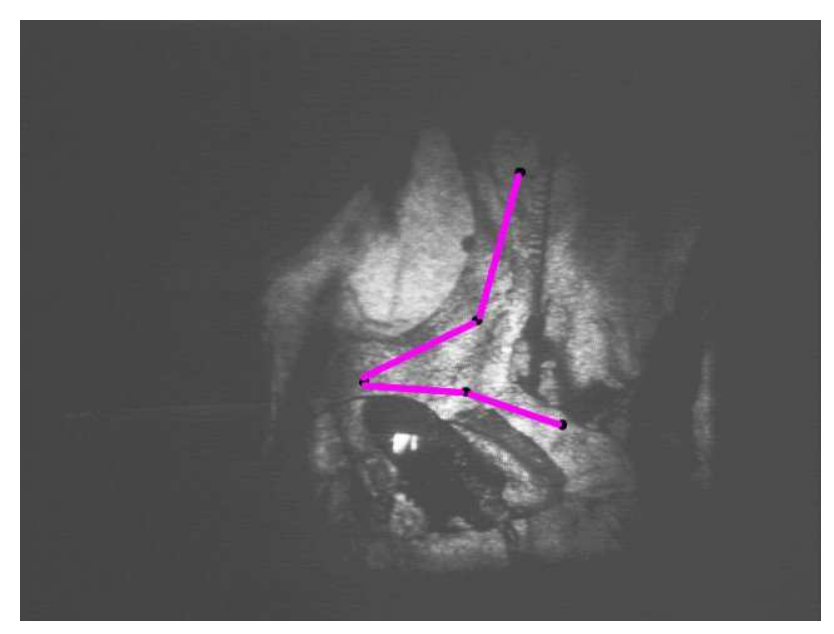

Figura 3.36: Área selecionada para análise das medidas com aplicação de tensão no pino cinco (TAE).

O deslocamento desta região com seis voltas no TAE, foi de $1,028 \mu m$ da região ascendente e de $1,285 \mu \mathrm{m}$ da região horizontal.

A SCI do músculo TAE com sete voltas, figura 3.37, mostra o aumento na densidade das franjas com um deslocamento de 1, 285 $\mu \mathrm{m}$ da região ascendente e de $1,542 \mu m$ da região horizontal. As franjas se distribuem na apófise temporal do osso zigomático, esquema na figura 3.26. 


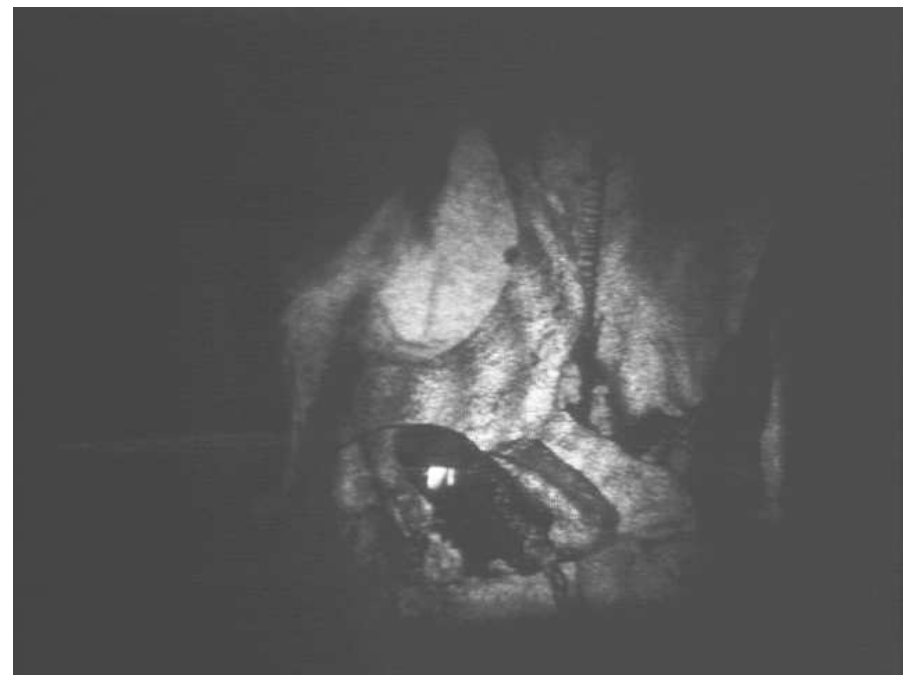

Figura 3.37: Tensões resultantes após sete voltas no pino cinco (TAE).

A SCI do músculo TAE com oito voltas, figura 3.38, mostra que as franjas se distribuem para o osso temporal, esquema na figura 3.32. O deslocamento da região ascendente foi de $1,542 \mu m$ e de $1,799 \mu m$ da região horizontal.

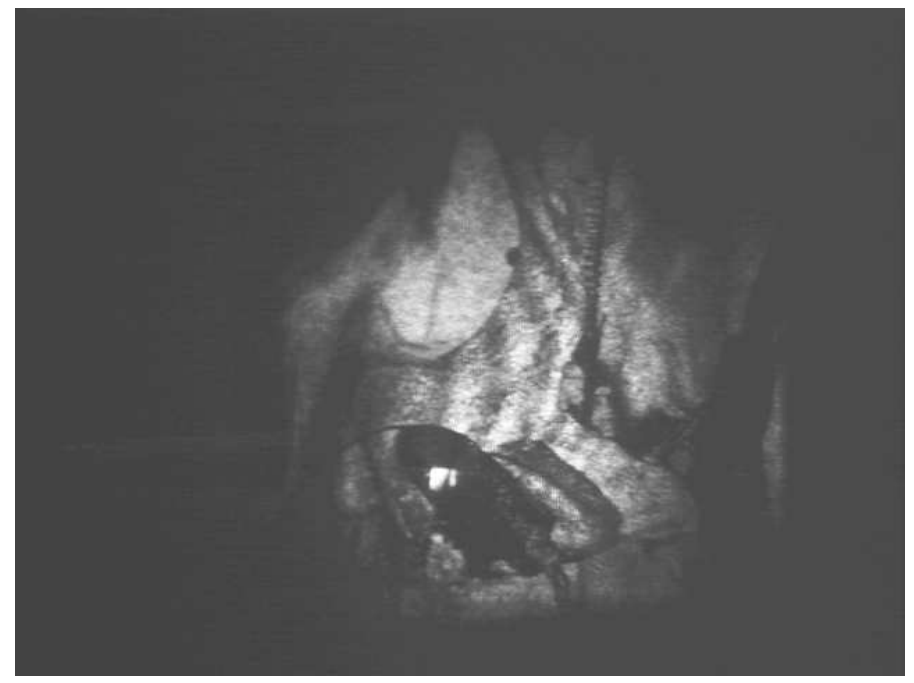

Figura 3.38: Tensões resultantes após oito voltas no pino cinco (TAE).

A tabela abaixo mostra a aplicação de força nestes dentes e o desloca- 
mento das regiões analisadas:

\begin{tabular}{|c|c|c|c|}
\hline Pino5 & Aplicação de força em $K g f$ & DA em $\mu m$ & DH em $\mu m$ \\
\hline \hline Seis voltas & 1,05 & 1,028 & 1,285 \\
\hline Sete voltas & 1,30 & 1,285 & 1,542 \\
\hline Oito voltas & 1,65 & 1,542 & 1,799 \\
\hline
\end{tabular}

$\mathrm{DA} \Longrightarrow$ deslocamento na região ascendente; $\mathrm{DH} \Longrightarrow$ deslocamento na região horizontal.

A região ascendente, que segue a lateral externa da órbita em direção ao osso frontal, e a região horizontal, em direção ao arco zigomático do osso temporal seguem as linhas de força descritas por Sicher e Tandler na seção 3.3, como é mostrado na figura 3.39. Isto mostra que estas medidas estão de acordo com o modelo das linhas de força (neste modelo estas linhas são resultantes de todos os músculos envolvidos no processo de mastigação) descrito na odontologia.
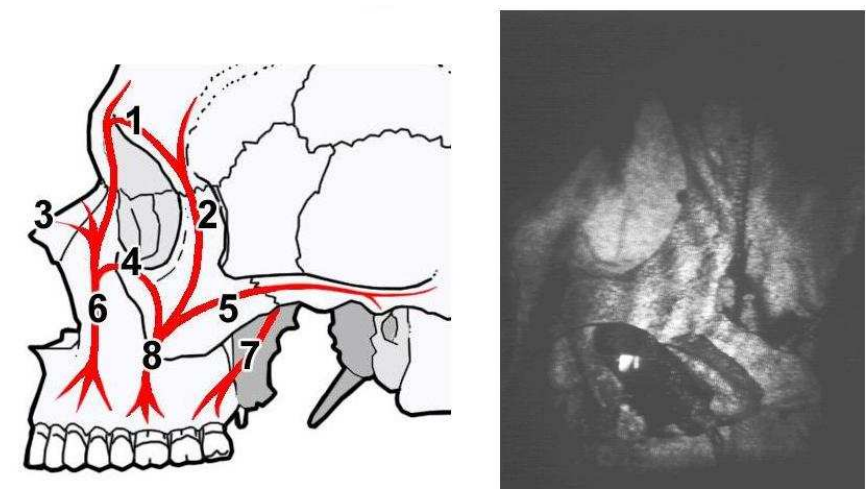

Figura 3.39: Comparação da distribuição de tensão no crânio, segundo

o modelo da odontologia, e o resultado encontrado experimentalmente.

As próximas medidas mostram os interferogramas resultantes da aplicação de tensões no masseter profundo esquerdo e no temporal anterior esquerdo, simultaneamente. 


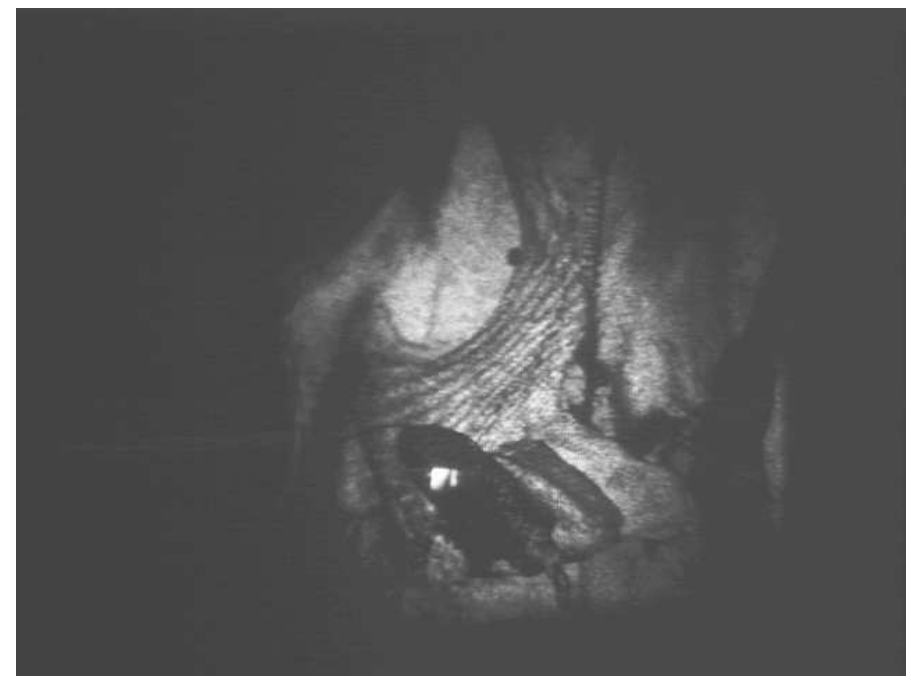

Figura 3.40: Tensões resultantes após cinco voltas no pino três (MPE) e cinco voltas no pino cinco (TAE). Apresentaram densidade maior de franjas que a SCI com o mesmo número de voltas, isoladamente.

Para estas medidas as regiões analisadas pelo programa foi a mesma, descrita anteriormente, para o músculo MPE como mostra a figura 3.41.

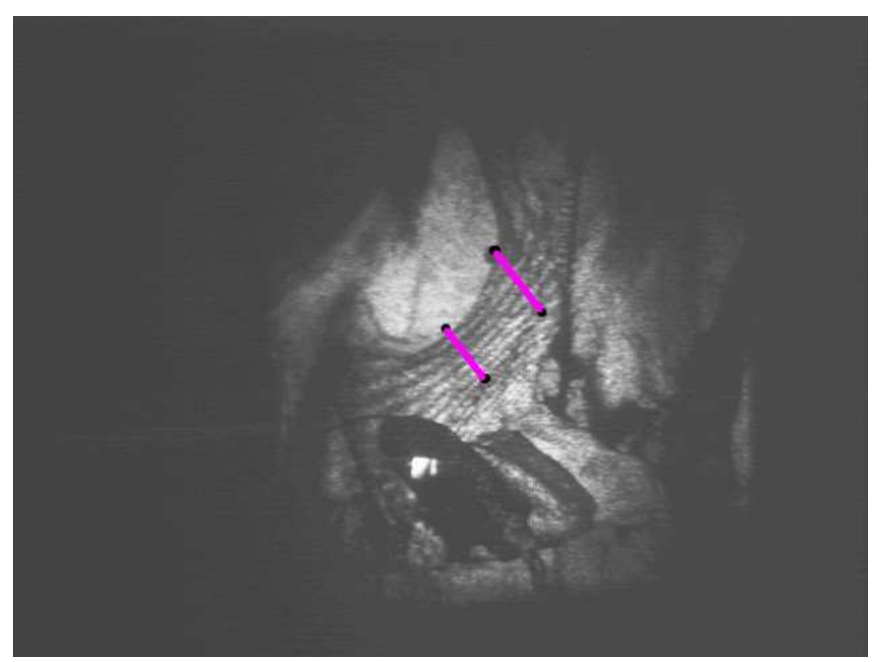

Figura 3.41: Região analisada para as medidas no pino três (MPE) e no pino cinco (TAE) simultaneamente. 
A SCI com seis voltas nos músculos MPE e TAE, figura 3.42, mostram o predomínio das franjas do MPE na região lateral da órbita. Diferenças sutis aparecem no início da região da borda inferior e na região supra orbitária. As distribuições das franjas nesta região têm maior contribuição do músculo MPE.

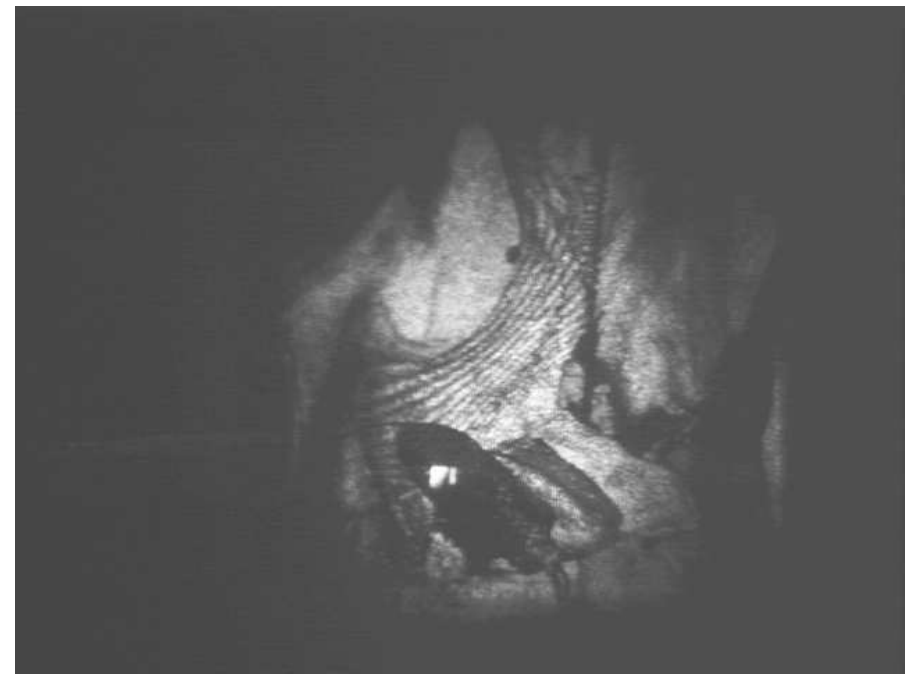

Figura 3.42: Tensões resultantes após seis voltas no pino três (MPE) e seis voltas no pino cinco (TAE).

Com cinco voltas no pino três e cinco, simultaneamente, foi medido um deslocamento de $1,542 \mu m$ da região inferior e de $1,285 \mu m$ da região superior, enquanto que com seis voltas nestes mesmos músculos simultaneamente ocorreu um aumento do deslocamento da região inferior para 2,056 $\mu \mathrm{m}$ e da região superior para $1,799 \mu m$.

Com os resultados quantitativos demonstrou-se que a SCI de dois músculos simultaneamente não resulta na somatória da SCI isoladamente, pois a direção e o sentido da contração de cada músculo pode resultar numa ação sinérgica (mesma direção) ou antagônica (ações opostas).

A tabela abaixo mostra a aplicação de força nestes dentes e o deslocamento das regiões que foram selecionadas para a análise quantitativa: 


\begin{tabular}{|c|c|c|c|c|}
\hline Pino3 & Pino5 & Aplicação de força em $K g f$ & DI em $\mu m$ & DS e $\mu m$ \\
\hline \hline Cinco voltas & Cinco voltas & 1,70 & 1,542 & 1,285 \\
\hline Seis voltas & Seis voltas & 1,90 & 2,056 & 1,799 \\
\hline
\end{tabular}

$\mathrm{DI} \Longrightarrow$ deslocamento na região inferior; $\mathrm{DS} \Longrightarrow$ deslocamento na região superior.

As medidas feitas utilizando os pinos três e cinco (simultaneamente) com cinco voltas, mostraram que na região inferior ocorreu um maior desloca-

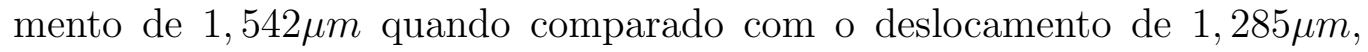
nesta mesma região, utilizando somente o pino três e na região superior o deslocamento permaneceu em 1,285 $\mu \mathrm{m}$. Assim, pode-se demonstrar que a participação do TAE é maior na região horizontal dissipando a carga para a apófise temporal do osso zigomático. E que o deslocamento da região superior manteve-se pelo fato de que o TAE necessita de um carregamento maior para que apareçam as franjas. Isso significa que a participação do MPE é maior no deslocamento desta região.

Os pinos três e cinco (simultaneamente) com seis voltas, apresentaram na região inferior um aumento substancial, para 2,056 $\mu \mathrm{m}$ demonstrando a grande contribuição do TAE quando submetido a um maior carregamento, o mesmo ocorreu também na região superior.

A análise feita aqui é bidimensional, pois sabemos somente a direção do deslocamento e não se consegue ter um perfil tridimensional dos deslocamentos destes ossos.

A utilização da técnica de interferometria demonstrou que a SCI do MPE e TAE, apresentaram resultados de acordo com o modelo de Sicher e Tandler $[28]$. 


\section{Capítulo 4}

\section{Conclusões e perspectivas}

O estudo em crânios secos, simulando esforços mastigatórios apresenta grande interesse para a anatomia e odontologia aplicada nas áreas de próteses, restaurações, nas cirurgias crânio-faciais programadas, nas áreas de traumas, ortopedia ou de plástica estética. O conhecimento da distribuição de tensões conforme as origens e inserções musculares, pode aumentar a previsibilidade nas intervenções que atuam sobre os ossos, músculos, por meio de enxertos ou remoção de estruturas.

Estudar ossos e músculos envolvidos na distribuição e geração das tensões no crânio e mandíbula, resultantes das funções do aparelho estomatognático (mastigar, deglutir, respirar, falar, tossir, etc.) é importante não só para a odontologia em suas várias especialidades, mas para a anatomia e também na área da evolução humana, principalmente o estudo da zona de reforço da região supra-orbitária dos símios e hominídeos.

A técnica utilizada para as medidas, com o crânio seco, permitiu-nos obter resultados mais realísticos quando comparados com outras técnicas, como os métodos de elementos finitos e ou resinas fotoelásticas. Estes métodos encontram dificuldades em simular as estruturas altamente complexas que compõe o crânio, ao contrário da técnica adotada neste trabalho.

O estudo da biomecânica destes músculos podem auxiliar no esclarecimento da geração e distribuição de tensões na mordida em cêntrica (posição 
de contato dos dentes com a boca fechada), no lado de trabalho (lado onde mastigamos), balanceio (onde não está ocorrendo a mastigação) e protrusiva (jogar a mandíbula para direita, esquerda e frente).

Os resultados obtidos foram satisfatórios, onde pôde-se observar como se comportaram a dissipação de tensão sobre o crânio e as direções dos deslocamentos estão de acordo com o modelo apresentado por Sicher e Tandler $[28]$.

Observou-se que na região dos pré-molares, na região do osso alveolar, ocorreu também a inclinação das franjas para mesial. De duas para três voltas ocorreu uma aproximação das franjas, porém de três para quatro voltas houve maior deformação na região do primeiro molar e pré-molares, sugerindo que possa ter ultrapassado o limite de tolerância da estrutura óssea ou demonstrando a grande elasticidade do tecido ósseo compatíveis com as características das cargas geradas durante a função mastigatória (cargas dinâmicas de alto impacto, na trituração ou cargas de menor impacto com maior duração, na deglutição).

No crânio seco as tensões são mais concentradas, pela rigidez excessiva do osso seco. No osso fresco (in vivo), as franjas estarão mais espaçadas pela elasticidade deste e pode se supor também que a deformação deva ser duas a três vezes maior que a do crânio seco [29], [30].

As medidas obtidas neste trabalho foram tratadas através de um programa computacional, que calcula o deslocamento da região estudada. No entanto, a resolução deste programa ainda é muito baixa, ou seja, ele não consegue contar grandes densidades de franjas.

As perspectivas com os resultados obtidos apontam para o aperfeiçoamento do programa no sentido de melhorar a resolução deste, para que seja capaz de identificar e contar densidade de franjas maior e para que possa contar franjas concêntricas com o objetivo de ter um tratamento melhor das medidas em interferometria holográfica e ser aplicado em outras áreas além da odontologia, como descrito no apêndice A.

Outra perspectiva é que se possa aperfeiçoar a técnica, para saber com o 
auxílio do programa computacional o sentido dos deslocamentos destes ossos do crânio e um aperfeiçoamento do sistema de aquisição das medidas.

Este é um estudo inicial com uma metodologia que se mostrou bastante precisa, sugerindo que se possa continuar com esta técnica para mapear todo o crânio, fazendo medidas com todos os ossos e manipulando todos os músculos da mastigação, com o objetivo de ter um estudo completo. 


\section{Apêndice A}

\section{Programa computacional}

O programa utilizado para o tratamento computacional das medições realizadas foi desenvolvido no laboratório de óptica, em plataforma MATLAB 6.5. O programa calcula os micro-deslocamentos sofridos por uma superfície quando submetida a uma tensão mecânica.

A rotina desenvolvida no programa é descrita como segue:

Primeiramente, tem-se uma função que busca a imagem no HD e guarda na memória, depois se escolhe a região que será analisada por meio de uma função do programa que determina a posição de dois pontos e traça uma reta de um ponto a outro. Em seguida, o programa determina a distância entre os pontos e divide esta em 100 partes iguais.

Feito isso, o programa faz uma interpolação para descobrir os pares ordenados $\left(x_{i}, y_{i}\right)$ do ponto limite superior e inferior para cada parte da linha. Estes pontos são então rastreados na matriz correspondente a imagem ${ }^{1} \mathrm{e}$ seleciona o nível de cinza.

Finalmente, o programa traça um gráfico do nível de cinza em função do número de elementos, que neste caso será 100 elementos. Neste gráfico, determinamos o número de picos correspondentes às franjas de interferência das medidas.

\footnotetext{
${ }^{1}$ Cada pixel corresponde a um elemento $(x, y)$ da matriz, o valor do elemento é o nível de cinza correspondente do pixel.
} 
O programa possui ainda uma sub-rotina que calcula o deslocamento relativo da região em análise quando se sabe o número de picos e o comprimento de onda $(\lambda)$ do LASER que foi utilizado nas medidas, desta forma calcula-se os micro-deslocamentos da região em unidades de nanômetros.

Para melhorar a visualização das franjas, foram desenvolvidas funções que melhoram o contraste, o brilho e o fator de gama das imagens. Sendo que a imagem original é salva na memória caso estas operações não sejam execultadas. Para auxiliar estas operações o programa também calcula o histograma da imagem ${ }^{2}$ para facilitar o controle das alterações.

As figuras A.1 e A.2, mostram as janelas do programa execultando suas funções:

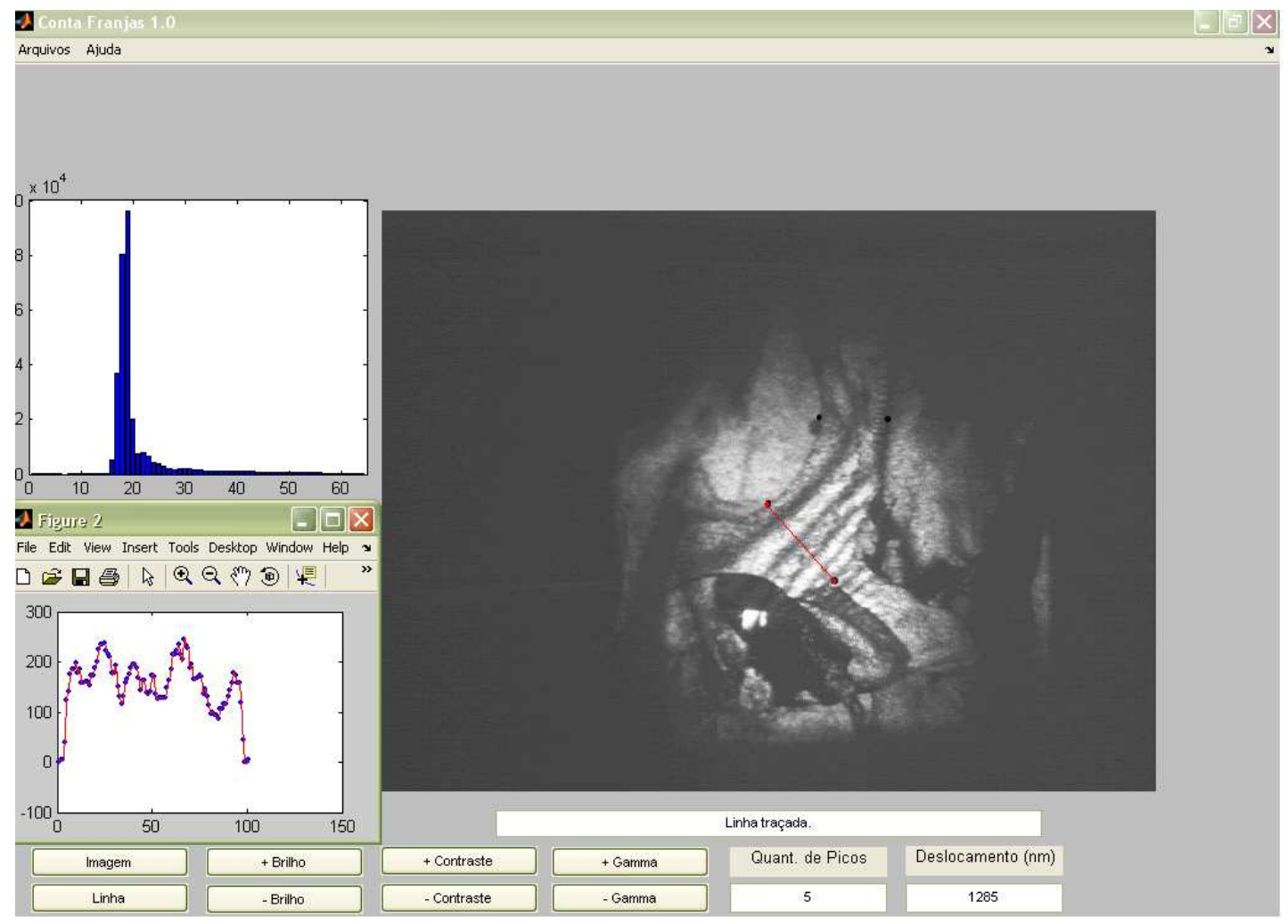

Figura A.1: Janela do programa conta-franjas execultando suas funções.

\footnotetext{
${ }^{2}$ Gráfico da quantidade de elementos em função do pixel.
} 


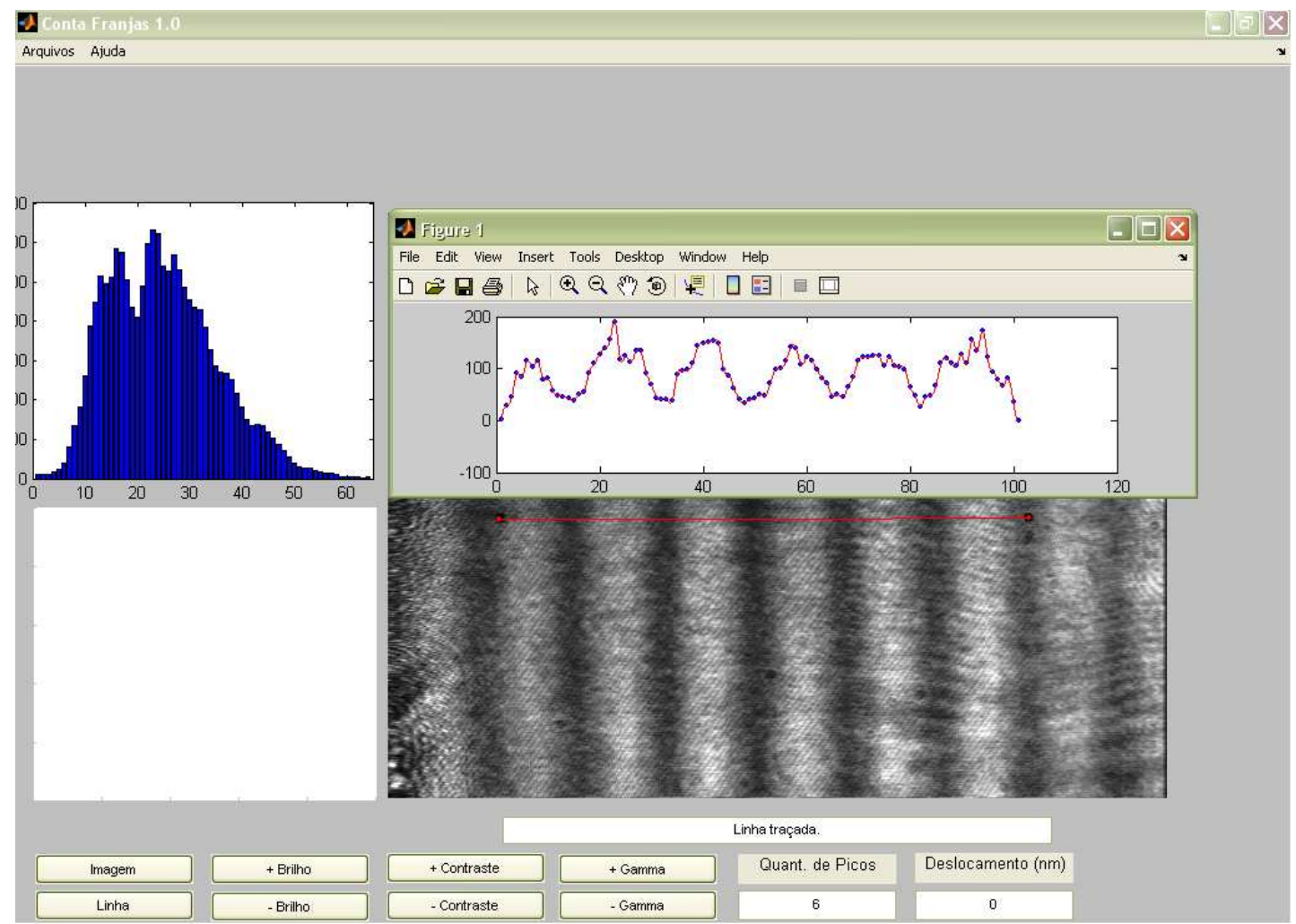

Figura A.2: Observa-se que a quantidade de picos está de acordo com o número de franjas que foram selecionadas na medida.

Pode-se observar, através da figura A.2 que a análise computacional do programa está de acordo com o número de franjas vistos na medida analisada.

Este programa é uma primeira versão que será melhorada, pois a resolução dele ainda é baixa. A figura A.3, mostra até onde o programa consegue ter resolução para contar as franjas selecionadas na medida e a figura A.4 mostra, onde o programa não consegue mais distinguir uma franja da outra. 


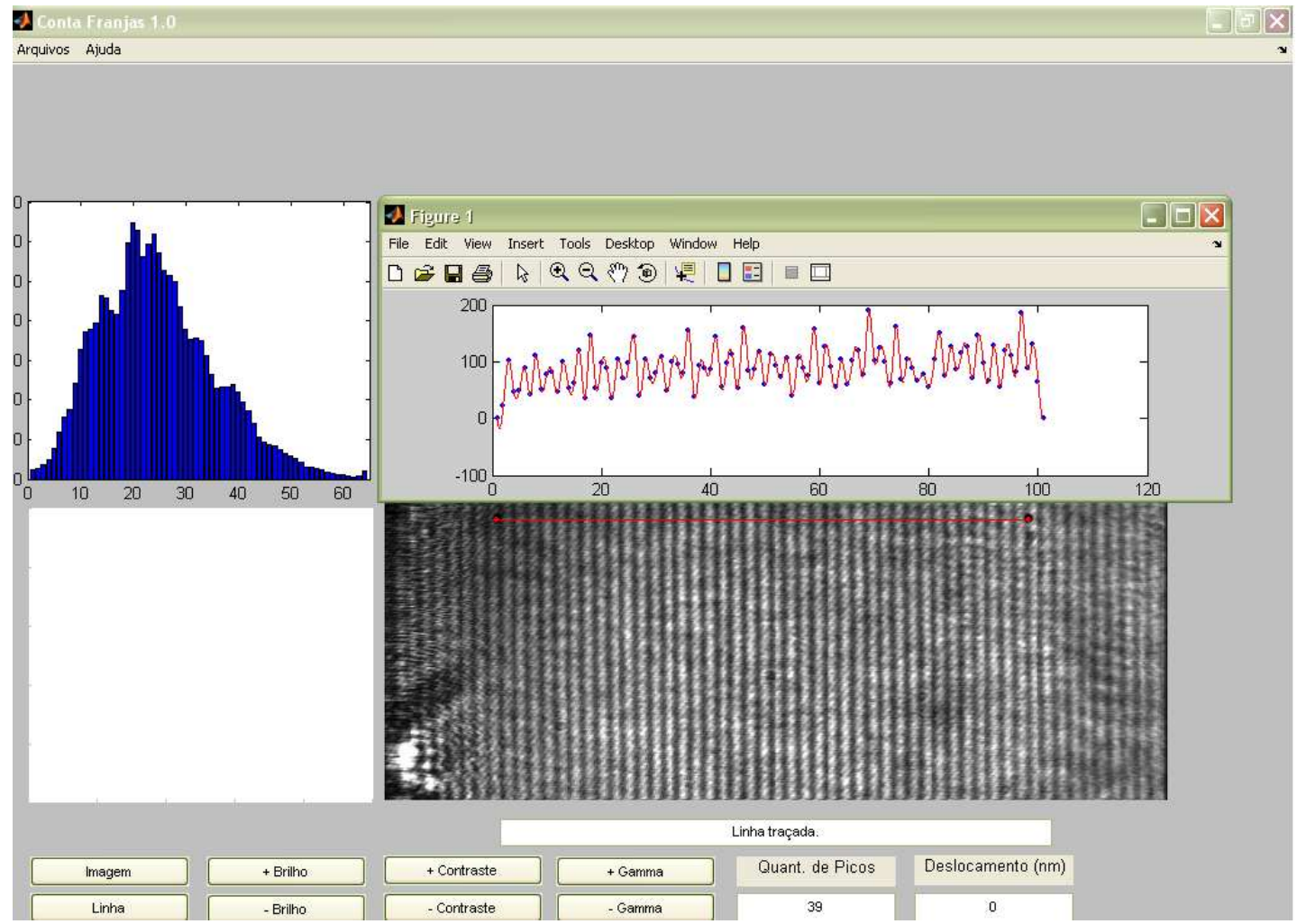

Figura A.3: O programa consegue contar as franjas que estão selecionadas nesta medida. 


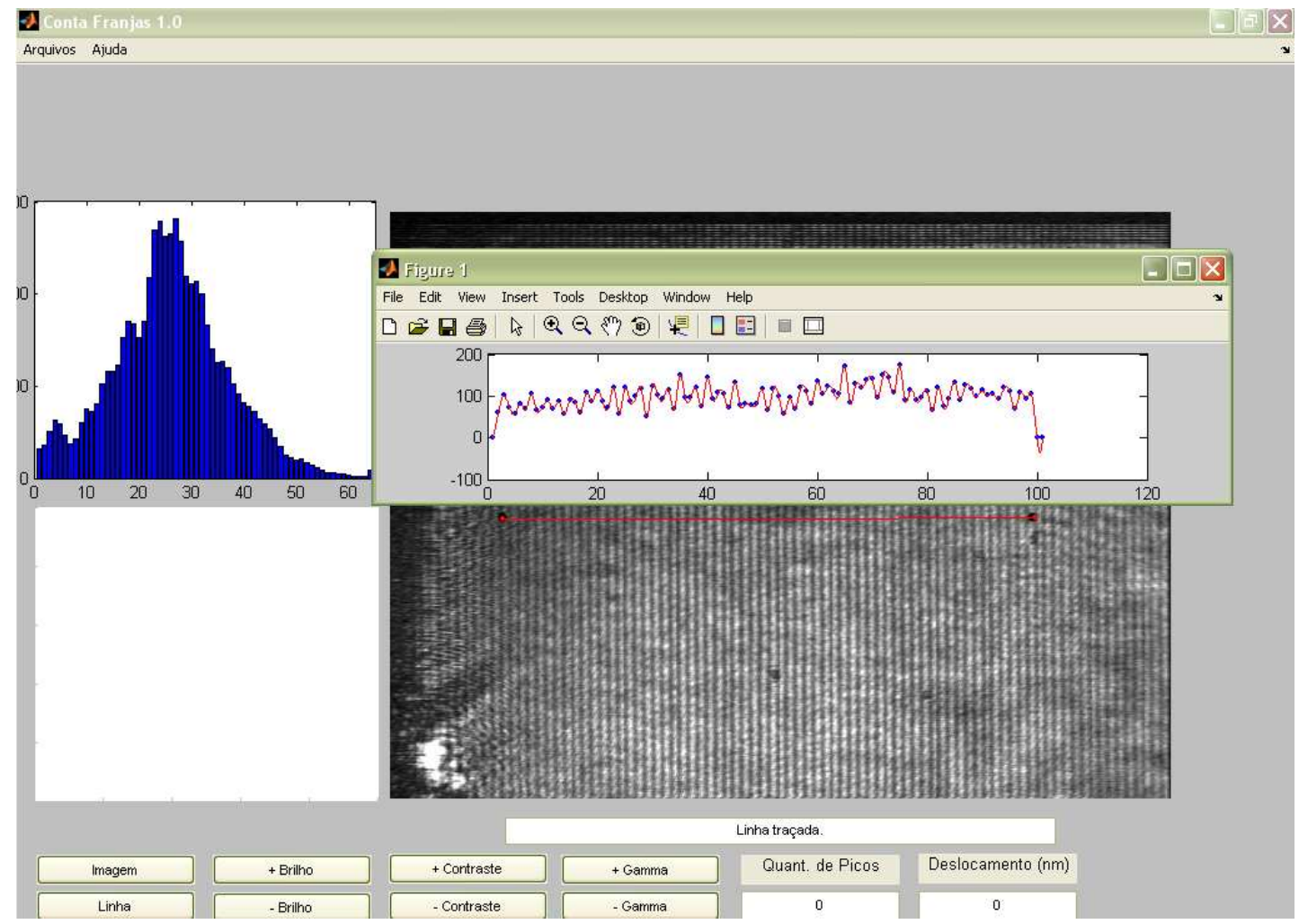

Figura A.4: O programa não consegue mais contar as franjas que estão selecionadas nesta medida.

Pode-se concluir que estas análises validam o programa e comprovam que os deslocamentos calculados por ele concordam com as medidas que foram analisadas.

\section{A.1 Perspectivas do programa}

As perspectivas apontam para um aperfeiçoamento do programa no sentido de melhorar sua resolução para que possa contar grandes densidades de franjas e para que ele mude a resolução do programa de acordo com a densidade das franjas.

Outra perspectiva para melhorar o programa é fazer com que ele tenha autonomia de contar as franjas, eliminar os ruídos e saber distinguir os picos 
referentes à estas franjas.

E por fim, aperfeiçoá-lo para que ele analise uma sequência de quadros das medidas, obtendo assim o sentido do deslocamento dos ossos em análise. 


\section{Apêndice B}

\section{Lista de siglas}

As siglas com seus respectivos nomes estão apresentadas abaixo:

$\mathrm{MPE}=$ Músculo masseter profundo esquerdo.

TAE $=$ Músculo temporal anterior esquerdo.

SCI = Simulação da contração isolada. 


\section{Apêndice C}

\section{Documentos da bioética}

A seguir é mostrado os documentos da bioética e a doação do crânio para a realização deste trabalho. 
Ilmo. Sr.

Prof. Dr. Luiz Vicente Rizzo

DD. Coordenador da Comissão de Ética de Pesquisa

em Seres Humanos do ICB/USP

Prezado Professor:

Segue, em anexo, resumo do trabalho intitulado "Estudo da dissipação de tensões no crânio seco, com a utilização da holografia em tempo real, por meio da simulação de contração isolada (SCI) dos feixes dos músculos: masseter superficial e profundo e feixe anterior do músculo temporal", que utilizará um único crânio humano macerado, pertencente ao acervo didático do Departamento de Anatomia do ICB/USP. Considerando-se que o mesmo faz parte de uma ampla coleção de crânios desde há muito existente no Departamento, venho solicitar a V.S . a isenção do envio dos demais documentos necessários à aprovação de pesquisa envolvendo seres humanos, por se tratar de um dos muitos exemplares freqüentemente utilizados por alunos de graduação.

Certo em contar com a atenção de V.S ${ }^{\text {a }}$. para com o meu pedido, aproveito o ensejo para enviar-lhe os mais elevados protestos de estima e consideração.

Atenciosamente,

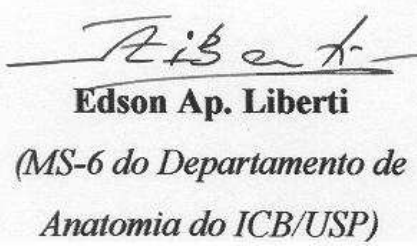




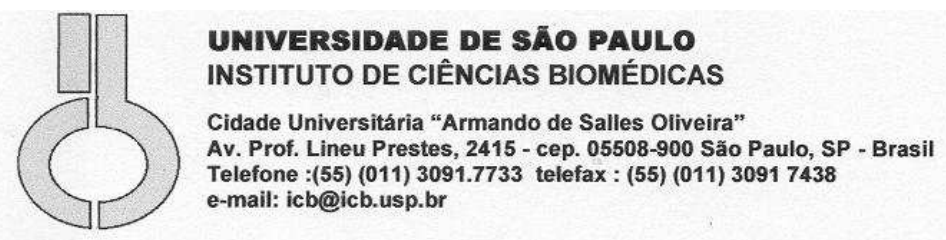

Of.CEPSH.132.05

São Paulo, 17 de junho de 2005.

Prezado Senhor,

Em atenção à correspondência enviada por V.Sa. nesta data, com referência ao trabalho intitulado: "Estudo da dissipação de tensões no crânio seco, com a utilização da holografia em tempo real, por meio da simulação de contração isolada (SCI) dos feixes dos músculos: masseter superficial e profundo e feixe anterior do músculo temporap", informo que por se tratar de um trabalho onde não serão utilizadas amostras provenientes de humanos, não cabe a emissão de parecer desta Comissão.

Atenciosamente

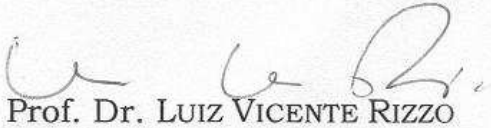

Prof. Dr. Luiz Vicente Rizzo

Coordenador da Comissão de Ética em

Pesquisas com Seres Humanos - ICB /USP

Ilmo. Sr.

Prof. Dr. EDSON APARECIDO LIBERTI

Departamento de Anatomia

Instituto de Ciências Biomédicas - USP

Comissão de Ética em Pesquisa com Seres Humanos do Instituto de Ciências Biomédicas / USP Aprovada

pela Comissão Nacional de Ética em Pesquisa - CONEP, em 10 de fevereiro de 1998. 


\section{Referências Bibliográficas}

[1] Leith, E. N. and Upatnieks, J., J. Opt. Soc. Am.,54, 1295-301 (1964).

[2] Saxby,G., Practical Holography, Prentice Hall, 1988.

[3] Powell, R.l. and Stetson, K. A., J. Opt. Soc. Am.,55, 1593-8 (1965).

[4] Benton, S.A., J. Opt. Soc. Am.,59, 1545 (1969).

[5] Hecht, E., Óptica, Fundação Calouste Gulbenkian, 1991.

[6] Sirohi, R. S., Chau, F. S., Optical Methods of measurement; Wholefied Techniques, Marcel Dekker,Inc. 1999.

[7] Ashkin, A., Boyd, G. D., Dziedzic, J. M., Smith, R. G., Ballman, A. A., Levinstein, J. J., Nassau, K., Appl. Phys. Letters,5, 72 (1966).

[8] Chen, F. S., J. Appl. Phys.,40(8), 3389 (1969).

[9] Chen, F. S., LaMacchia, J. T. and Fraser, D. B., Appl. Phys. Lett.,13(7), 223 (1968).

[10] Staebler, D. L. and Amodei, J. J., J. Appl. Phys.,43(3), 1042 (1972).

[11] Marrakchi, A., Johnson, R.V., Tanguay, Jr. A. R., J. Opt. Soc. Am. B,3, 321 (1986).

[12] Bally, G.V., Holography in Medicine and Biology, Springer-Verlag Berlin Heidelberg, New York 1979, vol. 18. 
[13] Bally, G.V. and Greguss, P. Optics in Biomedical Sciences, SpringerVerlag Berlin Heidelberg, New York 1982, vol.31.

[14] Barrekette, E. S., Kock, W.E., Ose, T., Tsujiuchi, J., Stroke, G. W. Applications of holography; Proceedings of the United States-Japan Seminar on information processing by holography, held in Washington, D.C., October 13-18,1969, Plenum Press., New York-London 1971.

[15] Lee, S.H., Optical Information Processing; Fundamentals, PrenticeHall,inc., 1981, segunda ed.

[16] Griffiths, D.J., Introduction to Electrodynamics, Springer-Verlag Berlin Heidelberg, New York, 1981.

[17] Frenkel, J., Pricípio de eletrodinâmica clássica, Edusp, 1996.

[18] Yariv, A., Introduction Optical Eletronics, Holt, Rineart and Winston, Inc., USA, 1971.

[19] Klein, M.B. and Schwartz, R.N., J. Opt. Soc. Am. B,3, 293 (1986).

[20] kukhtarev, N.V., Markov, V.B., Odulov, S.G., Soskin, M.S. and VinetskII, V.L., Ferroeletrics,22, 949 (1972).

[21] Yariv, A., Yeh, P., Optical Waves in Crystals-Propagation and Control of Laser Radiation, John Wiley e Sons, Inc., New York, 1984.

[22] Yeh, P., Introduction to Photorefractive Nonlinear Optics, John Wiley e Sons, Inc., New York, 1993.

[23] Kogelnik, H., Bell Syst. Tech. J., 48, 2909 (1969).

[24] Mallick, S. and Ronède, D., Appl. Phys. B,43, 239 (1987).

[25] Hariharan, P., Optical Holography-Principles, techniques and applications, Cambridge University press, New York, 1984. 
[26] Gesualdi, M. R. R., Técnicas de Interferometria Holográfica usando cristais Fotorrefrativos das famílias das Silenitas do tipo $\mathrm{Bi}_{12} \mathrm{SiO}_{20}(\mathrm{BSO})$, Dissertação de Mestrado, São Paulo, 2000.

[27] Robinson, D. W., Reid, G. T. Interferogram Analysis. Digital fringe pattern measurement techniques, IOP publisshing Ltd, 1993.

[28] Sicher, H., Tandler, J. Anatomia para dentistas, editora Labor S.A, Barcelona, 1930.

[29] Muramatsu, M., Campos, T. N., Batista, L. R., Campos, A. C., Adachi, L. K., Mori, M., Gioso, M. A., Chorres, J. R. Utilização da holografia na avaliação da distribuição de tensões em mandíbulas de caes., Pesquisa Odontológica Brasileira,17, (2003).

[30] Batista, L.R., Muramatsu, M., Campos, T. N. Stress analysis of fresh, fixed and macereted dog mandibles holographic interferometric double exposition method., Proceedings Of Spie, 4828, 979 (2002). 